\title{
Metodologia Para Automação de Inspeção Visual de Bolsas Para Coleta de Sangue
}

Dissertação apresentada à Escola de Engenharia de São Carlos da Universidade de São Paulo, como parte dos requisitos para obtenção do título de Mestre em Engenharia Elétrica.

Área de Concentração: Processamento de Sinais Orientador: Prof. Dr. Adilson Gonzaga

São Carlos

2008 


\section{Dedicatória}

A Deus, meus pais, minha filha Ana Lúcia, meus irmãos André e Márcia e minha Tia Esmeralda. 


\section{Agradecimentos}

Gostaria de agradecer a Deus por me presentear com minha família, com pessoas e amigos ao meu redor, que me ajudaram de diversas maneiras para realização deste trabalho.

Agradeço a toda minha família, pelo companheirismo, paciência, carinho e incentivo. Ressalto meus sinceros agradecimentos aos meus pais André e Therezinha e minha tia Esmeralda, pelo amor, apoio e incentivo não só durante meus estudos, mas por toda minha vida.

À minha filha Ana Lúcia, pelo amor, incentivo, energia, apoio, colaboração e principalmente pela compreensão pelos finais de semanas ausente durante meus estudos.

Ao professor Dr. Adilson Gonzaga pelos ensinamentos não só em processamento de sinais, ou mesmo na escrita deste trabalho, mas também por acreditar em meu potencial de trabalho.

Aos meus colegas do Lavi, pelo apoio e companheirismo durante meus estudos.

A todos meus professores de graduação, nos quais pude encontrar uma referência para alavancar meus conhecimentos em computação, além de ajuda para poder estar cursando o mestrado. Dentre todos gostaria de destacar a contribuição do Msc. Gilmar Cação, um especial agradecimento por tudo que fez e faz por mim.

A todos meus companheiros de serviços que de alguma forma contribuíram para o desenvolvimento deste trabalho. Dentre eles gostaria de destacar a Renata e todas as meninas da área de inspeção e embalagem, Luciana e todos do Controle de qualidade e ao Marcelo Coelho. Gostaria de agradecer de maneira especial aos meus grandes companheiros de trabalho Adalberto e Tozete. 


\section{Resumo}

Adorni, C. A. Metodologia Para Automação de Inspeção Visual de Bolsas Para Coleta de Sangue. 2007. Dissertação (Mestrado) - Escola de Engenharia de São Carlos, Universidade de São Paulo, São Carlos, 2007.

As bolsas para coleta de sangue necessitam cuidados técnicos que assegurem sua esterilidade biológica durante o processo de fabricação até a entrega do produto final. As bolsas para coleta de sangue não devem conter qualquer tipo de resíduo, para que o seu uso ou conteúdo não seja comprometido causando diversos transtornos. É preciso eliminar o risco de contaminação; no entanto muitas empresas fazem a inspeção de bolsas para coleta de sangue visualmente, a olho $\mathrm{nu}$, por funcionários treinados no uso de equipamento simples, o qual não pode garantir que todas as bolsas estejam livres de resíduos, por depender do fator humano. Para assegurar a esterilização das bolsas comercializadas, este trabalho propõe uma metodologia para automação de um sistema de visão computacional baseado em conjunto de técnica de extração de características de imagens e reconhecimento de padrões para detectar resíduos em imagens de bolsas para coleta de sangue durante o processo de fabricação, e assim, melhorar a qualidade das bolsas comercializadas. Os resíduos encontrados nas imagens capturadas se apresentam como componentes de alta freqüência. A metodologia proposta utiliza a Transformada Wavelet (Wavelet de Haar) em dois níveis de decomposição, como filtro passa - alta para destacar as altas freqüências, e assim detectar a existência de resíduos nas imagens capturadas. Os resultados obtidos com a inspeção visual manual realizada em bolsas para coleta de sangue, mostram que existem resultados divergentes na análise de uma mesma bolsa, o que reforça a necessidade de automatização dessa tarefa para que sejam obtidos resultados mais uniformes com padrões definidos, e dessa maneira melhorar a qualidade das bolsas comercializadas para coleta de sangue.

Palavras-Chave: Inspeção Visual, Transformada Wavelet, Wavelet Haar, Bolsa para Coleta de Sangue. 


\section{Abstract}

Adorni, C. A. Methodology to Automation Visual Inspection For blood bags. 2007. Dissertation (Master) - São Carlos Engineering School, Univerty of São Paulo, São Carlos, 2007.

The blood bags require technician attention to assure its biological sterility in the process of manufacture and in the final product. The blood bags must not contain any type of waste, so that its use or content is not compromised causing various disorders; it is necessary to eliminate any contamination risk; however many companies perform a visually inspection of the blood bags, by naked eye, by trained employees in the use of a simple equipment, which cannot guarantee that all the bags are residue-free because depending on the human factor. The residues showed on the pictures were characterized as high frequency components. So the proposed methodology applies two levels decomposition of Haar's Wavelet as high pass filter to evidence high frequencies, and to evidence the residues at the pictures and to evidence the existence of residues on the captured pictures. To assure the sterilization of the commercialized blood bags, this work propose a methodology of an automated computational system based in a group of techniques of image characteristics extraction and recognition patterns to detect residues in blood bag images in the process of manufacture, in order to improve the quality of the commercialized blood bags. This technique is used as high-pass filter, to detach the high frequencies, using a Haar-wavelet in two decomposition levels. The results obtained with the manual visual inspection indicate that were found divergent results in the analysis of the same blood bag, which reinforces the necessity of the automation of this task in order to obtain more uniform results with defined standards.

Keywords: Visual Inspection, Wavelet Transform, Wavelet of Haar, Blood bag 


\section{Lista de Figuras}

1.1 - Processo de inspeção visual

1.2 - Imagem de bolsa para coleta de sangue com resíduo ........................................ 3

2.1 - Partes e componentes da Bolsa para coleta de sangue com plaqueta cinco dias .. $\quad 11$

2.2 - Esquema da extrusora e calandra utilizada no processo de obtenção dos filmes . 12

2.3 - Placa já estampada e soldada ................................................................................. 13

2.4 - Equipamento de confecção de bolsas e inspeção ................................................. 14

2.5 - Área de montagem da bolsa .................................................................. 14

2.6 - Diagrama do processo de fabricação .................................................................. 16

3.1 - Convenção dos eixos para representação de imagens digitais ............................... 19

3.2 - Etapas da visão computacional ................................................................ 19

3.3 - (a) Função-Janela no domínio do espaço - (b) Base WFT no domínio de espaço

- (c) Base daWFT no domínio da freqüência

23

3.4 - (a) Janelas de análise do plano tempo-freqüência para WFT e WT -

(b) cobertura do espectro de freqüência pela WFT e pela WT

25

3.5 - Exemplos de Wavelets - Mãe

27

3.6 - (a) 3 exemplos de escala de sinal em wavelet - (b) deslocamento de sinal em Wavelet 28

3.7 - Processo de decomposição das wavelets 30 
3.8 - Processo de filtragem do sinal em 3 níveis

3.9 - (a) Esquema de organização dos coeficientes wavelets (b) Imagem original

(c) Decomposição em 3 níveis (d) Três níveis de decomposição (L1, L2,L3)

vistos individualmente com seus respectivos coeficientes 32

3.10 - Representação da Wavelet de Haar 33

4.1 - Sistema de visão computacional para análise das bolsas para coleta de sangue ...

4.2 - Imagem da bolsa para coleta de sangue com resíduo na borda

4.3 - Imagem do Filme da bolsa com Resíduo 39

4.4 - Iluminação omni-direcional 40

4.5 - Equipamento de iluminação 40

4.6 - Interior do sistema de iluminação

4.7 - Câmera e conjunto de lentes usadas na captura das imagens

4.8 - Imagens geradas de uma bolsa de sangue

4.9 - Exemplos de imagens capturadas

4.10 - Ajustes do conjunto de lentes macro zoom

4.11 - (a) Imagem do menor resíduo detectado; (b) Imagem do maior resíduo detectado 44

4.12 - Exemplo de resíduo em bolsa para coleta de sangue

4.13 - Aplicação da Transformada de Fourier em imagens de bolsa para coleta de sangue; (a) com borda e resíduo; (b) sem resíduos; (c) com resíduo 46

4.14 - Resultado da decomposição em dois níveis 47

4.15 - Imagem do segundo nível de decomposição 48

4.16 - Exemplo de processamento de bolsa com ruído 49 
5.1 - Comparação dos resultados da inspeção realizada pela Inspetora 1 e a classificação do laboratório de controle de qualidade 56

5.2 - Comparação dos resultados da inspeção realizada pela Inspetora 2 e a classificação do laboratório do controle de qualidade 57

5.3 - Comparação dos resultados da inspeção realizada pela Inspetora 3 e a classificação do laboratório de controle de qualidade

5.4 - Comparação entre a média do processo de inspeção visual e a classificação do laboratório de controle de qualidade (Resultado Esperado)

5.5 - Digrama de blocos do algoritmo desenvolvido

5.6 - (a) Imagem do resíduo da bolsa 6; (b) Imagem do resíduo da bolsa 13

5.7 - Comparação dos resultados da inspeção visual automática e a classificação do laboratório de controle de qualidade

5.8 - (a) Imagem do resíduo da bolsa 7; (b) Imagem do resíduo da bolsa 12

5.9 - Comparação dos resultados da Inspeção Visual Automática das bolsas retiradas da linha de produção

B.1 - Imagem com resíduo 96

B.2 - Resultado do processamento da imagem da figura B1através da metodologia proposta 97

B.3 - Imagem com resíduo e borda 98

B.4 - Realce do resíduo e eliminação da borda da bolsa 99

B.5 - Imagem sem resíduo 100

B.6 - Eliminação da borda da bolsa e ausência de resíduo 101 
B.7 - Imagem com hímem e resíduo …................................................................ 102

B.8 - Eliminação do hímen, borda da bolsa e realce do resíduo ................................... 103 


\section{Lista de Tabelas}

5.1 - Resultados da inspeção visual manual com número de resíduos encontrados em cada bolsa

5.2 - Resultados da inspeção visual manual .............................................................. 55

5.3 - Coeficientes de correlação das análises realizadas .............................................. 55

5.4 - Resultados obtidos com a inspeção visual manual e com a metodologia proposta neste trabalho (número de resíduos encontrados em cada bolsa) .......... $\quad 60$

5.5 - Tempo de processamento das imagens ................................................................ 62

5.6 - Resultados da Inspeção Visual Automática aplicada a bolsas retiradas da linha de produção 


\section{Lista de Abreviaturas e Siglas}

\begin{tabular}{|c|c|}
\hline ABO & Sistema de identificação de tipo sanguíneo \\
\hline $\mathbf{A C D}$ & Solução de Glicose e Citrato \\
\hline ACPD & Solução de Glicose, Fosfato e Citrato \\
\hline BMP & Formato Bitmaps \\
\hline CPD & Solução de Glicose, Fosfato e Citrato \\
\hline CPDA & Solução de Adenina, Glicose, Fosfato e Citrato \\
\hline CWT & Transformada Wavelet Contínua (Continuous Wavelet Transfom) \\
\hline DC & Corrente continua (Direct Current) \\
\hline DEHP & Di (2- etilhexil) ftalato \\
\hline DWT & Transformada Wavelet Discreta (Discrete Wavelet Transform ) \\
\hline FT & Transformada de Fourier (Fourier Transform) \\
\hline HD & Disco rígido (Hardware Disk) \\
\hline MRA & Análise Multiresolução (Multiresolution Analisys) \\
\hline PIXEL & Picture element \\
\hline PVC & Poli Cloreto de Vinila \\
\hline QMF & Filtros de quadratura (Quadrature Mirros Filters) \\
\hline RH & Sistema Rhesus \\
\hline RPM & Rotações Por Minuto \\
\hline SAG-M & Solução de Glicose, Citrato e Manitol \\
\hline STFT & Transformada de Fourier Limitada (Short Time Fourier Tar \\
\hline
\end{tabular}


TEHTM Tri (2-etilhexil) trimelitato

WFT Transformada de Fourier Janelada (Windowed Fourier Transform)

WT Transformada Wavelet (Wavelet Transform) 


\section{Sumário}

Dedicatória ii

Agradecimentos iii

Resumo iv

$\begin{array}{lll}\text { Abstract } & \text { v }\end{array}$

Lista de Figuras vi vi

$\begin{array}{lc}\text { Lista de Tabelas } & x\end{array}$

Lista de Siglas $\quad$ xi

1 Introdução 1

1.1 Considerações Iniciais e Justificativas ................................ 1

1.2 Objetivos ..................................................................... 4

1.3 Organização do trabalho ................................................... 5

2 Bolsas para Coleta de Sangue 6

2.1 Processo de Fabricação de bolsa para coleta de sangue .......... 12

3 Fundamentos Teóricos da Metodologia Proposta 17

3.1 Considerações Iniciais .................................................... 17

3.2 Representação de Imagens Digitais ..................................... 18

3.3 Visão Computacional ........................................................ 19

3.4 Transformada Wavelet no domínio da Freqüência .................. 21

3.4.1 Transformada de Fourier .............................................. 22

3.4.2 Transformada Wavelet ............................................. 25

3.4.3 Transformada Wavelet Contínua .................................. 27

3.4.4 Transformada Wavelet Discreta .................................... 29

3.4.5 Wavelet de Haar ........................................................ 33

3.4.6 Wavelet no Processamento de imagens ........................ 34 
3.5 Considerações Finais ................................................................. 34

4 Materiais e Métodos 36

4.1 Considerações Iniciais ...................................................... 36

4.2 Sistema de Iluminação e Aquisição de Imagem ....................... 39

4.3 Banco de Imagens ............................................................ 42

4.4 Processamento das Imagens ............................................... 45

4.5 Considerações Finais ..................................................... 50

5 Resultados e Conclusões $\quad 52$

5.1 Considerações Iniciais ....................................................... 52

5.2 Resultados da Inspeção Visual ............................................... 53

5.2.1 Análise Estatística dos Resultados ............................... 55

5.3 Resultados da Inspeção Visual Automática Aplicada ao Banco de Imagens ........................................................................ 58

5.3.1 Análise Estatística dos Resultados ................................ 63

5.4 Resultados da Inspeção Visual Automática Aplicada às Bolsas Retiradas da Linha de Produção ................................... 64

5.4.1 Análise Estatística dos Resultados ............................... 67

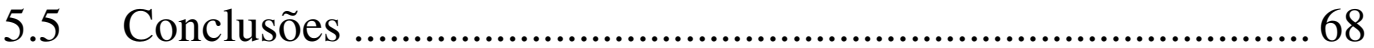

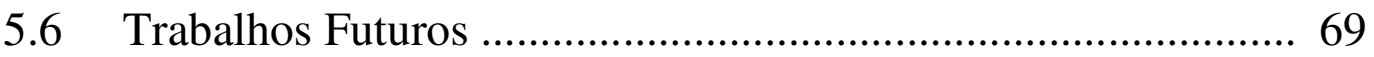

Referências Bibliográficas $\quad 70$

$\begin{array}{ll}\text { Apêndice A } & 75\end{array}$

$\begin{array}{ll}\text { Apêndice B } & 96\end{array}$

$\begin{array}{ll}\text { Apêndice C } & 104\end{array}$

$\begin{array}{ll}\text { Apêndice D } & 105\end{array}$ 
Capítulo

Introdução

\subsection{Considerações Iniciais e Justificativas}

A produção de fármacos e outros produtos médicos exigem acurados cuidados técnicos que possam garantir sua composição e qualidade e que assegurem a esterilidade biológica que pode ser comprometida pela presença de resíduos que são agentes de contaminação.

Estes resíduos são partículas de poeira ou pequenos pelos humanos, que de alguma maneira penetram no filme da bolsa para coleta de sangue durante o processo de fabricação.

As bolsas para coleta de sangue, utilizadas para armazenamento de sangue e seus componentes, devem estar livres de resíduos para que o uso de seu conteúdo não seja comprometido causando transtornos de variadas ordens e magnitudes.

No processo de fabricação e no produto final, é imprescindível uma rigorosa inspeção nas bolsas para coleta de sangue. A embalagem adequada reduz substancialmente os riscos de contaminação. 
Em muitas empresas a inspeção de bolsas para coleta de sangue é feita visualmente, a olho desarmado ou olho nu, fato que não permite garantir a ausência de resíduos por estar diretamente ligado ao fator humano e a juízo de valor.

As inspeções de bolsas rotineiramente são feitas por funcionários treinados no uso de um equipamento simples que contém iluminação fluorescente e uma placa com uma parte na cor branca e outra na cor preta. Com esse equipamento cada funcionário, que para isso foi treinado, usa as duas partes da placa, branca e negra, para detectar possíveis resíduos, como pode ser visto na figura 1.1 .

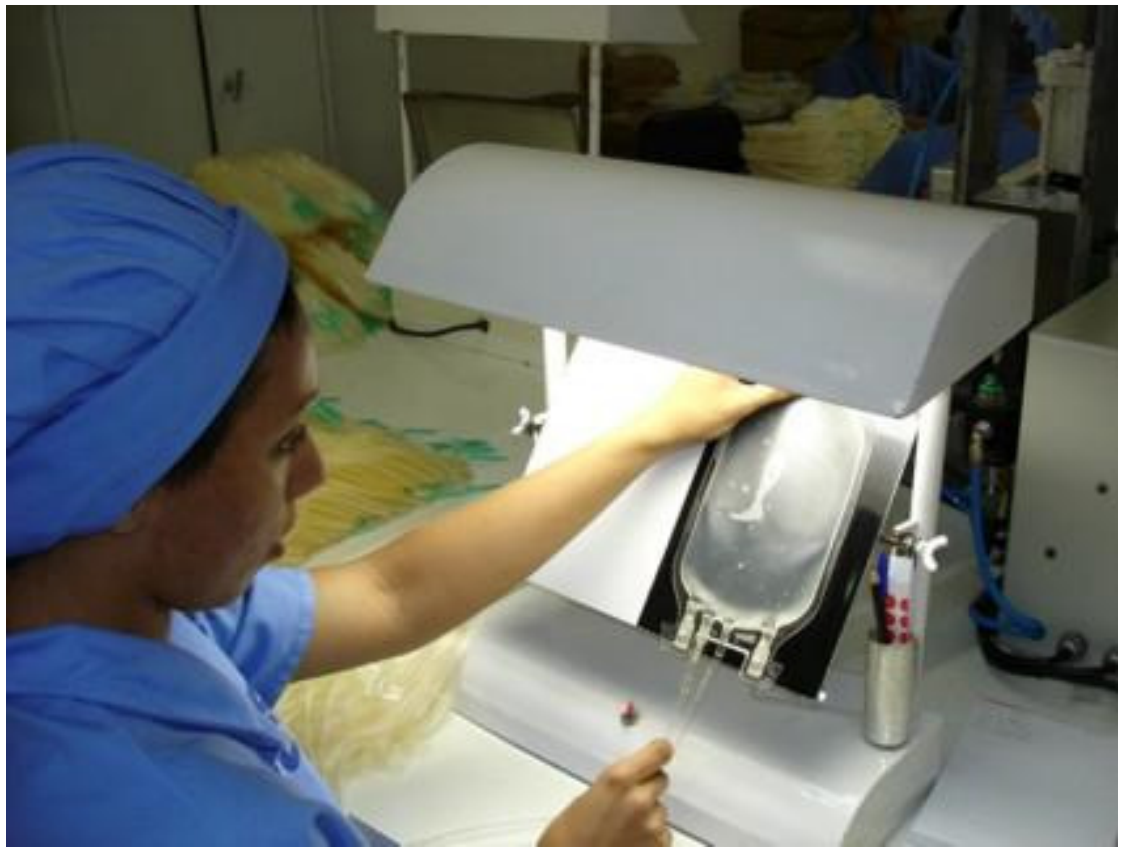

Figura 1. 1- Processo de Inspeção Visual

Se, durante o processo de inspeção visual, o funcionário encontrar algum tipo de resíduo ele precisa identificar o filme da bolsa para coleta de sangue, o local onde se encontra o resíduo e deve separar esse material para descarte.

Este processo de inspeção é realizado conforme toda a legislação, normas e a farmacopéia vigente, mas não é possível garantir que todas as bolsas estejam livres de resíduos, porque esta seleção depende do fator humano nele envolvido e está relacionado a 
situações como estado emocional, vontades, situação afetiva, capacidade de atenção do funcionário, deformação física; ademais, enganos podem ser cometidos devido à deformação física da própria bolsa; além de, na tarefa de inspeção, haver dificuldades maiores ou menores decorrentes das diversas formas, cores e tamanhos de resíduos.

A figura 1.2 ilustra a dificuldade de se identificar ou classificar um resíduo, onde pode se ver um achado no filme na parte inferior da bolsa. A imagem foi ampliada para ser possível a boa visualização do resíduo.

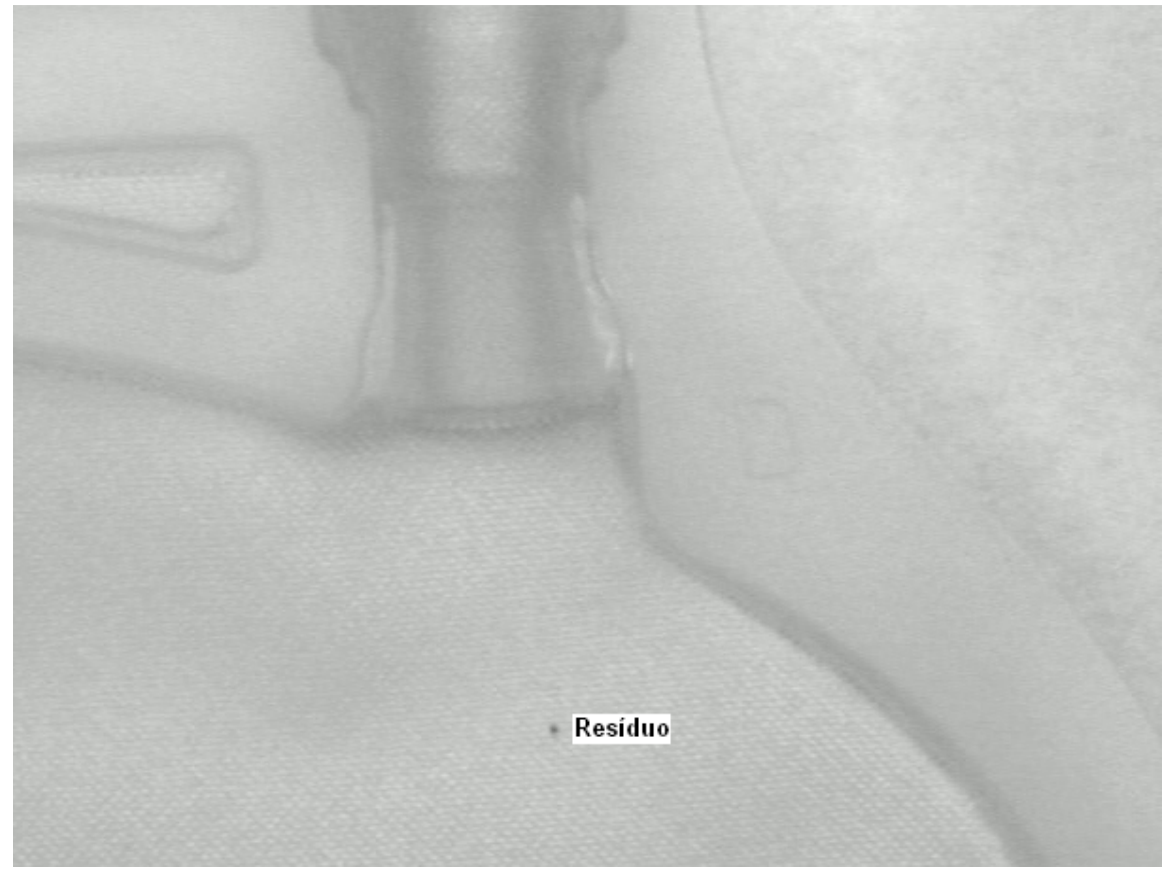

Figura 1. 2 - Imagem de bolsa para coleta de sangue com resíduo.

O processo de inspeção das bolsas para coleta de sangue e seus componentes precisa ser automatizado para que seja garantida a sua qualidade e o seu conteúdo.

$\mathrm{Na}$ área de produtos médicos hospitalares existem sistemas automatizados para realizarem esta tarefa, mas esses sistemas são complexos, não produzidos no Brasil, tem alto custo de aquisição, implantação do equipamento e treinamento de pessoal. $O$ alto 
investimento a ser realizado dificulta a competitividade das empresas do setor e acaba por inviabilizar seu uso.

Garantir que as bolsas comercializadas para coleta de sangue não contenham qualquer tipo de resíduo, a um custo que não inviabilize a competitividade comercial das empresas, somente pode ser conseguido com sistemas automatizados porque o processo de inspeção visual manual não consegue garantir a ausência de resíduos em todas as bolsas produzidas (ADORNI, 2006).

As técnicas de processamento de imagens têm apresentado expressivo crescimento para diferentes áreas de aplicações: no diagnostico médico, em tarefas laboratoriais que exigem alto grau de precisão, aplicadas a robôs com visão artificial e para realizar as mais diferentes tarefas de precisão (MARQUES FILHO, 1999).

Gonzalez (GONZALEZ, 2000) reporta que os problemas típicos em percepção, como visão computacional industrial para montagem e inspeção de produtos rotineiramente usam técnicas de processamento de imagens.

\subsection{Objetivos}

Este trabalho propõe uma metodologia para automatizar o processo de inspeção visual através de visão de máquina, com o objetivo de detectar resíduos em imagens de bolsas para coleta de sangue durante o processo de fabricação, e avaliar a necessidade do uso de um sistema de inspeção visual no processo de controle de qualidade. 


\subsection{Organização do trabalho}

O capítulo um apresentou o processo de inspeção visual de uso corrente na atualidade, as justificativas, os objetivos e a organização do trabalho.

O capítulo dois apresenta o objeto de estudo, ou seja, as bolsas de sangue. Descreve um histórico, as bolsas para coleta de sangue, desde o primeiro recipiente para armazenamento até as bolsas para coleta de sangue de uso em nossos dias; a formulação básica da bolsa para coleta de sangue, suas características, os principais danos que um resíduo pode causar à bolsa e o processo de fabricação.

O capítulo três aborda a visão computacional, descreve as técnicas de processamento de imagens digitais, equipamentos e funções. Introduz os conceitos teóricos da Transformada Wavelet, a Wavelet de Haar, e sua aplicação no processamento de imagens.

O capítulo quatro apresenta a abordagem proposta e métodos utilizados na captura das imagens, na montagem do banco de imagens e no processamento.

O capítulo cinco apresenta a inspeção visual realizada nas bolsas para coleta de sangue usadas, os resultados obtidos com o algoritmo desenvolvido e as conclusões. 
Capítulo

\section{Bolsas para Coleta de Sangue}

Ao longo do tempo, a necessidade de armazenar sangue para transfusão levou ao desenvolvimento de produtos e técnicas que garantissem a durabilidade do sangue por um período de tempo.

A primeira tentativa da qual se tem notícia do uso de sangue como terapia foi em 1492 com o papa Innocent VIII em Roma. Desde então muito foi feito, mas não foi confirmado sucesso durante grande período, devido a várias questões como: espirituais, éticas, fascinação, superstição e principalmente a falta de registros (VERCEZE, 2006).

Em 1818, James Blundel, obstetra inglês, após realizar experimentos bem sucedidos com transfusões em cães, fez a primeira transfusão com sucesso em humanos, em uma paciente com hemoterapia ${ }^{1}$ pós-parto (VERCEZE, 2006).

Assim surgiram vários instrumentos para auxiliar as transfusões. O mais usado foi a seringa de Jubé, que trouxe mais segurança às transfusões realizadas de braço a braço, quando o sangue era retirado através da seringa e por movimentos do êmbolo era transfundido ao receptor (VERCEZE, 2006).

\footnotetext{
${ }^{1}$ Hemoterapia é o emprego terapêutico do sangue, que pode ser transfundido com seus componentes (hemocomponentes) e derivado (hemoderivados).
} 
Na época o grande desafio era a utilização de conservantes e anticoagulantes, puros ou em mistura, que realizassem a conservação e manutenção do sangue armazenado para utilização futura, até que em 1869 Braxton Hicks realizou os primeiros estudos documentados para preservação do sangue com fosfato de sódio (VERCEZE, 2006).

O fato que impulsionou a transfusão de sangue foi o registro, em 1901, pelo médico australiano Karl Landsteiner, dos três grupos sanguíneos A, B e O, o sistema ABO. Mais tarde, em 1902 foi registrado o quarto tipo, o AB (VERCEZE, 2006).

Em 1916, Francis Rous e J.R. Turner desenvolveram o primeiro anticoagulante introduzido na transfusão de sangue, o que permitiu o armazenamento do sangue em frascos de vidro por vários dias, depois da coleta. Este foi o primeiro recipiente adotado e utilizado pelos ingleses na primeira guerra mundial (1914-1918) (VERCEZE, 2006).

Entre 1939 e 1940, Karl Landsteiner descobriu o sistema Rhesus (Rh), que foi reconhecido como o causador das reações nas transfusões quando o grupo sanguíneo era incompatível. Com este sistema foi possível restabelecer a compatibilidade e assim, as reações tornaram-se raras (VERCEZE, 2006).

O professor Edwin Cohn, desenvolveu o fracionamento de componentes de plasma e obteve a albumina, a gama globulina e fibrinogênio. No ano seguinte, foi usada a albumina de Cohn em vítimas do ataque a Pearl Harbor, para evitar o colapso das veias e no estado de choque causado pela hipovolemia ${ }^{2}$ (VERCEZE, 2006).

O armazenamento e preservação do sangue atingiram grandes avanço em 1943, com J.F. Loutit e P.L.Mollison, que ao proporem a introdução do ácido cítrico na solução de citrato e glicose (ACD), conseguiram aumentar o tempo de conservação, elevando a preservação do sangue coletado para vinte e um dias, em frasco de vidro.

\footnotetext{
${ }^{2}$ Hipovolemia é o estado de diminuição do volume sanguíneo, mais especificamente do volume de plasma sanguíneo.
} 
Em 1957, Gibson, introduziu o fosfato de sódio (ACPD ou CPD) como conservante do sangue, elevando a conservação e estocagem para 28 dias e promoveu a conservação das células vermelhas de 70\% para 80\% (VERCEZE, 2006).

Em 1960, Nakao, adicionou adenina à solução de fosfato de sódio (CPDA). Com a adenina foi possível aumentar o período de conservação e estocagem para 35 dias, mantendo a conservação das células vermelhas em $80 \%$. Esta solução usada atualmente foi introduzida na prática de hemoterapia em 1979 (VERCEZE, 2006).

A introdução da solução preservante de cloreto de sódio, glicose, adenina e manitol a solução de fosfato de sódio (CPD/SAG-M), ou solução salina AS3, possibilita estocar ou conservar as células vermelhas por 42 dias (VERCEZE, 2006).

Com o fim da segunda guerra mundial, o desenvolvimento de bolsas plásticas flexíveis e sistemas de acondicionamento de sangue mudaram os Serviços de Hemoterapia, tornando-o rápido, eficiente e facilitando a preparação dos componentes do sangue (HASHIMOTO, 1997).

Carl Walter e W.P. Murphy Jr estudaram e propuseram o uso do plástico na fabricação de bolsas para coleta de sangue. Nos anos de 1949 e 1950, introduziram uma bolsa plástica para a coleta e armazenamento do sangue em substituição aos frascos de vidro que se perdiam por serem facilmente quebráveis. O material utilizado nessas bolsas foi definido como “Resina Polivinílica” (CARMEN, 1993).

Staudinger, H., prêmio Nobel de Química em 1953, consolidou definitivamente o desenvolvimento de materiais poliméricos e sua participação em substituição a materiais clássicos como metal, vidro, madeira e cerâmica (TITOW, 1984).

Desde então, muitos materiais poliméricos têm sido avaliados para uso em bolsas para coleta de sangue, mas somente o PVC atende certas exigências quanto à composição e 
tem suprido as necessidades de conservação para a transfusão do sangue humano (CARMEN, 1993).

O PVC iniciou sua longa história com o monômero de cloreto de vinila, sintetizado pela primeira vez em laboratório, por Justus Von Liebig, em 1835.

Em 1860, Hoffmann publicou um relatório sobre a obtenção do polibrometo de vinila. Em 1872, Baumann sintetizou o PVC, mas a base para sua produção técnica somente foi descoberta em 1912 por Fritz Klatte (OLIVEIRA, 1991).

No final dos anos 20, Goodrich deu inicio à fabricação do PVC plastificado, flexível e facilmente moldável por extrusão, injeção e calandragem (VERCEZE, 2006).

O PVC é um polímero termoplástico composto por duas matérias-primas básicas, o etileno, proveniente do craqueamento do petróleo (que é a quebra de moléculas grandes em moléculas menores com a ação de catalisadores para aceleração do processo) e o cloro, proveniente do sal marinho. A reação dos dois produtos resulta o dicloroetano que, em altas temperaturas, é convertido no gás cloreto de vinila, monômero da fabricação do PVC. Através da reação de polimerização, o cloreto de vinila torna-se um pó quimicamente estável e inerte: o PVC (TITOW, 1984).

Para utilização do PVC, em processos industriais ou processos com máquinas de transformação em resinas plásticas, é necessário adicionar aditivos para torná-lo flexível (SHAPIRO, 1976). Os aditivos são usados de maneiras diferentes, dependendo da propriedade que se quer obter no produto acabado. Para cada tipo de aplicação existe determinada especificação, para os diferentes aditivos.

Na conservação e armazenamento do sangue e seus componentes são usados os plastificantes di (2-etilhexil) ftalato (DEHP) e o tri (2-etilhexil) trimelitato (TEHTM) e estabilizantes à base de cálcio, zinco e óleo de soja ou linhaça epoxidados (HOLME, 1989). 
Atualmente, a formulação deve atender aos limites da Farmacopéia Européia vigente, ISO3826-1, 2003 - Plastic collapsible containers for human blood and blood components, e ser aprovada pelo Ministério da Saúde Brasileiro (PORTARIA, 950 MS) (Apêndice A), tendo como formulação:

- $\quad$ Poli cloreto de vinila (PVC) com mais que 55\%.

- $\quad$ Di (2-etilhexil) ftalato (DEHP) não mais que $40 \%$ ou tri (2-hetilexil) trimelitato (TEHTM), não mais que $40 \%$,

- Óleo de soja ou linhaça epoxidados, não mais que $10 \%$ de cada ou mistura destes.

- Diacetilenodiamina não mais que $1 \%$.

- Estearato cálcio ou zinco ou mistura destes, não mais que $1 \%$.

Ao processo de aditivar a resina de PVC dá-se o nome formulação.

O TEHTM ainda não é inscrito nesta portaria, mas é muito utilizado na conservação das plaquetas derivadas das bolsas convencionais e por aférese (VERCEZE, 2006).

Também é importante frisar que a legislação em defesa do consumidor e as normas técnicas no mundo todo pró́bem o uso do plástico reciclado em embalagens de alimentos, medicamentos, brinquedos e artigos médico-hospitalares.

As bolsas para coleta de sangue precisam ter determinada topografia, rugosidade e porosidade, frente à permeabilidade aos gases adequados durante a conservação do sangue, componentes e derivados. Alguns componentes requerem trocas gasosas entre o sangue armazenado e o ambiente (COMYN, 1986; VERCEZE, 1996). 
Estas bolsas têm que resistir a grandes alterações de temperaturas: de $115^{\circ}$ a $120^{\circ} \mathrm{C}$ durante o processo de esterilização, a $-70^{\circ} \mathrm{C}$ durante o armazenamento do plasma congelado e também a sucessivas centrifugações de até 5000 RPM a 4º (CARMEN, 1993).

Se, durante o processo industrial ou de conservação do sangue, o filme contiver algum material que cause alteração em seu estado ou em resistência, poderá haver abertura do sistema por ruptura da bolsa, a perda do conteúdo e por conseqüência graves transtornos (VERCEZE, 1996).

A bolsa para coleta de sangue uma vez montada, além do filme, possui vários componentes, adicionados durante o processo de fabricação, de acordo como modelo de bolsa produzido. A figura 2.1 mostra as principais partes e componentes de uma bolsa para coleta de sangue.

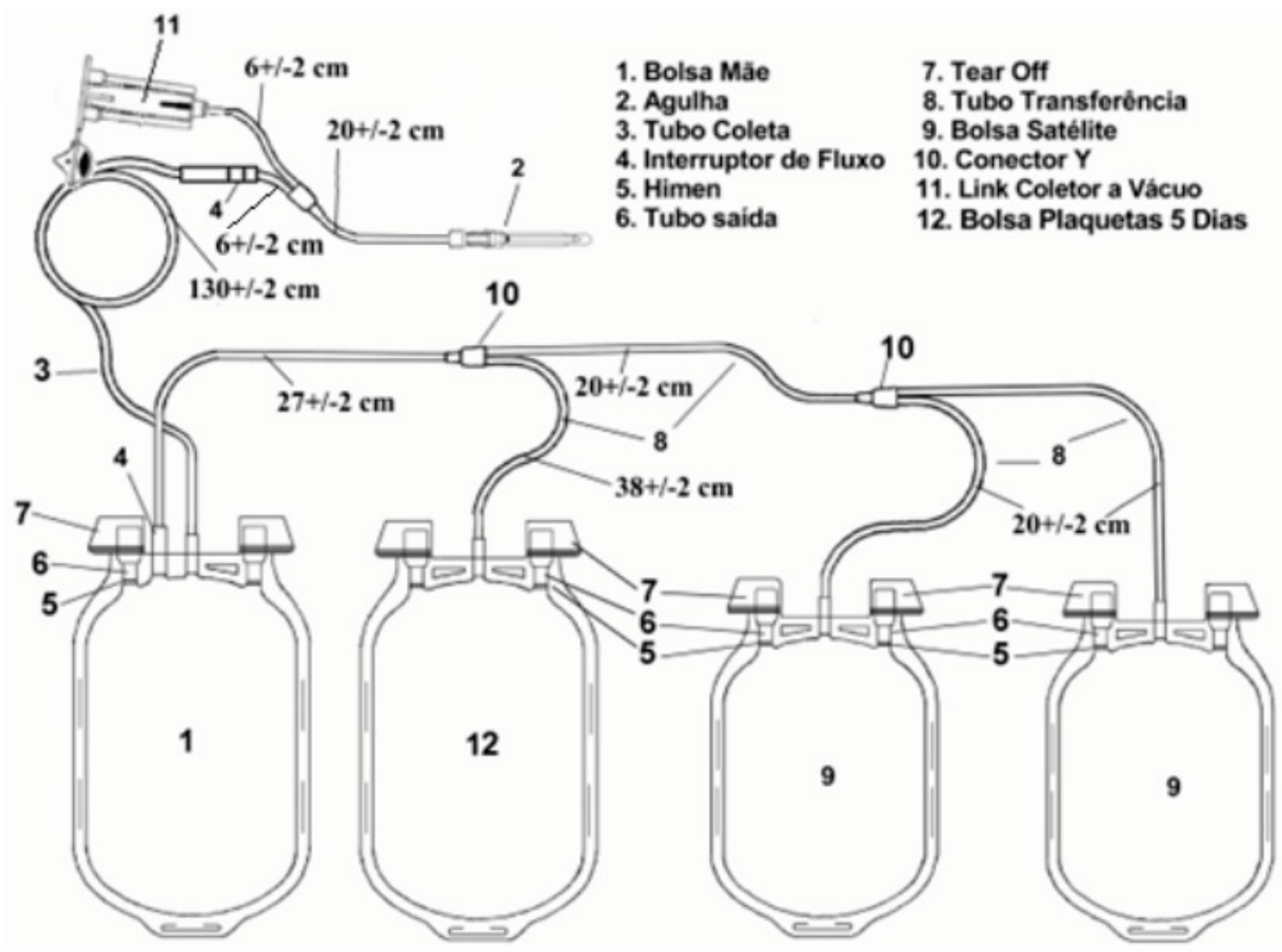

Figura 2. 1- Partes e componentes da Bolsa para coleta de sangue com plaqueta cinco dias. 
Na figura 2.1 há dois tipos de bolsa para coleta de sangue, a bolsa mãe e a bolsa satélite. A bolsa mãe possui dois interruptores de fluxo, um para o tubo de transferência e outro para o tubo de coleta. A sua capacidade de armazenamento é de $500 \mathrm{ml}$ e sua função é de receber o sangue coletado do doador.

Diferente da bolsa mãe, a bolsa satélite tem apenas um interruptor de fluxo, somente para o tubo de transferência, a capacidade de armazenamento varia de acordo com o tipo de filme produzido: com DEHP a capacidade é de 400ml e com TEHTM a capacidade é de $500 \mathrm{ml}$. A função desta bolsa e de armazenar os componentes do sangue após este ser processado.

\subsection{Processo de Fabricação de Bolsa para Coleta de Sangue}

O primeiro passo para a confecção das bolsas para coleta de sangue é a fabricação do filme a ser utilizado, conforme a formulação descrita no item anterior, iniciando com a pesagem e mistura dos componentes da formulação.

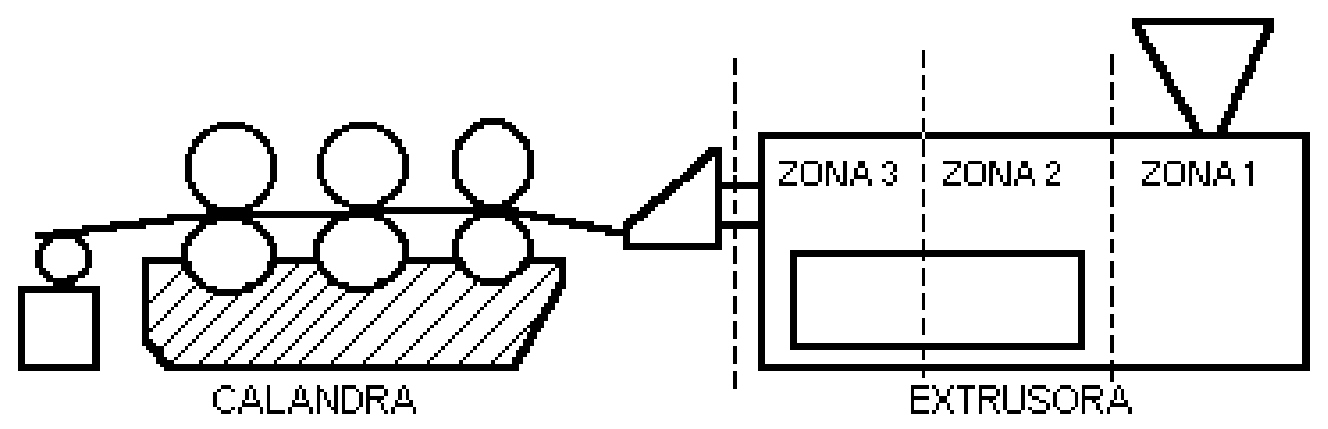

Figura 2. 2 - Esquema da extrusora e calandra utilizada no processo de obtenção dos filmes. Fonte: (VERCENZE, 2006).

O processo de modelagem dos filmes para produção de bolsas de sangue engloba extrusão e calandragem, processos acoplados entre si, em que a massa polimérica é 
introduzida entre cilindros para obtenção de um filme com espessura e gravação de superfícies controladas (MANO, 1991), como podemos observar na figura 2.2.

O filme produzido de acordo com sua formulação pode ser de dois tipos, um contendo DEHP, utilizado em bolsas para coleta de células vermelhas e componentes, e outro com TEHTM, usado somente em bolsa para coleta de plaquetas.

Este filme deve possuir boa resistência ao calor, para suportar o processo de esterilização com temperaturas entre $115^{\circ}$ e $120^{\circ} \mathrm{C}$, e não encolher mais que $4 \%$ para garantir a qualidade da confecção das bolsas de sangue.

O filme então é cortado, bobinado e enviado para a confecção de bolsas, as quais são processadas em equipamento que realiza a estampa, as soldas e a colocação dos hímens e interruptores de fluxo. Após o processamento neste equipamento o filme é transformado em placas com bolsas já com sua forma final, como se pode observar na figura 2.3.

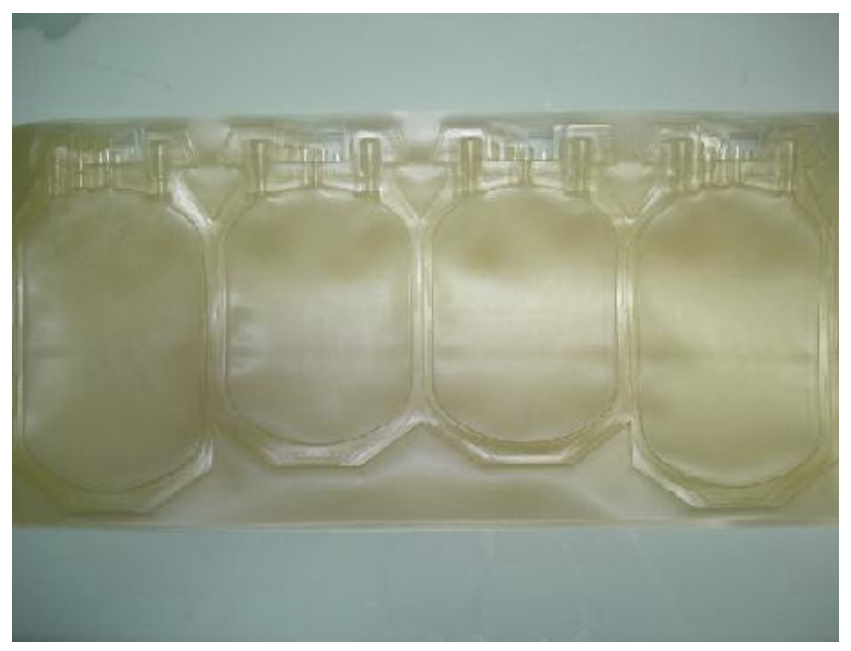

Figura 2. 3 - Placa já estampada e soldada.

Nesse momento, é feita uma inspeção visual utilizando apenas iluminação, como ferramenta de trabalho para detectar possíveis resíduos nessas placas oriundos da fabricação dos filmes como se pode observar na figura 2.4. 


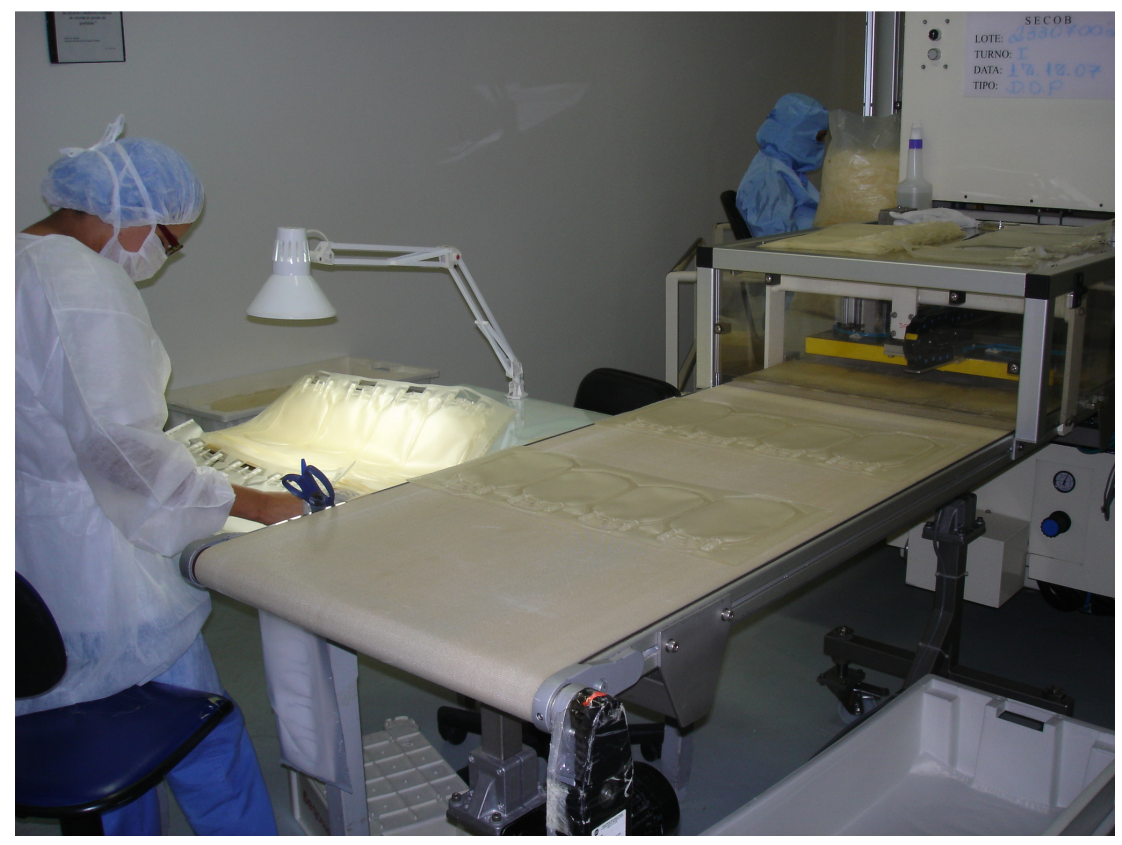

Figura 2. 4 - Equipamento de confecção de bolsas e inspeção visual.

Esta etapa de produção é realizada em ambiente fechado e controlado, com acesso restrito. Os funcionários são paramentados com trajes adequados segundo as especificações da Vigilância Sanitária. As áreas que têm ambiente controlado, acesso restrito e a exigência de trajes específicos são chamadas "Área Limpa".

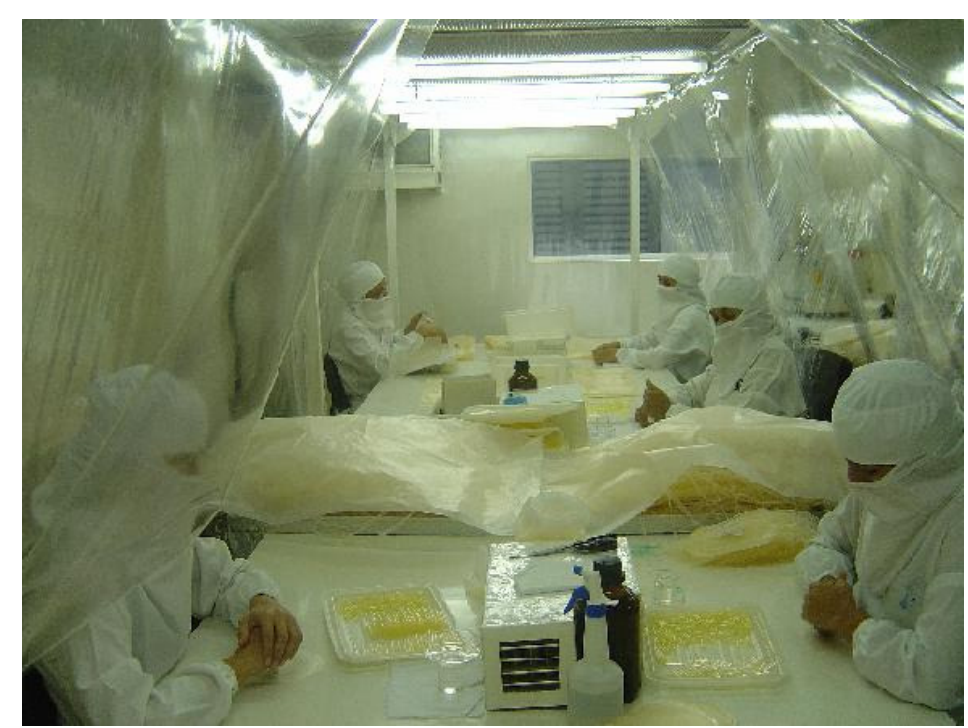

Figura 2. 5 - Área de montagem da bolsa. 
A seguir, conforme o modelo de bolsa para coleta de sangue que está sendo produzido, as bolsas estampadas são destacadas dessas placas, montadas e colados os tubos, filtros, agulhas e a solução anticoagulante é envasada. Esta etapa é executada também em “Área Limpa“, apenas com funcionários treinados para realização desta tarefa, como se pode observar na figura 2.5 .

Depois de montadas, as bolsas são identificadas, embaladas individualmente e esterilizadas em autoclaves à temperatura de $115^{\circ} \mathrm{C}$.

As autoclaves são equipamentos de esterilização que controlam a pressão e temperatura no seu interior, utilizando água aquecida ou vapor quente para elevar a temperatura. Elas possuem sistema automatizado de controle e monitoramento do seu funcionamento garantindo a qualidade e eficácia do processo de esterilização.

O último passo do processo de fabricação é a embalagem final.

Todas as etapas do processo produtivo são monitoradas por exames laboratoriais realizados em laboratório próprio (Laboratório de Controle da Qualidade), de acordo com a farmacopéia vigente e as exigências da Vigilância Sanitária.

O processo de fabricação industrial pode ser resumido no diagrama da figura 2.6. 


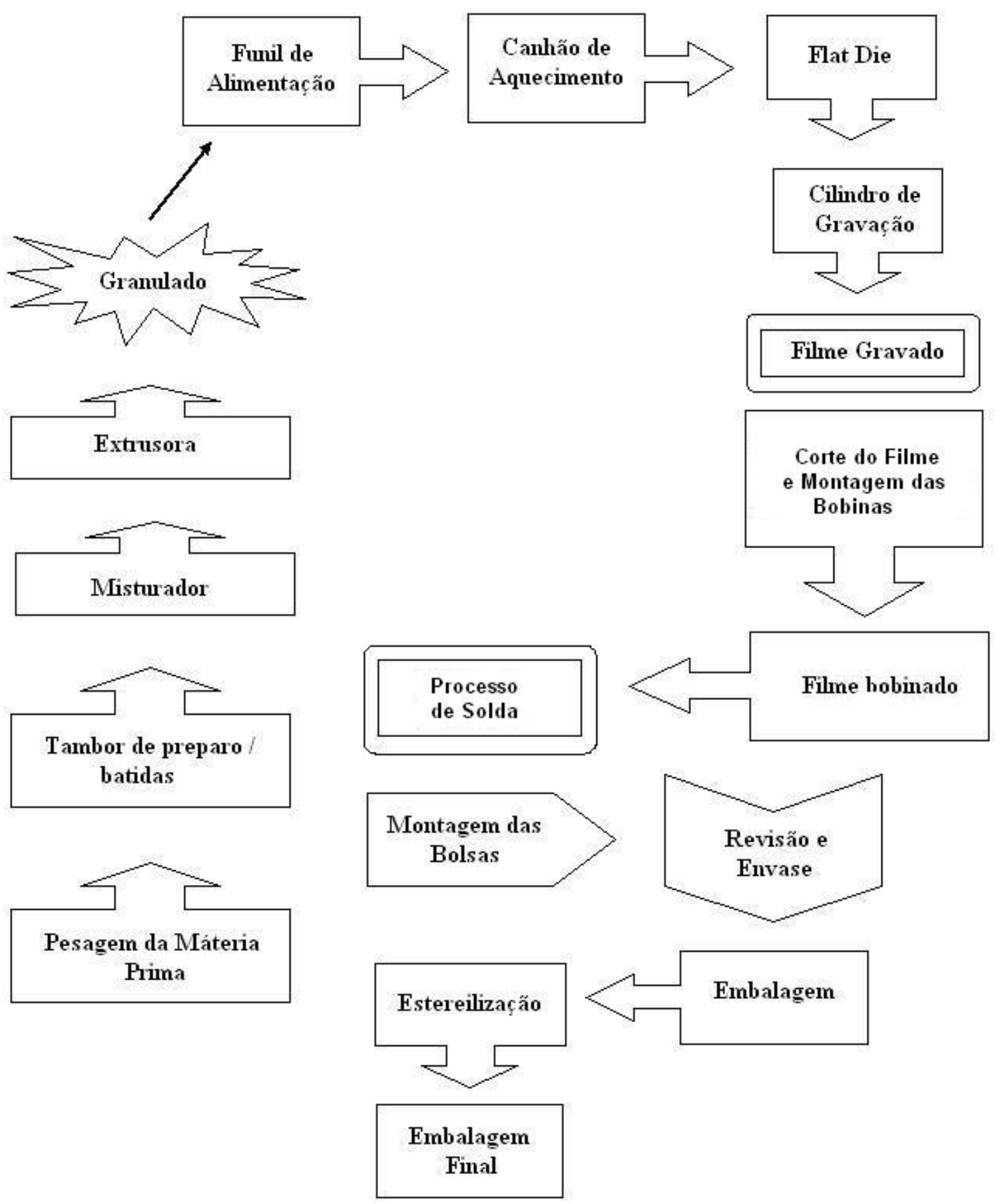

Figura 2. 6 - Diagrama do processo de fabricação. 
Capítulo

\section{Fundamentos Teóricos da Metodologia Proposta}

\subsection{Considerações Iniciais}

As primeiras aplicações com processamento de imagens datam do início do século XX, na busca de maneiras de aprimorar a qualidade de impressão de imagens digitalizadas transmitidas através do sistema Bartlane (GONZALEZ, 2000).

Processamento de imagens é o nome dado a qualquer forma de processamento de dados em que a entrada e a saída são imagens, como fotografia ou quadros de vídeo. Diferente do tratamento de imagens, que diz respeito à manipulação de figuras para sua representação final, o processamento de imagens é um estágio para novos processamentos de dados como aprendizagem de máquinas ou reconhecimento de padrões.

A maioria das técnicas envolve o tratamento das imagens como sinal bidimensional, no qual são aplicados padrões de processamento de sinal. Há algumas décadas o processamento de imagens era feito quase que exclusivamente de forma analógica, através de dispositivos ópticos.

O grande impulso para a área de processamento de imagens surgiu com os primeiros computadores de grande porte e o início do programa espacial americano que, em 
1964, usou o computador para corrigir vários tipos de distorções nas imagens da Lua transmitidas pela sonda Ranger (MARQUES FILHO, 1999).

A partir daí a área de processamento de imagens tem apresentado crescimento expressivo em suas aplicações em diversos setores de atividade humana, como em medicina, biologia, geografia, geoprocessamento, meteorologia, automação industrial etc.

A área de processamento de imagens está dividida em duas categorias bem distintas: o aprimoramento de informações pictóricas para interpretação humana ou apenas processamento para interpretação humana e a análise automática por computador de informações extraídas de uma cena ou aplicações de técnicas de processamento digitais (GONZALEZ, 2000).

\subsection{Representação de Imagens Digitais}

A imagem digital, monocromáticas ou coloridas, é uma função $f(x, y)$ discretizada tanto em coordenadas espaciais quanto em brilho. Uma imagem digital pode ser considerada como uma matriz $\mathrm{M}$ x $\mathrm{N}$ cujos índices de linhas e colunas $(x, y)$ identificam um ponto na imagem, e o valor da função $f(x, y)$ é a escala do nível de cinza naquele ponto. Os pontos dessa matriz são chamados elementos da imagem ou simplesmente “pixels”, proveniente da abreviação de Picture Elements (GONZALEZ, 2000). Na figura 3.1 pode-se observar a convenção dos eixos para representação de imagens digitais e um pixel na imagem. 


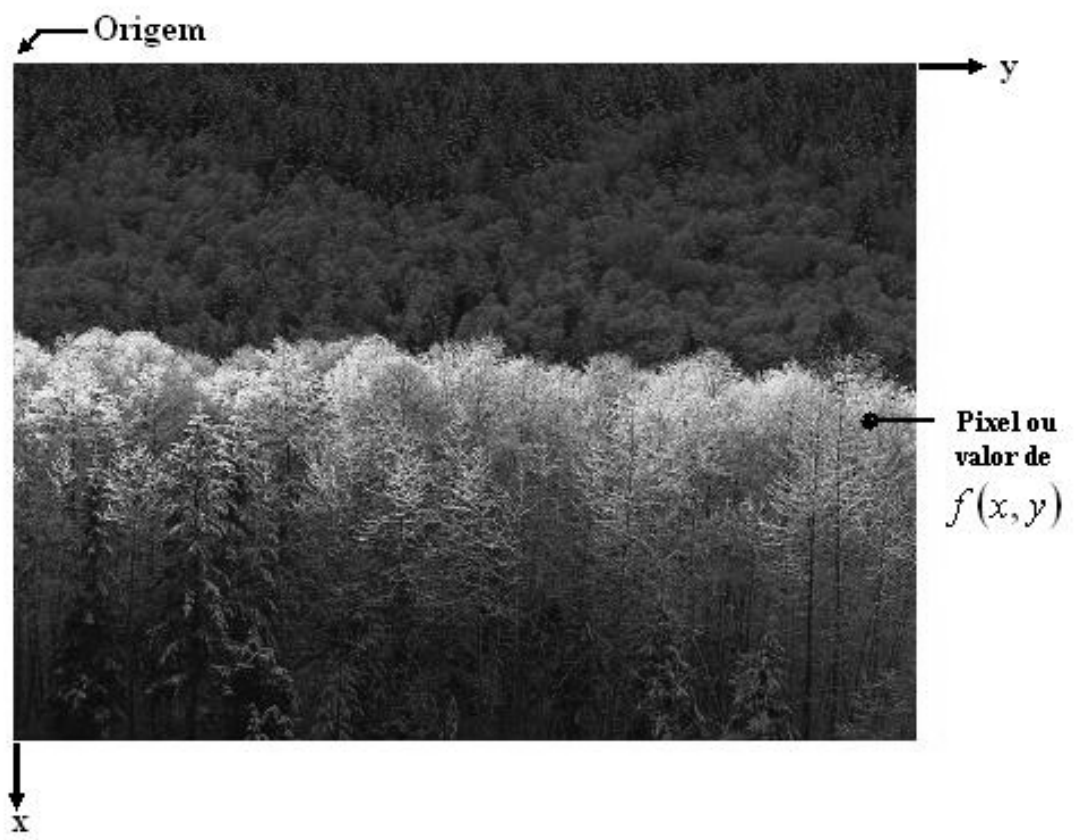

Figura 3. 1 - Convenção dos eixos para representação de imagens digitais. Adaptado: (GONZALEZ, 2000).

\subsection{Visão Computacional}

As etapas necessárias para solucionar um problema, utilizando visão computacional, podem ser ilustradas através da figura 3.2.

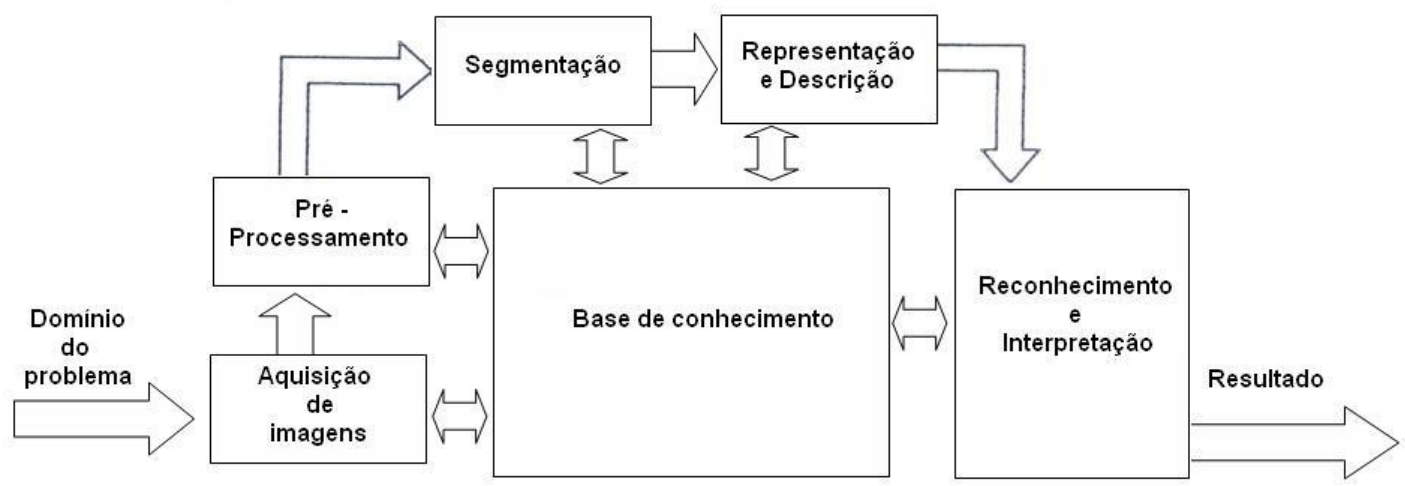

Figura 3. 2 - Etapas da visão computacional.

Fonte: (GONZALEZ, 2000).

Para aplicações em cenas reais, o "Domínio do problema" consiste em avaliar as condições da cena, ou seja, iluminação, reflexo, cor dos objetos, sombras etc., e procurar 
resolver os problemas inerentes ao meio físico para que as imagens tenham a melhor qualidade possível.

$\mathrm{Na}$ aquisição de imagens é necessário avaliar e definir os equipamentos para a captura das mesmas, o conjunto de lentes e os requisitos de velocidade de aquisição.

O pré-processamento tem a função de melhorar a imagem de forma a aumentar as chances de sucesso dos passos seguintes. O pré-processamento envolve tipicamente o uso de filtros.

A segmentação tem como tarefa básica dividir uma imagem em partes ou unidades significativas, ou seja, em objetos de interesse que a compõem. Esta tarefa é uma das mais difíceis no processamento, mas se for realizada corretamente, contribui positivamente para a solução do problema.

Durante a representação e descrição, transformam-se os segmentos em valores adequados para reconhecimento.

Reconhecimento / Interpretação envolve a atribuição de significados a um conjunto de objetos reconhecidos.

Para melhorar as imagens e aumentar as chances de sucesso do sistema de visão computacional é importante usar filtros. Estes filtros dividem-se em duas categorias: filtros no domínio espacial e no domínio da frequiência. As técnicas no domínio espacial operam diretamente sobre a matriz de pixels, ou seja, na imagem digitalizada, enquanto que as técnicas no domínio da frequiência são baseadas no teorema da convolução, como a Transformadas de Fourier e a Transformada Wavelet (GONZALEZ, 2000). 


\subsection{Transformada Wavelet no Domínio da Freqüência}

A análise de sinais têm sido de grande importância para pesquisa e desenvolvimento em diversas áreas do conhecimento, como engenharia biomédica, geofísica, processamento de imagens, medicina, entre outros (ALMEIDA, 2006).

Por meio da análise de sinais é possível conhecer ou descobrir detalhes importantes destes sinais, como o comportamento de sua fonte, ou identificar parâmetros que influenciam, com maior ou menor intensidade de atuação (ALMEIDA, 2006).

Há várias técnicas para análise de sinais, a mais conhecida e utilizada é a Transformada de Fourier (Fourier Transform - FT), contudo esta técnica possui uma deficiência no que diz respeito à análise de sinais não estacionários, pois não representa a informação temporal do sinal analisado (ALMEIDA, 2006; BIANCHI, 2006).

Desse modo é necessária outra abordagem para a análise de sinais não estacionários, quando esta informação é necessária. Uma proposta bem aceita e com bons resultados nesses casos é a utilização da Transformada Wavelet (Wavelet Transform - WT) (ALMEIDA, 2006; BIANCHI, 2006).

A Transformada Wavelet é sugerida como próximo passo à Transformada de Fourier, e à Transformada de Fourier por janelas, a qual minimiza os problemas da análise de sinais não estacionários, mas não resolve totalmente a perda da informação temporal do sinal (ALMEIDA, 2006; BIANCHI, 2006).

Com a utilização da Transformada Wavelet obtém-se uma forma flexível de análise de sinais, onde a informação temporal do sinal é preservada e pode-se utiliza-la para representar uma característica importante do sinal (ALMEIDA, 2006).

No processamento de imagens a Transformada Wavelet se destaca por possuir funcionalidades que podem ser usadas como banco de filtros para extrair características das 
imagens e permite ter a interpretação invariante da escala, ou seja, em razão de alguns fatores como: distância entre a cena ou o centro óptico. (BIANCHI, 2006; USER, 1996).

A Transforma Wavelet usada como banco de filtros é capaz de analisar e destacar as altas freqüências, gerando filtros passa - alta, que podem realçar ou destacar detalhes na imagem (STRANG,1996).

Por se tratar de uma metodologia para análise de imagens envolvendo processamento digital será dado ênfase à Wavelet de Haar, por sua simplicidade para implementação, baixo custo computacional, e ser amplamente usada em processamento de imagens digitais.

\subsubsection{Transformada de Fourier}

A Transformada de Fourier (Fourier Transform - FT) é uma das ferramentas mais conhecidas e utilizadas no processamento de sinais; seu objetivo é transformar um sinal do domínio espacial para o domínio da frequiência, decompondo o sinal espacial original em componentes de seno e co-senos de diferentes freqüências. (GONZALEZ, 2000; WANG, 2000). A função responsável pela transformação é dada por:

$$
F(u)=\int f(t) e^{-2 i \pi u t} d t
$$

No entanto, existem alguns domínios para o qual essa técnica não se mostra tão eficiente quanto o desejado. A FT possui uma característica indesejável: no momento da transformação do sinal do domínio espacial para o da freqüência perde-se totalmente a informação de localização temporal do sinal (ALMEIDA, 2006; BIANCHI, 2006).

Assim, a FT gera uma representação Amplitude x Freqüência do sinal, ou seja, ela diz simplesmente se uma componente de frequiência existe ou não, o que a torna inadequada 
para sinais cujas freqüências variam no tempo, os chamados sinais não-estacionários ou transitórios (BIANCHI, 2006).

Para minimizar este problema, Dennis Gabor, no ano 1946, propôs a Transformada de Fourier por janelas ou Windowed Fourier Transform (WFT) ou Short Time Fourier Transform (STFT) (FORNIER, 1995; GABOR 1946). Gabor adaptou a Transformada de Fourier para analisar uma pequena porção de sinal em um tempo, introduzindo as “janelas".

Na WFT o sinal é subdividido em segmentos pequenos o suficiente para serem considerados estacionários. Para esse propósito é escolhida uma função janela $j(t)$, cuja largura deve ser igual ao segmento do sinal que é assumido como estacionário. Essa função janela é localizada inicialmente em $t=0$ e multiplicada pelo sinal. Em seguida obtêm-se a FT dessa porção de sinal e desloca-se a função janela, repetindo-se o processo até o final do sinal. A função da WFT pode ser definida, considerando o sinal contínuo de $f(t)$, como:

$$
F(u, b)=\int f(t-b) f(t) e^{-2 i \pi u t} d t
$$

Na figura 3.3 pode-se observar a função janela, a WFT no domínio do espaço e no domínio da freqüência.

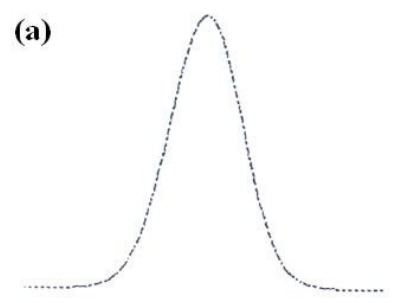

(b)

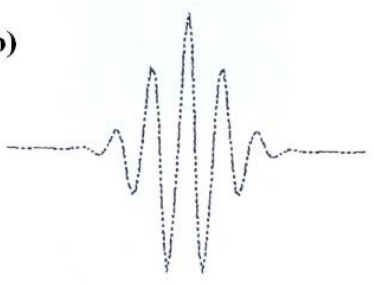

(c)

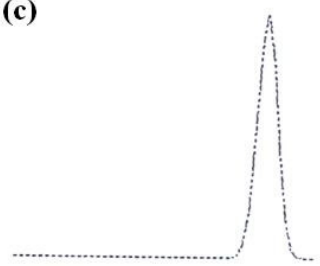

Figura 3.3 - (a) Função-Janela no domínio do espaço - (b) Base WFT no domínio do espaço - (c) Base da WFT no domínio da frequiência.

Fonte: (ENCINAS JÚNIOR, 2000). 
A deficiência da WFT está no chamado Princípio da Incerteza de Heisenberg, cuja formulação original afirma que o momento e a posição de uma partícula em movimento não podem ser conhecidos simultaneamente (FORNIER, 1995). Assim a informação de tempo e freqüência para um ponto exato no plano Tempo $x$ Freqüência não podem ser simultaneamente conhecidos, ou seja, não podemos saber qual componente ocorre em um determinado instante de tempo.

Esse fato gera um problema de resolução. Este problema de resolução está relacionado à largura da função janela usada. Isso ocorre porque a janela se mantém constante para todas as frequiências; entretanto em muitos casos, os sinais necessitam de uma janela variável para se observar com precisão um evento no tempo e na frequiência (ALMEIDA, 2006).

Por este motivo os pesquisadores têm substituído a WFT pela WT, por possuir suporte compacto, ou seja, a sua função possui uma janela limitada.

A WT foi desenvolvida para superar o problema de resolução da WFT, eliminando o problema de qual tamanho de janela usar, pois se pode analisar um sinal utilizando a Análise Multiresolução (Multiresolution Analisys - MRA), fornecendo boa resolução de tempo, para altas freqüências, com janelas mais estreitas e boa resolução de freqüência, para baixas freqüências.

Na figura 3.4 pode-se observar a forma generalizada janelas de análise no plano tempo-frequiência para a WFT e WT. 
WFT<smiles>C1CCCC1</smiles>
Wh
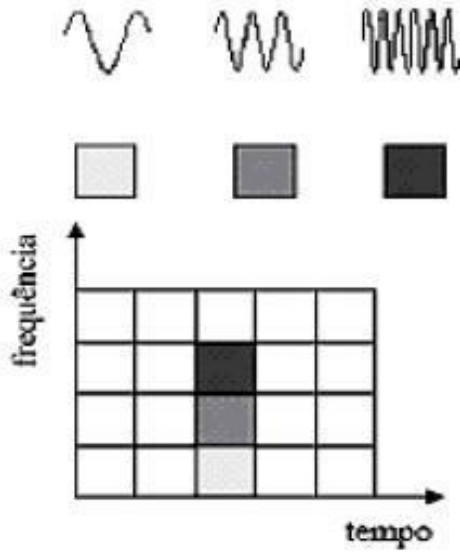

WT

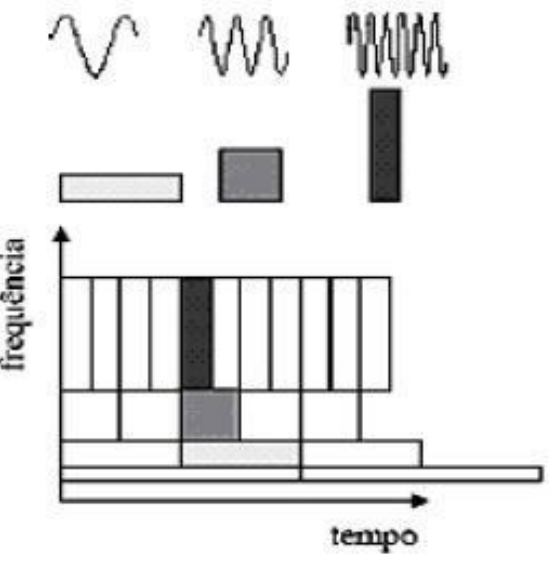

(a)

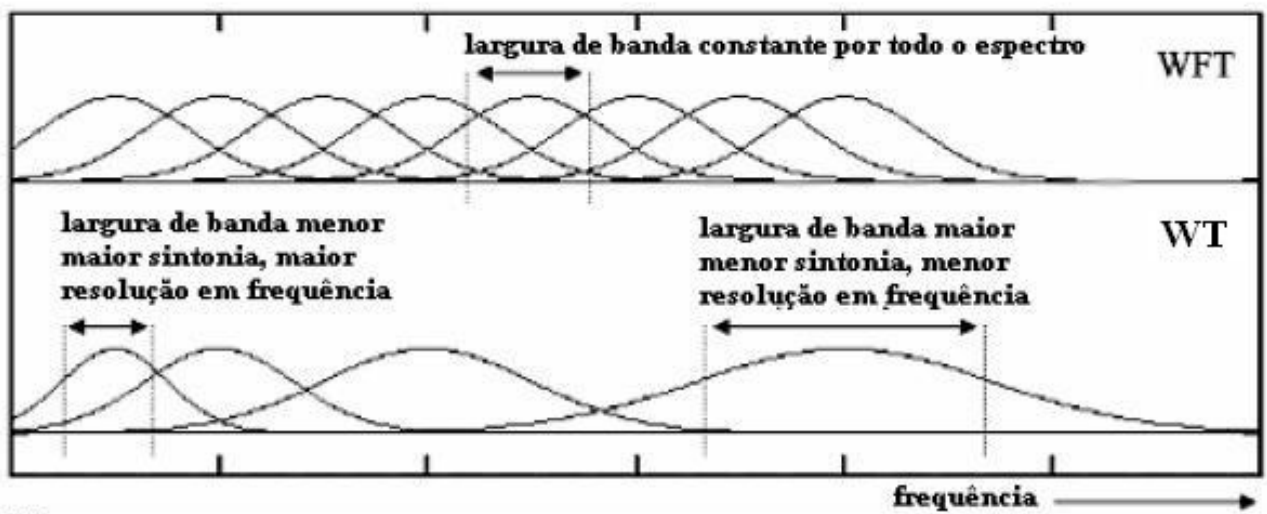

(b)

Figura 3.4 - (a) Janelas de análise do plano tempo-freqüência para WFT e WT - (b) cobertura do espectro de freqüência pela WFT e pela WT.

Fonte: (FARIA, 1997).

\subsubsection{Transformada Wavelet}

As Wavelets são funções que satisfazem a certos requisitos matemáticos e são usadas na representação de dados ou de outras funções. A idéia fundamental por trás das Wavelets é analisar de acordo com a escala (ALMEIDA, 2006).

A idéia de funções representando funções, não é nova. Sua origem se baseia no trabalho de Joseph Fourier, que no século XIX descobriu que poderia utilizar senos e co-senos para representar outras funções (ALMEIDA, 2006; CASTELANO, 2006). A novidade em 
relação a Fourier é que a análise Wavelet não é feita segundo a freqüência, mas sim segundo a escala. Assim os algoritmos Wavelet processam dados em diferentes escalas e resoluções, permitindo que sejam vistos tanto o global quanto os detalhes (ENCINAS JÚNIOR, 2000).

Desse modo um sinal pode ser observado por uma janela grande de tempo, se as características observadas desse sinal são grosseiras, e por uma janela pequena de tempo se as características do sinal são mais refinadas (ALMEIDA, 2006). Isso permite observar tanto características mais aparentes quanto as menos perceptíveis.

Para obter as características das janelas variáveis e analisar os sinais de maneira flexível, a WT é considerada como um sinal contínuo de $f(t)$, e dada pela equação 3.3 , onde o parâmetro $a$ representa a escala (resolução) e o parâmetro $b$ representa o deslocamento (translação) (CASTELANO, 2006).

$$
F(a, b)=\int f(t) \psi_{a, b}(t) d t
$$

A função $\psi_{a, b}(t)$ chamada "wavelet", e derivada de uma função $\psi$ denominada "wavelet-mãe", através da transformação apresentada na equação 3.4 (GALVÃO et al, 2001).

$$
\psi_{a, b}(t)=\frac{1}{\sqrt{a}} \Psi\left(\frac{t-b}{a}\right)
$$

Dessa maneira a análise por wavelet permite usar intervalos longos de tempo (janelas grandes) para encontrar informações de baixa freqüência, e intervalos curtos (janelas pequenas) para localizar informações de alta freqüência (MISITI et al., 2005).

Existem várias possibilidades de escolha para a função $\psi$. A figura 3.5 apresenta algumas alternativas. 


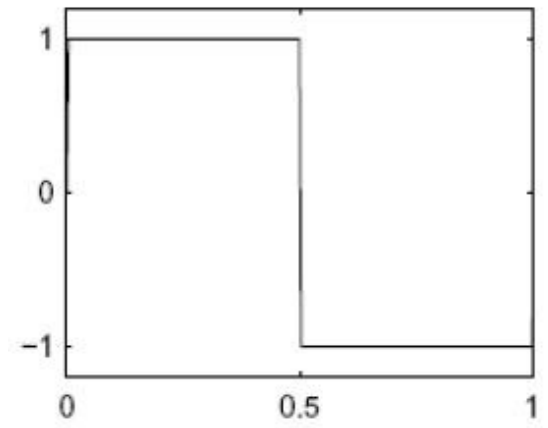

(a) Haar

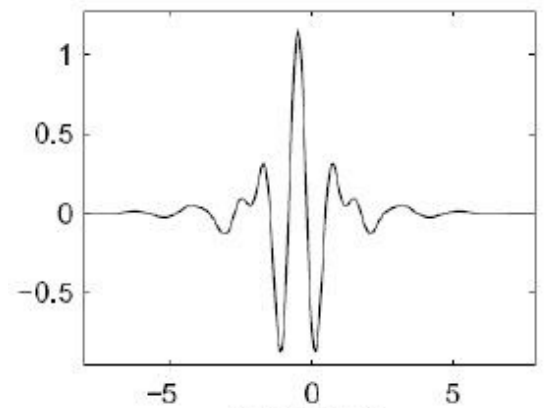

(c) Meyer

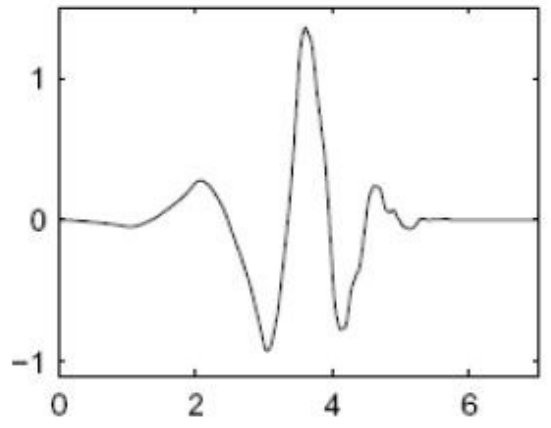

(b) Daubechies - db4

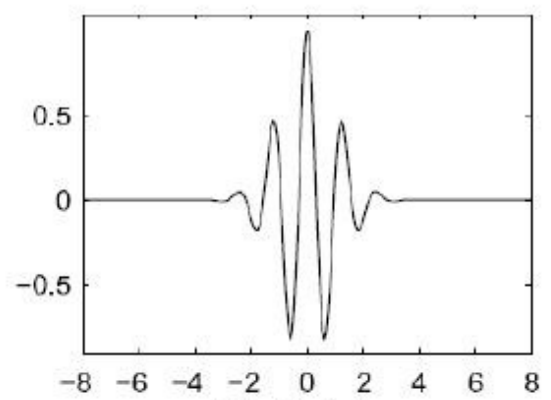

(d) Morlet

Figura 3. 5 - Exemplos de Wavelets - Mãe.

Fonte: (CASTELANO, 2006).

Também é necessário que a wavelet, satisfaça as restrições: $\int|\psi(t)|^{2} d t=1$ e $\int \psi(t) d t=0$. Estas restrições garantem que a $\psi$ tenha energia unitária e caráter ondulatório, ou seja, se comporte como uma onda (ALMEIDA, 2006).

\subsubsection{Transformada Wavelet Contínua}

A Transformada de Wavelet Continua (Continuous Wavelet Transform- CWT) é definida como a soma sobre todos os tempos do sinal multiplicado por uma versão escalada e deslocada da Wavelet-mãe. Assim a CWT é definida como produto interno na forma dada pela equação 3.5, onde $\psi_{a, b}(t)$, a "wavelet-mãe", e os parâmetros $a$ e $b$ estão apresentados pela transformação da equação 3.4 . 


$$
C W T_{f(a, b)}=\left\langle f(t), \psi_{a, b}(t)\right\rangle=\int f(t) \cdot \psi_{a, b}(t) \cdot d t
$$

Assim a CWT é constituida da soma de todos os sinais $f(t)$ no tempo, multiplicados por versões de escala e deslocamento da função wavelet-mãe (MISITI et al., 2005), tendo como resultado vários coeficientes Wavelet $(C)$, que são em função da escala e posição, conforme a equação 3.6.

$$
C(\text { escala }, \text { posição })=\int f(t) \psi(\text { escala }, \text { posição, } t) d t
$$

O fator escala na wavelet representa a forma de comprimir ou expandir um sinal, e o fator posição representa o deslocamento do sinal, através de avanço ou retardo do seu ponto inicial. A figura 3.6 mostra o escalonamento em Wavelets.

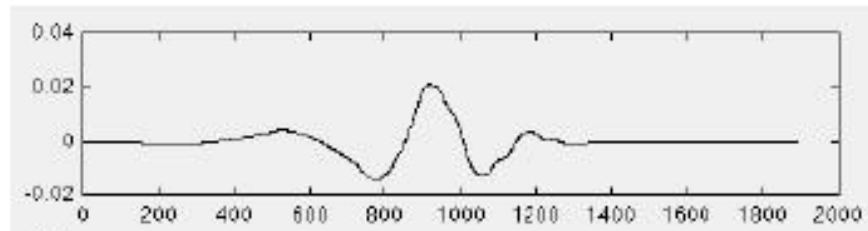

$$
\begin{aligned}
& f(t)=\psi(t) \quad ; \quad a=1 \\
& f(t)=\psi(2 t) ; \quad a=\frac{1}{2}
\end{aligned}
$$
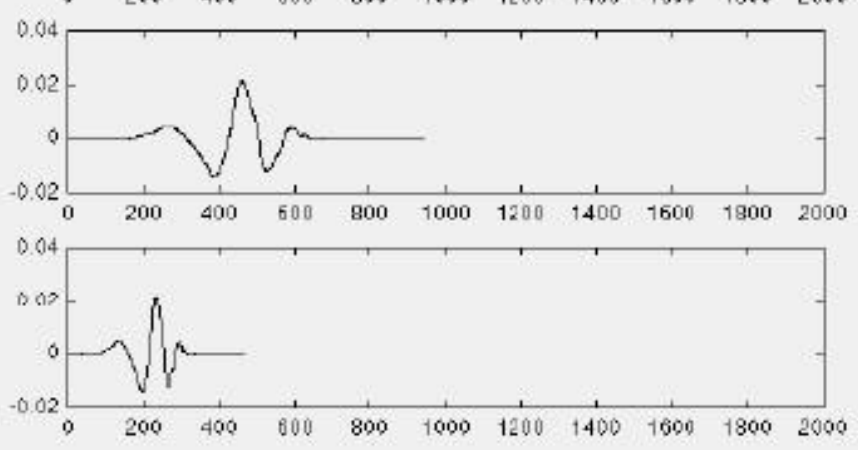

$$
f(t)=\psi(4 t) ; \quad a=\frac{1}{4}
$$

(a)

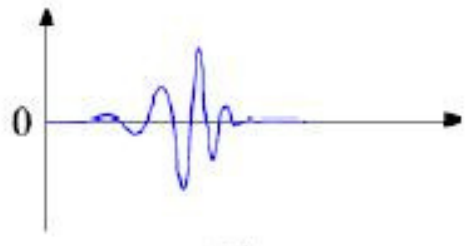

$\psi(t)$

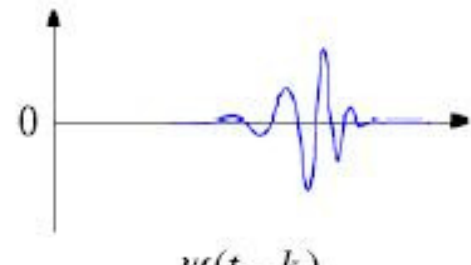

$\psi(t-k)$

(b)

Figura 3.6 - (a) 3 exemplos de escala de sinal em wavelet - (b) deslocamento de sinal em Wavelet. Fonte: (MISITI et al., 2005).

Para se obter os coeficientes de wavelets em cada escala possível requer-se uma grande quantidade de cálculos, pois a wavelets é deslocada sobre todo o domínio da função 
analisada, calculando-se a correlação entre as duas. Este processo gera grande quantidade de informação redundante, requerendo grande quantidade de tempo e recurso computacional .

\subsubsection{Transformada Wavelet Discreta}

A Transformada Wavelet Discreta (Discrete Wavelet Transform - DWT) escolhe um subconjunto de escala e posições sobre as quais realiza os cálculos. Desse modo fornece informações tanto para análise, decomposição ou reconstrução do sinal, com esforço computacional menor, podendo ser aplicada recursivamente sobre diferentes escalas, utilizando algoritmos rápidos.

Na DWT escalas e posições geralmente são escolhidas baseadas em potência de dois, chamadas escalas e posições dyadic, então a analise é mais eficiente, no sentido de aumentar o desempenho do algoritmo, mantendo sua exatidão.

Segundo Daubechies (1992), dentro da DWT distinguem-se duas abordagens: sistemas discretos (frames) e o ortonormal. A segunda abordagem considera a estratégia de análise de multiresolução (Multiresolution Analisys - MRA), desenvolvida por Mallat (MALLAT, 1989).

A MRA é uma maneira eficiente de implementar o uso de bases ortonormais de wavelets. Quando Mallat trabalhou com análise de imagens, utilizou pela primeira vez as wavelets de Meyer, a idéia era estudar imagens em várias escalas simultaneamente. Isso o estimulou a ver bases ortonormais de wavelets como uma ferramenta para descrever matematicamente o "incremento da informação" para ir de uma aproximação grosseira para uma aproximação com maior resolução (DAUBECHIES, 1990).

Na MRA a função Wavelet $\psi(t)$ está relacionada a um filtro passa - alta, o qual produz os coeficientes de detalhes. Há uma função adicional que está relacionada ao filtro passa - 
baixa, chamada de função de escalonamento, que produz os coeficientes de aproximação da decomposição Wavelet (PARRAGA, 2002).

Este processo de decomposição dos sinais pode ser comparado a uma caixa por onde o sinal passa e é convertido em coeficientes de wavelets de detalhe e aproximação, conforme representado na figura 3.7.

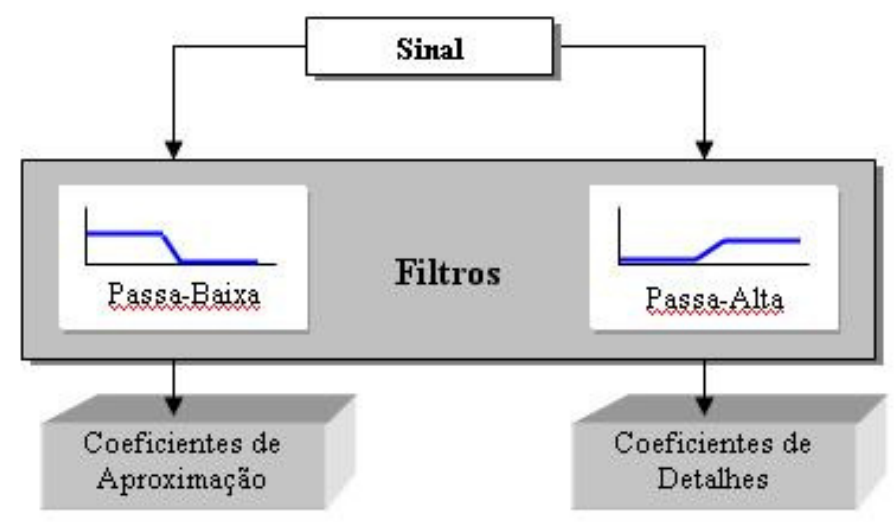

Figura 3. 7 - Processo de decomposição das wavelets.

Adaptado: (CASTELANO, 2006).

Neste processo o sinal passa por filtros passa - alta para analisar as altas frequiências e por filtros passa - baixa para analisar as baixas frequiências gerando um banco de filtros.

Este banco de filtros serve para suavizar ou realçar detalhes da imagem, ou minimizar efeitos de ruídos. No filtro passa - baixa as altas freqüências são atenuadas, ou seja, as informações de altas freqüências são reduzidas, mas a escala permanece inalterada. No filtro passa - alta os detalhes (bordas, linhas curvas etc.) são realçados. Desta forma podem-se enfatizar ruídos nas imagens.

Esta seqüência de filtragens digitais sobre o sinal original, é conhecido como codificação sub-banda, onde um par de filtros digitais, definidos como filtros de quadratura ou QMF (Quadrature Mirror Filters), é representado pelas funções $h(n)$ e $g(n)$, que são 
respectivamente, as funções de filtro passa - baixa e passa - alta, cada um com metade da banda original (CASTELANO, 2006).

Este processo de filtragem pode ser repetido várias vezes. A cada nível de filtragem obtém-se a metade do número de amostras e conseqüentemente metade do tempo de resolução. A figura 3.8 ilustra esse processo de filtragem em três níveis de decomposição

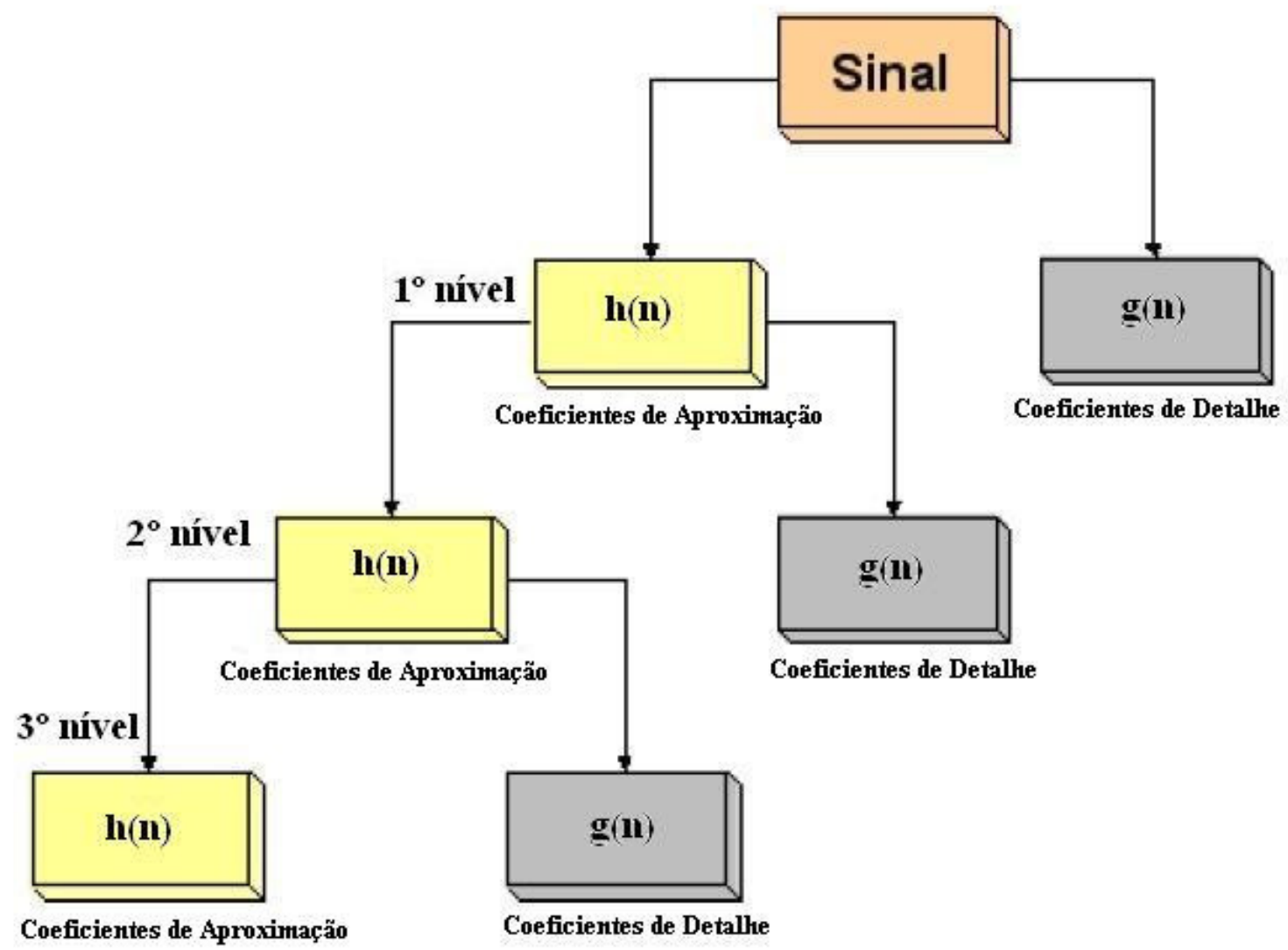

Figura 3. 8 - Processo de filtragem do sinal em 3 níveis.

Adaptado: (CASTELANO, 2006).

Na análise de imagens, onde os sinais são tratados em 2-D, a DWT produz uma matriz de coeficientes chamados de coeficientes de wavelets. Quando se aplica a DWT em uma imagem, são gerados quatro tipos de coeficientes: aproximação, detalhes horizontais, 
detalhes verticais e detalhes diagonais (CASTELANO, 2006). A figura 3.9 mostra o resultado da DWT aplicada a uma imagem com três níveis de decomposição.

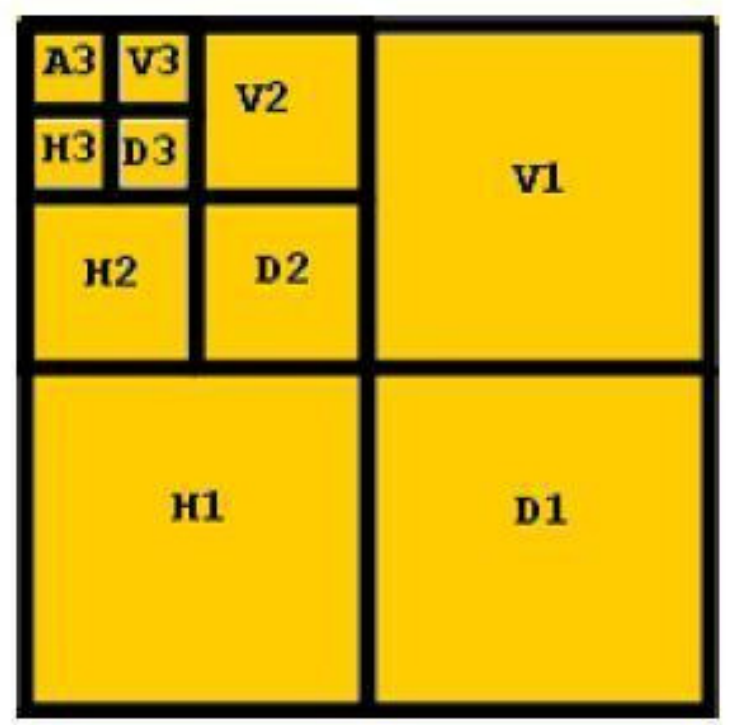

(a)
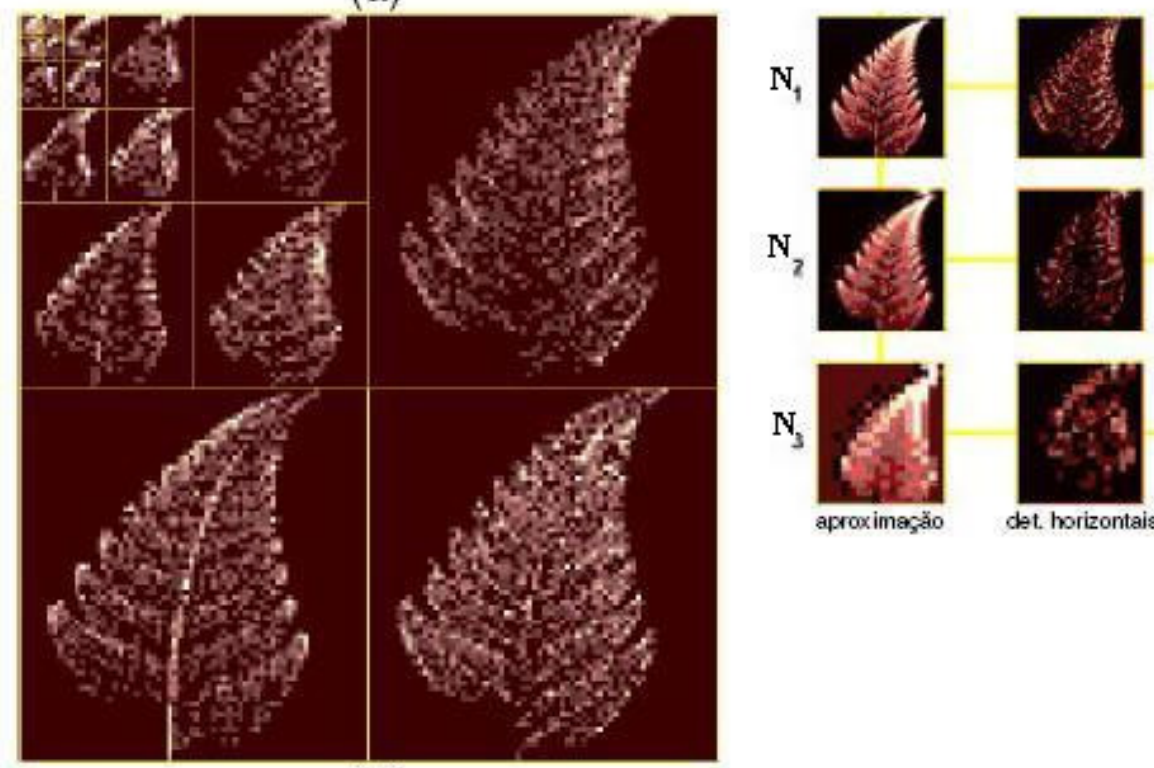

dat. horizontais

(d)

(c)

Figura 3. 10 - (a) Esquema de organização dos coeficientes wavelets (b) Imagem original (c) Decomposição em 3 níveis (d) Três níveis de decomposição (N1, N2,N3) vistos individualmente com seus respectivos coeficientes. Adaptado: (CASTELANO, 2006).

Neste exemplo, a cada nível de decomposição se obtém uma subimagem com os coeficientes de aproximação (passa - baixa) e três subimagens que correspondem aos coeficientes de detalhe (passa - alta), contendo os detalhes horizontais, diagonais e verticais. 
Neste processo de decomposição dos subníveis da transformada, apenas os coeficientes de aproximação são novamente divididos em coeficientes de aproximação e detalhes, chamado de segundo nível. Assim o processo pode ser repetido $n$ vezes.

\subsubsection{Wavelet de Haar}

Em 1909, Alfred Haar apresentou a primeira menção a wavelets, e a mais simples de todas as wavelets, que pertence à família da wavelets ortonormais (ALMEIDA, 2006; HAAR, 1910). A Wavelet de Haar pode ser definida como mostrado na equação 3.7 e graficamente como na figura 3.10:

$$
\psi(x)= \begin{cases}1, & \text { se } x \in\left[0, \frac{1}{2}\right) \\ -1, & \text { se } x \in\left[\frac{1}{2}, 1\right) \\ 0, & \text { caso contrário }\end{cases}
$$

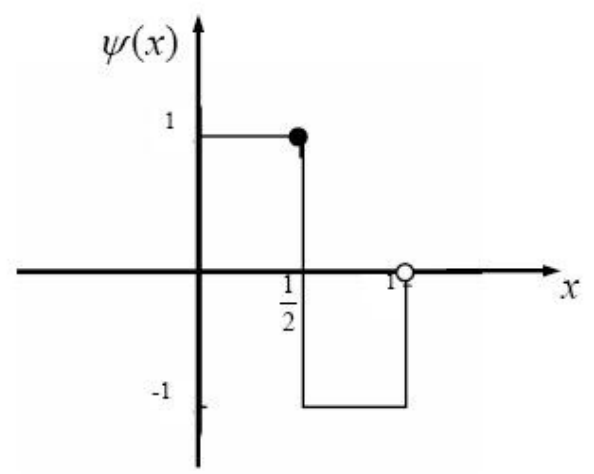

Figura 3. 11 - Representação da Wavelet de Haar.

Fonte: (HAAR, 1910).

A Wavelet de Haar tem como uma das propriedades ter suporte compacto o que significa que tende a zero fora de um intervalo finito, e apesar de não ser suave, é amplamente usada em muitas aplicações, especialmente em processamento de imagens digitais (LIMA, 2004). 


\subsubsection{Wavelet no Processamento de Imagens}

Em uma imagem digital $f(x, y)$, suas linhas e colunas podem ser tratadas como se fossem "imagens unidimensionais".

Desse modo, a decomposição de uma imagem é obtida aplicando-se a transformada unidimensional, primeiro nas colunas da imagem e depois sobre as linhas. Isto é possível uma vez que a WT é uma transformada unitária, e sendo assim, a transformada bidimensional torna-se separável, caindo no caso da aplicação da transformada unidimensional sobre as linhas e colunas da imagem.

Existem duas formas de se processar a decomposição: a padrão e a não padrão (LIMA, 2004). Na forma padrão processa-se toda a transformada unidimensional das colunas da imagem, gerando os coeficientes de detalhe correspondentes, e em seguida processam-se as linhas criando os coeficientes finais.

$\mathrm{Na}$ forma não padrão, aplica-se, alternadamente, passos da transformada unidimensional às colunas e às linhas da imagem. O resultado é similar à construção de uma árvore quaternária de região, onde cada nível da árvore corresponde a um nível da aplicação de parte da transformada.

A decomposição padrão é considerada mais simples para implementar, enquanto que a decomposição não padrão se apresenta como um pouco mais eficiente para calcular.

\subsection{Considerações Finais}

Neste capítulo foram mostrados os fundamentos teóricos utilizados no desenvolvimento da metodologia proposta, a representação da imagem digital, as etapas de um sistema de visão computacional, a Transformada Wavelet e o seu uso em processamento de imagens. 
A teoria Wavelet foi apresentada a partir da Transformada de Fourier, mostrando Transformada Wavelet Contínua, a Transformada Wavelet Discreta e a Wavelet de Haar. A Transformada Wavelet demonstra grande capacidade no que se refere à extração de características em imagens.

A WT pode obter de um sinal as componentes de baixa e alta freqüência, e assim, as Wavelet podem destacar ruídos em imagens (altas frequiências), sendo esta uma característica importante para o desenvolvimento da metodologia proposta neste trabalho, uma vez que os resíduos nas imagens de bolsa para coleta de sangue são componentes de alta freqüência. 
Capítulo 4

\section{Materiais e Métodos}

\subsection{Considerações Iniciais}

Este trabalho propõe uma metodologia para automatizar a inspeção visual de bolsas para coleta de sangue. Para isso, todo o processo, desde a aquisição das imagens até a análise dos resultados da detecção de resíduos, será descrito.

$\mathrm{Na}$ aquisição de imagens foram utilizados os seguintes equipamentos: uma câmera de vídeo monocromática com um sistema de iluminação capaz de distribuir de maneira uniforme a luz por todo ambiente da captura da cena, minimizando reflexos ou sombras e também as interferências do ambiente.

O método de iluminação utilizado apresentado no livro de Batchelor (1985) foi escolhido devido a sua capacidade de isolar o elemento sob inspeção (bolsa para coleta de sangue) do ambiente externo (linha de produção) e que será detalhado na seção 4.2. 
$\mathrm{O}$ armazenamento e processamento foram realizados por um microcomputador que, com auxílio de uma placa digitalizadora, recebe os sinais da câmera, converte-os em imagens digitais e os grava no HD do computador.

A figura 4.1 mostra o sistema de visão computacional proposto.

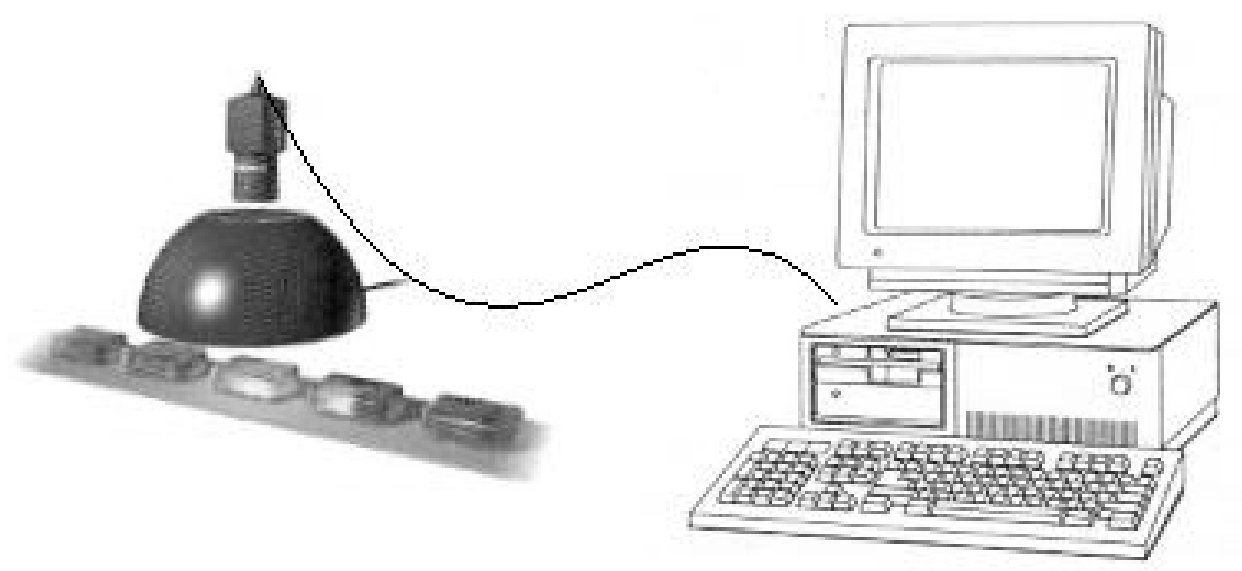

Figura 4. 1 - Sistema de visão computacional para análise das bolsas para coleta de sangue.

Na aquisição das imagens está o primeiro e maior desafio a ser superado, e para se conseguir imagens melhores deve-se utilizar boa iluminação (BATCHELOR, 1985). Uma boa imagem significa otimização do tempo de processamento na detecção de um resíduo, aumento da eficiência do sistema de visão computacional e redução do custo.

Observando-se a figura 4.2 notam-se algumas das dificuldades a serem superadas pelo sistema de visão computacional durante a aquisição das imagens. A primeira é a iluminação, que não está uniformemente distribuída em toda a imagem, causando variações e distorções. 


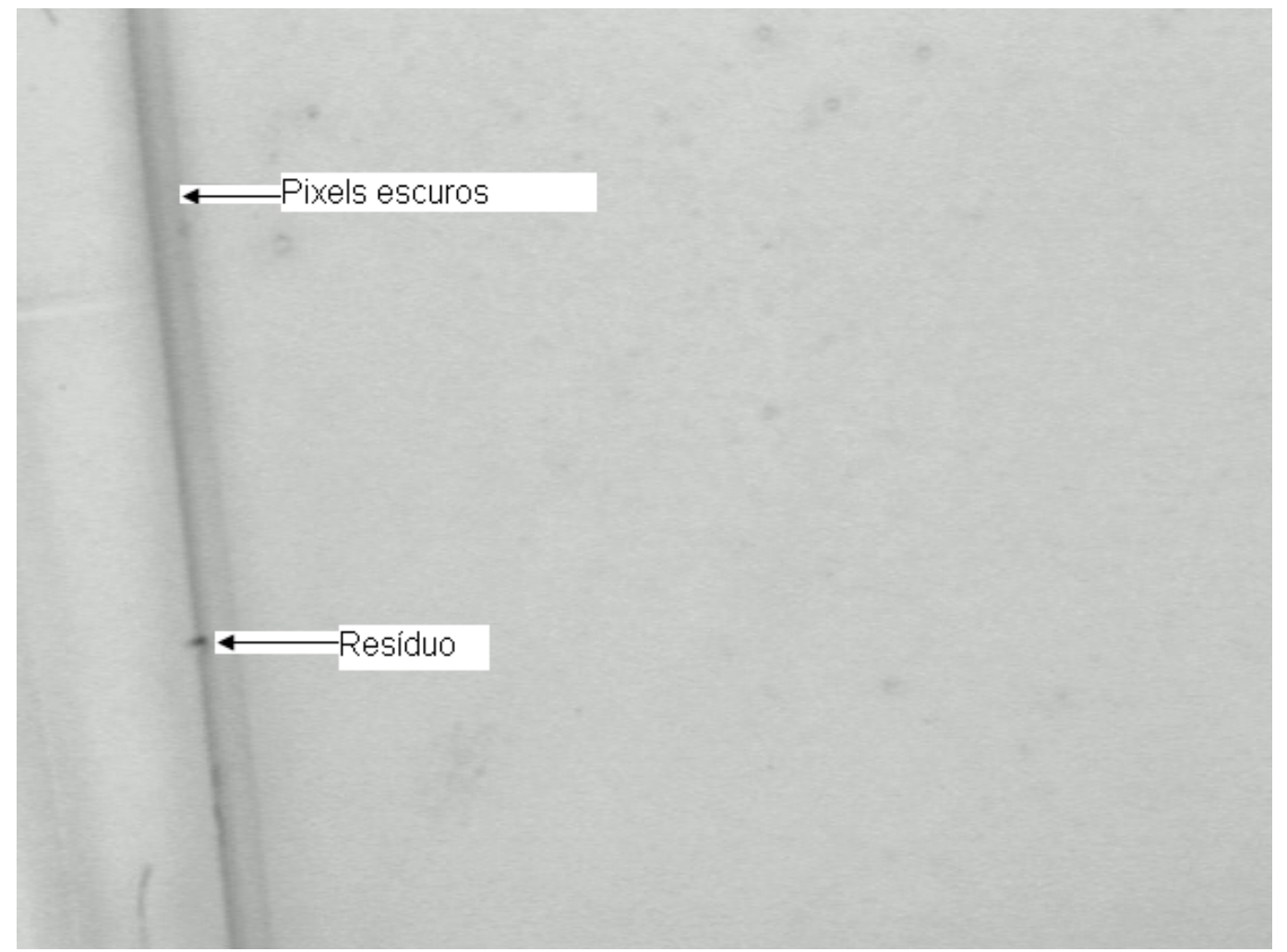

Figura 4. 2 - Imagem da bolsa para coleta de sangue com resíduo na borda.

A segunda dificuldade está nos ruídos gerados durante a captura das imagens. $\mathrm{Na}$ figura 4.2 pode-se notar que próximo à borda da bolsa do lado esquerdo existem pixels escuros. Estes pixels são ruídos gerados durante o processo de captura das imagens devido a iluminação não estar uniformemente distribuída.

A terceira dificuldade vem do próprio filme da bolsa. O filme é translúcido e retém parte da iluminação. O resíduo no filme pode ter várias formas e ser de vários materiais, como pêlos, poeira etc., e finalmente a textura do filme plástico da bolsa pode gerar imagens que prejudicam a detecção de um resíduo como mostra a figura 4.3. 


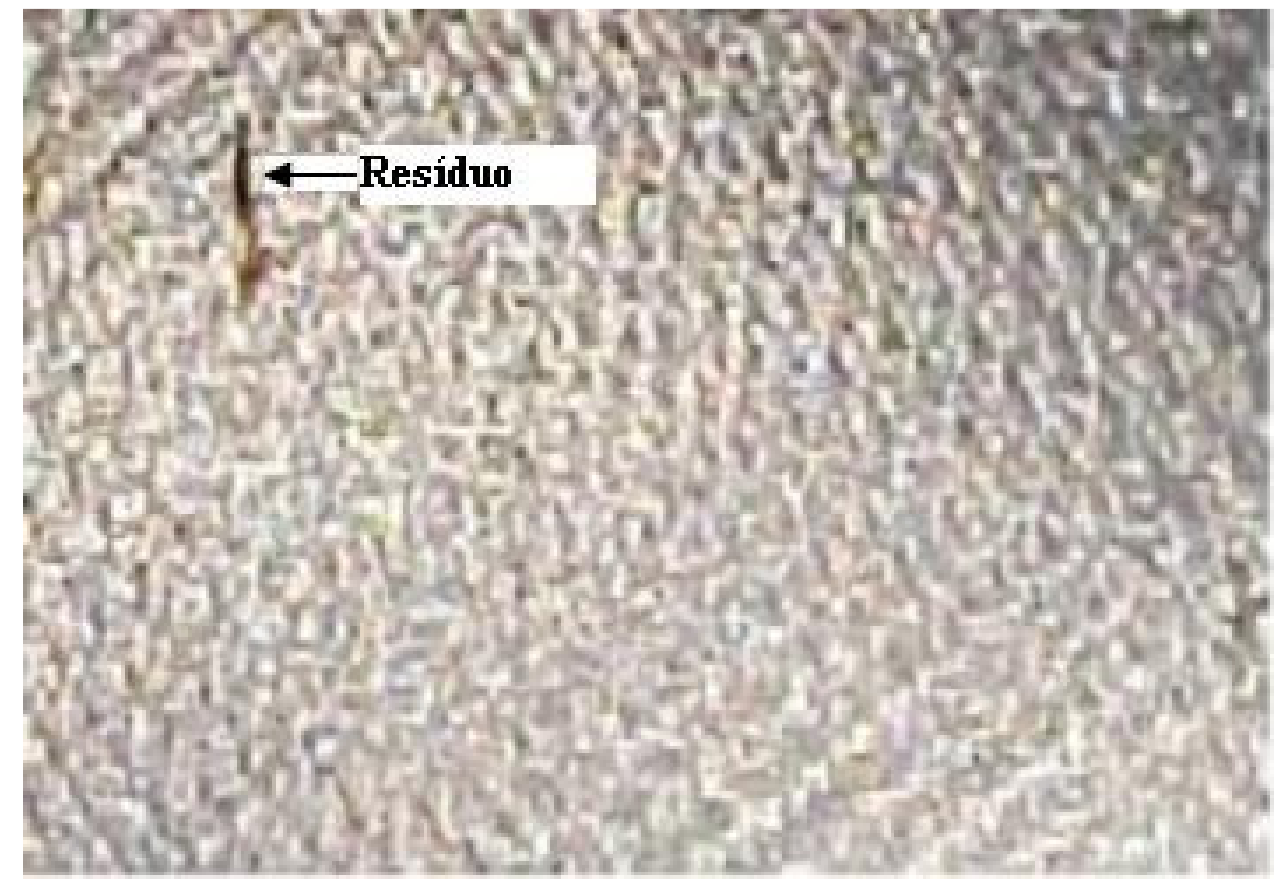

Figura 4. 3 - Imagem do Filme da bolsa com Resíduo.

\subsection{Método de Iluminação e Aquisição de Imagem}

Para a escolha de uma fonte de iluminação é importante considerar a intensidade, a direcionalidade e a distribuição espectral (BATCHELOR, 1985). Para este trabalho foi escolhido o método de iluminação ommi-direcional, que tem como características distribuir uniformemente a iluminação e eliminar sombras. Este tipo de iluminação é indicado para visualização de partes complexas, superfícies fibrosas, visualização de superfícies refletoras e sem interferência do brilho do objeto (BATCHELOR, 1985).

O sistema de iluminação ommi-direcional utiliza um difusor hemisférico no qual é refletida a luz gerada por um tubo fluorescente excitado por fonte DC ou de alta frequiência. $\mathrm{O}$ difusor espalha então, de maneira homogênea, a luz sobre o objeto (bolsa para coleta de sangue). 


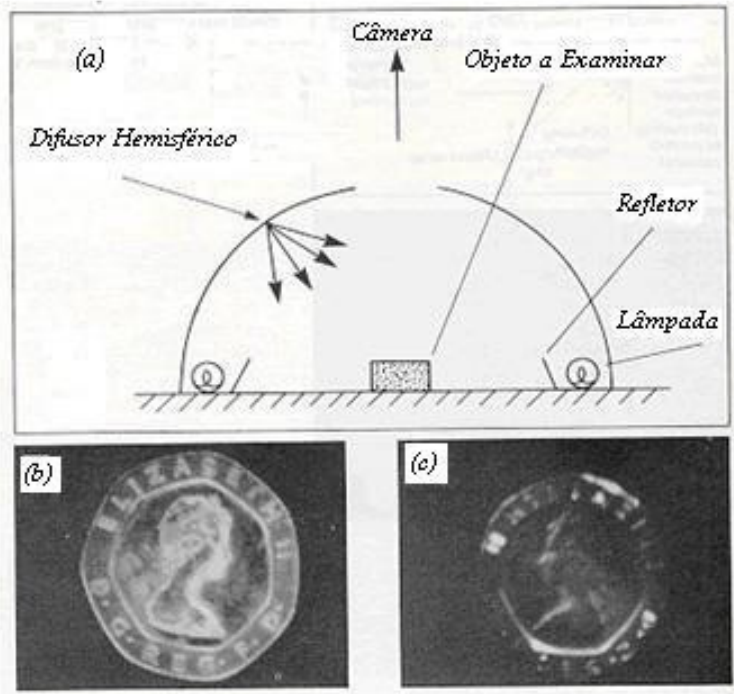

Figura 4. 4 - Iluminação omni-direcional Fonte: adaptado de (BATCHELOR, 1985).

A figura 4.4 mostra a incidência de iluminação em dois objetos. Um com iluminação omni-direcional (figura 4.1 b) e outro com iluminação comum (figura 4.1 c). A iluminação omni-direcional gera uma imagem com maior nitidez, e sem sombras.

Na figura 4.5 pode-se ver o sistema de iluminação omni-direcional utilizado neste trabalho. A parte superior possui uma abertura e um suporte no qual é fixada a câmera para digitalização das imagens. A iluminação é realizada através de quatro lâmpadas fluorescentes tubulares de luz branca excitadas por fonte de alta frequiência (15 KHZ). Estas lâmpadas estão direcionadas para a parte superior do difusor como mostra a figura 4.6.

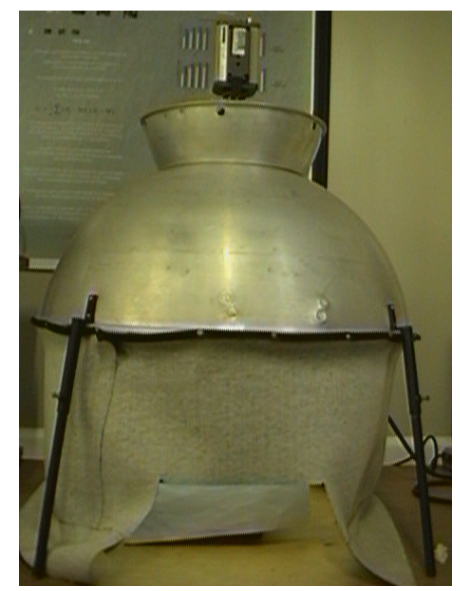

Figura 4. 5 - Equipamento de iluminação. 

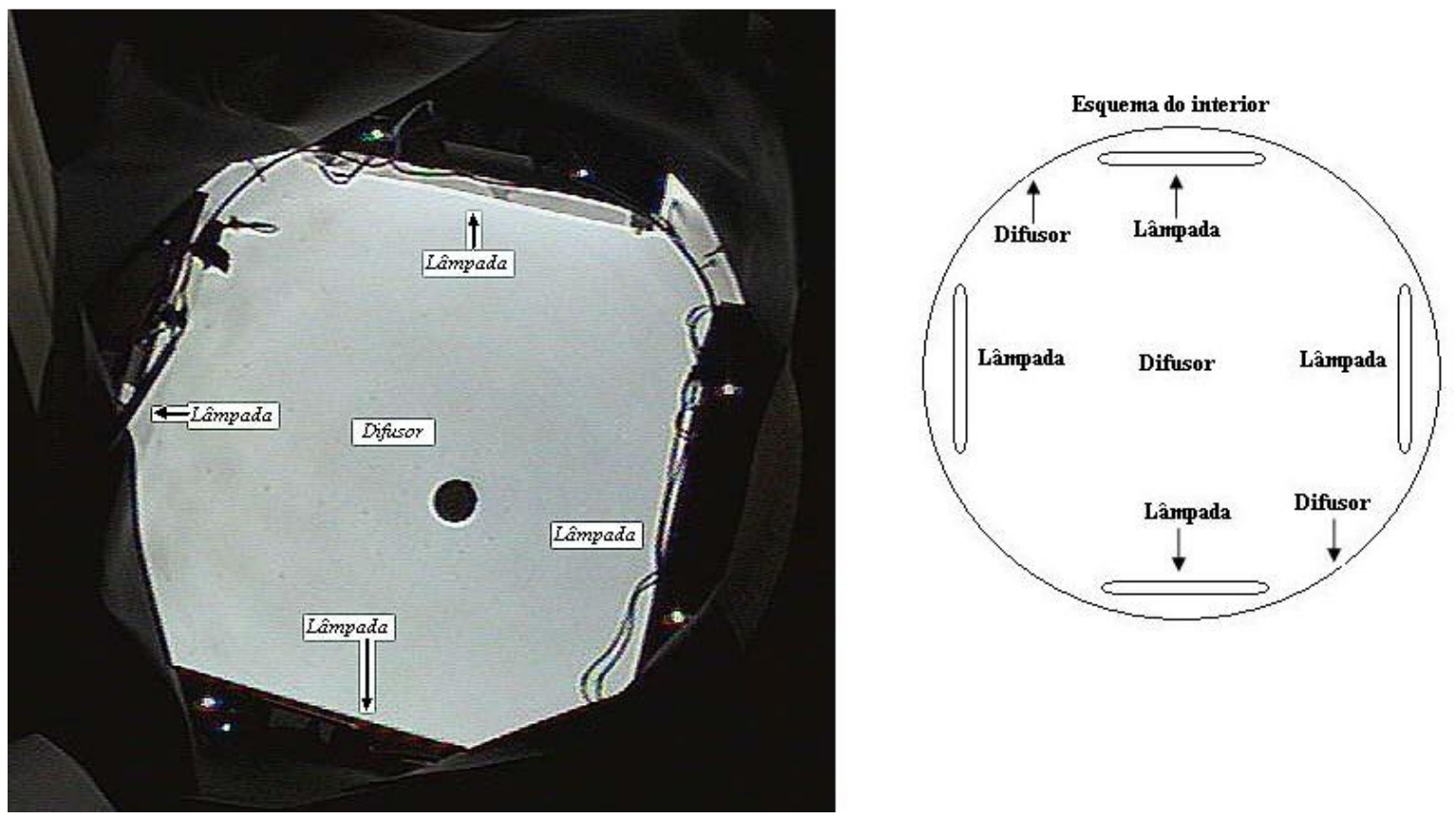

Figura 4. 6 - Interior do sistema de iluminação.

O equipamento de iluminação foi desenvolvido no LAVI (Laboratório de Visão Computacional) para a digitalização de imagens em projetos de inspeção visual.

Para a captura das imagens foi utilizada câmera de vídeo KP-110CCD da Hitachi, com um conjunto de lentes de zoom óptico de 16 vezes e controle de abertura do diafragma como na figura 4.7 .

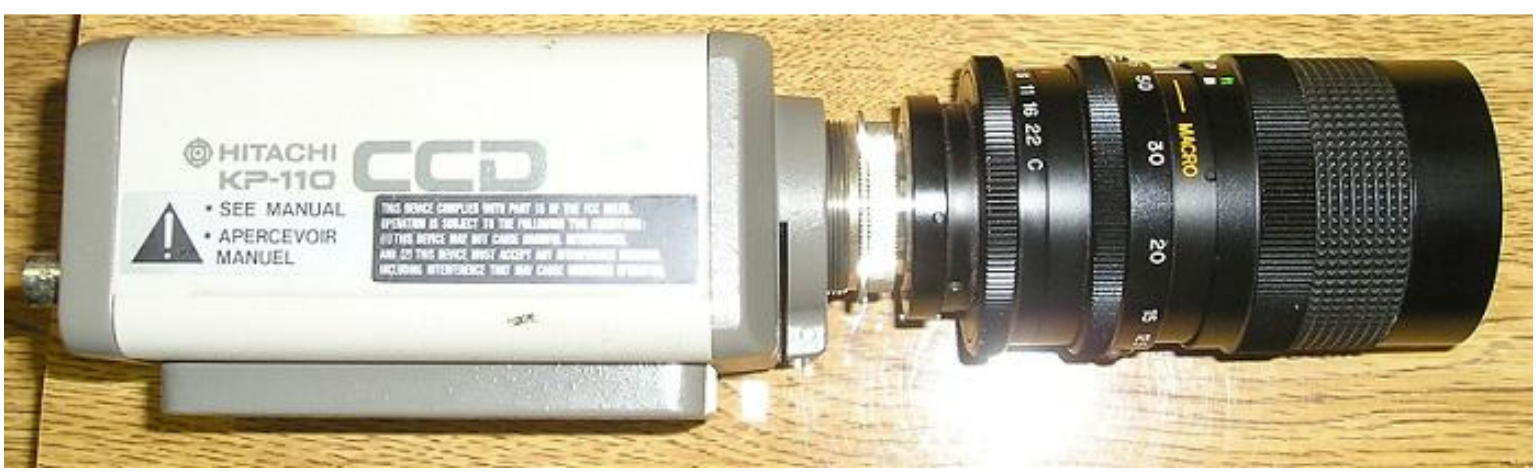

Figura 4. 7 - Câmera e conjunto de lentes usadas na captura das imagens. 
Esta câmera gera imagens analógicas que posteriormente são digitalizadas em 256 níveis de cinza, com resolução de 608 x 456 pixels.

\subsection{Banco de Imagens}

Para a formação do banco de imagens foram utilizadas 48 bolsas para coleta de sangue com os dois tipos de filmes, contendo DEHP e TEHTM, nos formatos de bolsa satélite e mãe. Estas bolsas foram retiradas da linha de produção, e classificadas por um laboratório de controle da qualidade em "Com resíduo" e "Sem resíduo", determinando-se a quantidade de resíduos em cada bolsa.

Cada bolsa para coleta de sangue foi catalogada, numerada e dividida em oito partes, como mostra a figura 4.8 .

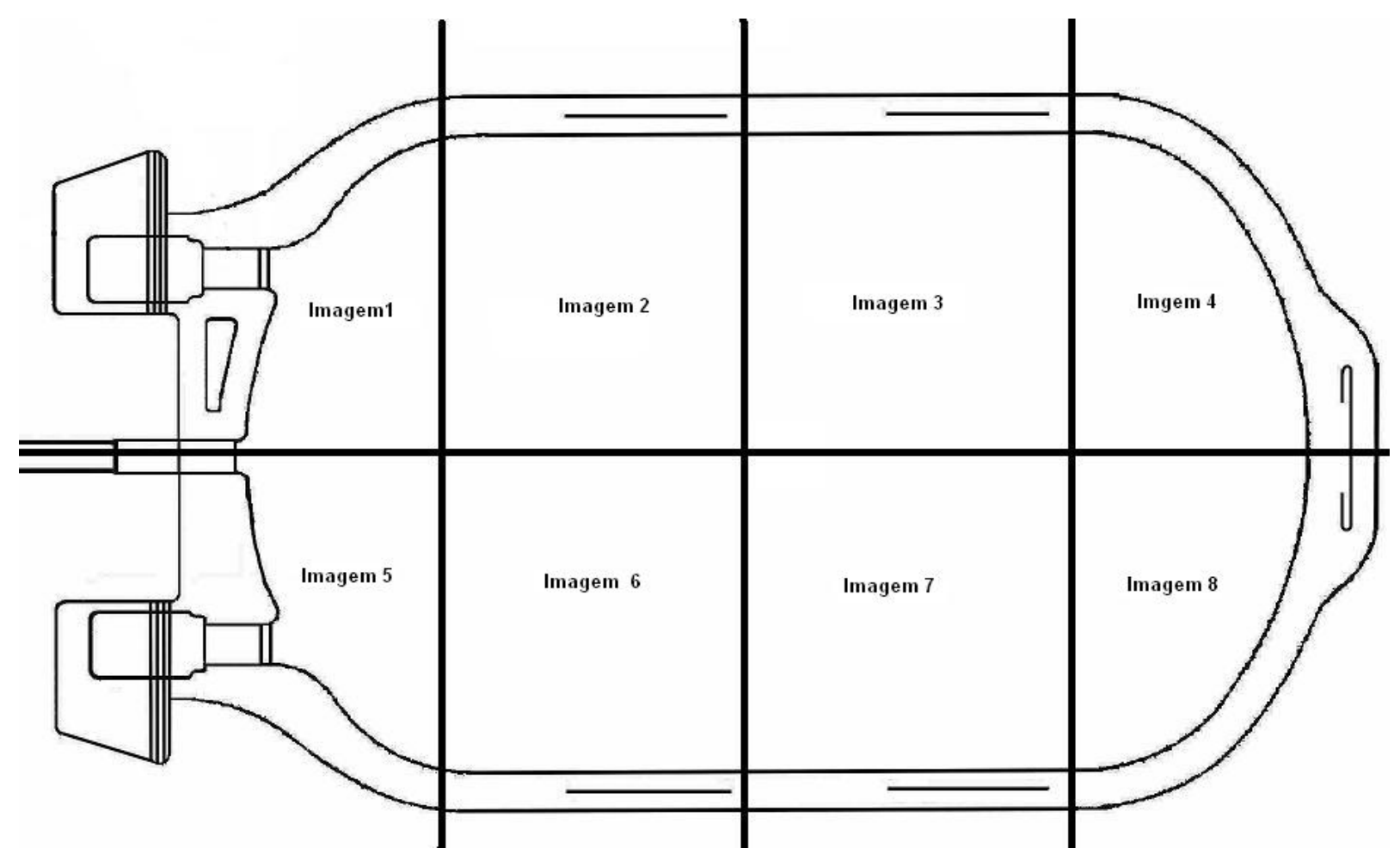

Figura 4. 8 - Imagens geradas de uma bolsa de sangue.

Além das oito imagens de cada bolsa foram capturadas imagens de partes das bolsas que representem cenas que possam gerar dificuldades no processamento e na 
classificação dos pixels de resíduos. Estas imagens geralmente são partes escuras, com níveis de cinza próximos aos de resíduos, ou que tem grande variação. As imagens contêm hímens, tear off, tubos de saída, interruptor de fluxo e vários resíduos próximos às bordas e com níveis de cinza diferentes, como pode ser visto na figura 4.9.

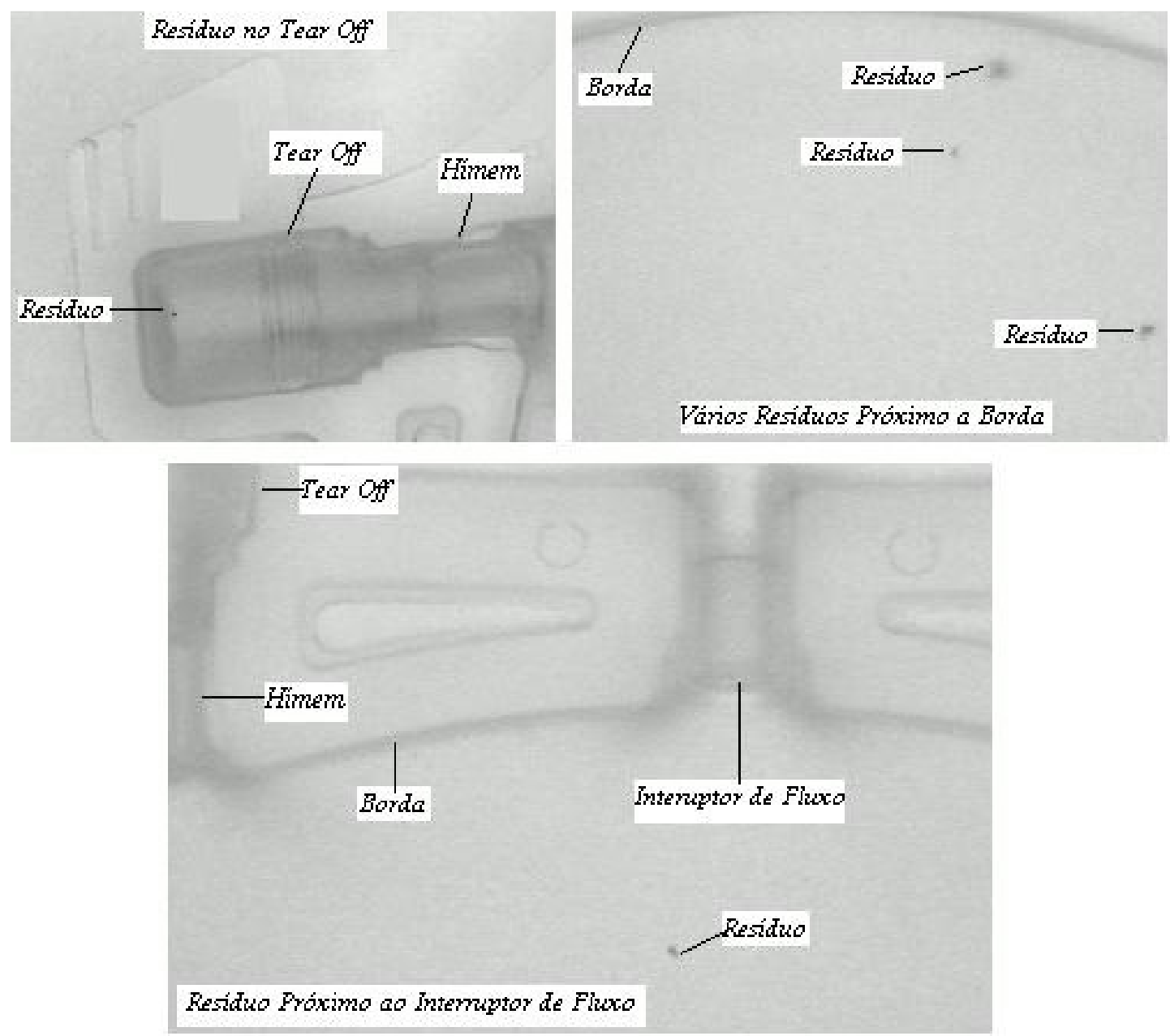

Figura 4. 9 - Exemplos de imagens capturadas.

A captura das imagens foi realizada fixando-se a câmera e movendo-se a bolsa de maneira a se digitalizar todas as oito partes da bolsa para coleta de sangue. A câmera foi posicionada na distância de 45,5 centímetros da bolsa e o conjunto de lentes macro zoom foi ajustado como na figura 4.10. Cada pixel na imagem representa $0,5 \mathrm{~mm}^{2}$ da bolsa para coleta de sangue. 


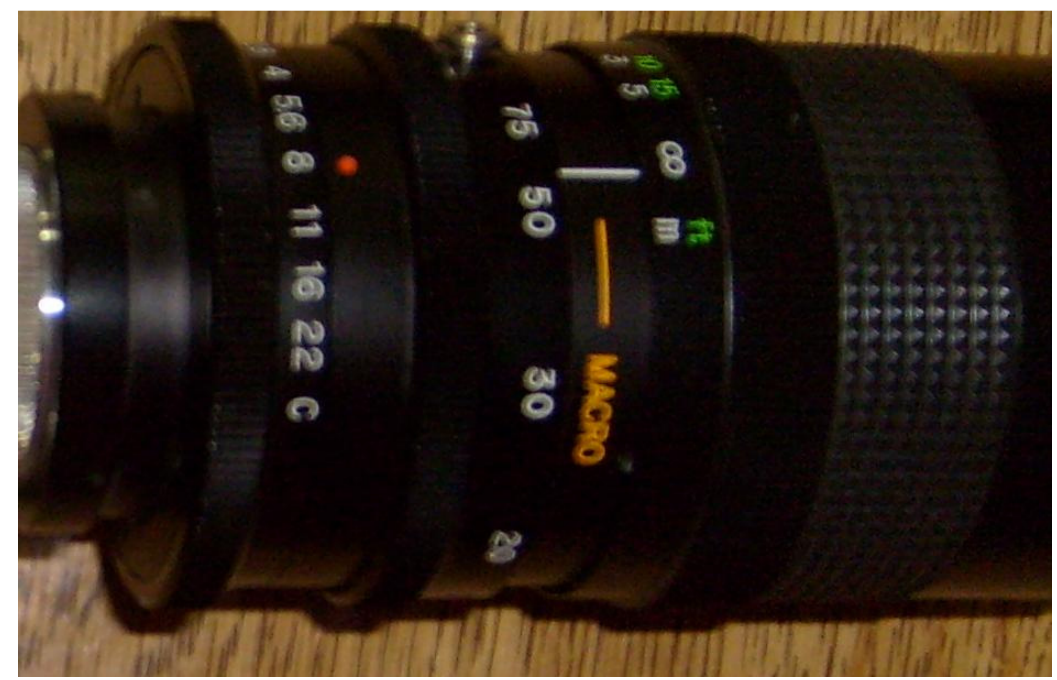

Figura 4. 10 - Ajustes do conjunto de lentes macro zoom.

O banco de imagens foi gerado no formato BMP, resolução de $608 \times 456$ pixels e 256 níveis de cinza, com 504 imagens das quais 380 sem resíduos e 124 imagens com resíduos. Todas as imagens do banco foram rotuladas de modo a ser possível identificar que bolsa a gerou.

Nas imagens capturadas existem resíduos com diversas características e tamanhos. O menor resíduo detectado nas imagens tem o tamanho de $0.5 \mathrm{~mm}$, representando na imagem 10 pixels e o maior tem o tamanho de $3 \mathrm{~mm}$, representando 60 pixels na imagem, como mostra a figura 4.11 .
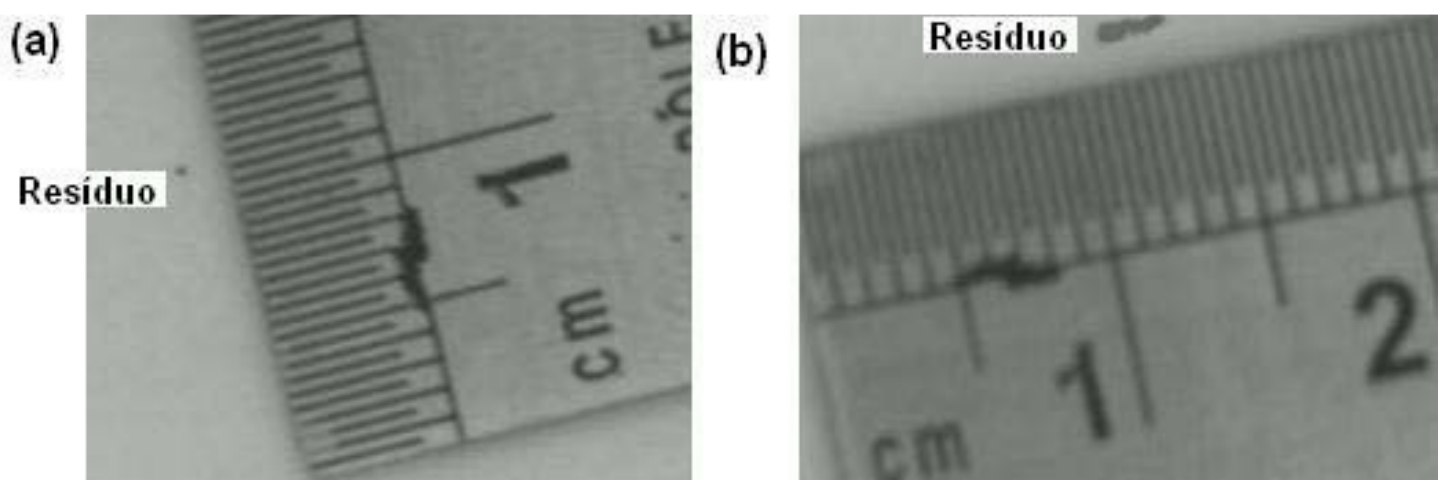

Figura 4. 11 - (a) Imagem do menor resíduo detectado; (b) Imagem do maior resíduo detectado. 


\subsection{Processamento das Imagens}

O objetivo da metodologia proposta é identificar os resíduos nos filmes das bolsas para coleta de sangue. Esses resíduos podem ser desde pequenos pêlos até resíduos de materiais diversos e por isso possuem diferentes características visuais e ópticas.

As imagens digitalizadas e armazenadas no banco mostram que resíduos contrastam com o filme, sendo normalmente mais escuros que este, como mostra a figura 4.12 .

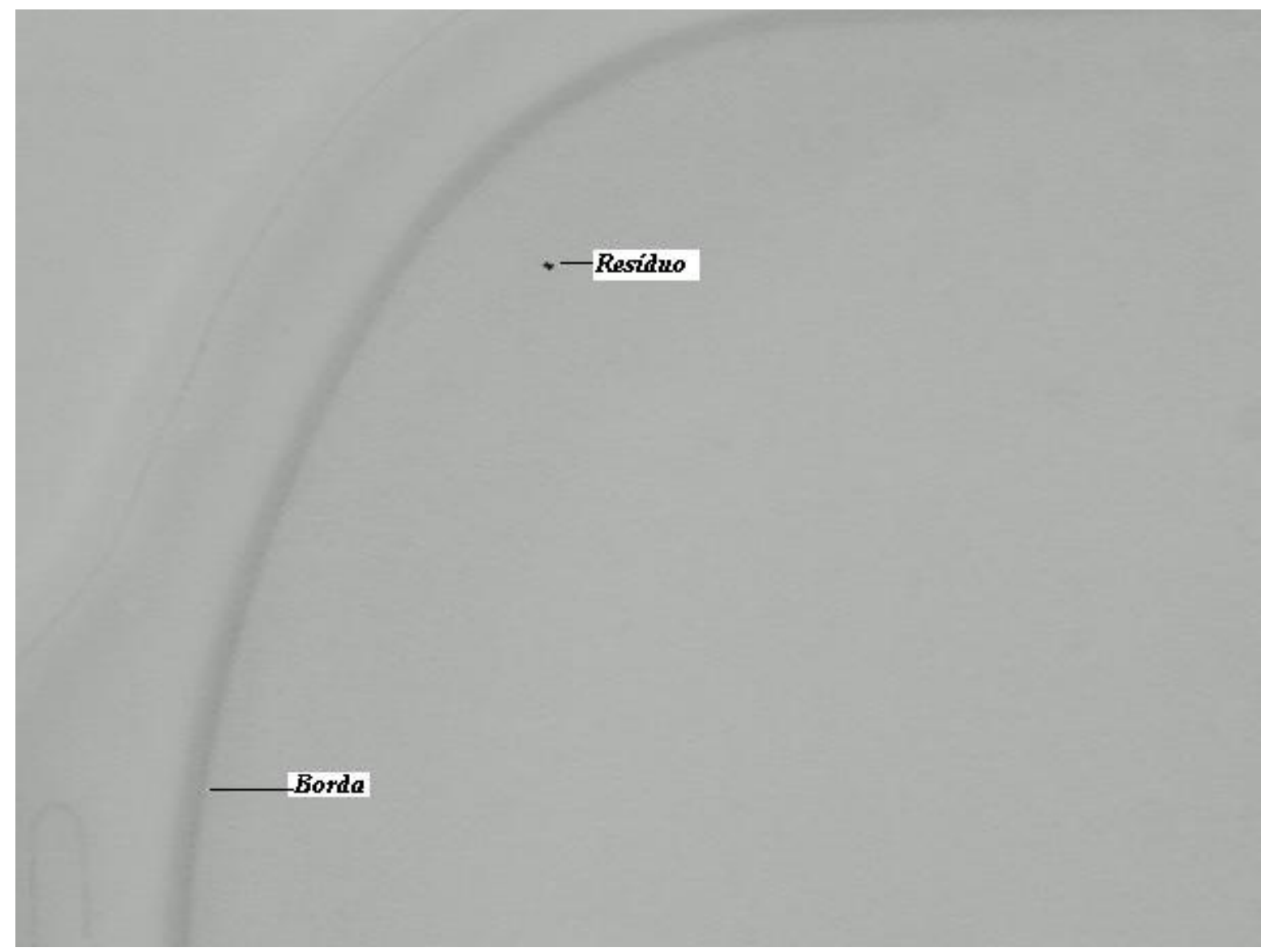

Figura 4. 12 - Exemplo de resíduo em bolsa para coleta de sangue.

Na figura 4.13, observando-se os gráficos da Transformada de Fourier, nota-se que os resíduos apresentam componentes de frequiências mais altas que o resto da imagem (ponto escuro sobre o fundo claro). Foi utilizada a Transformada Wavelet como técnica para 
destacá-los nas imagens, ou seja, realçar detalhes através de filtro passa - alta. A Wavelet de Haar em dois níveis de decomposição, foi escolhida devido sua facilidade de implementação e largo uso em Processamento de Imagens. (LIMA, 2004).

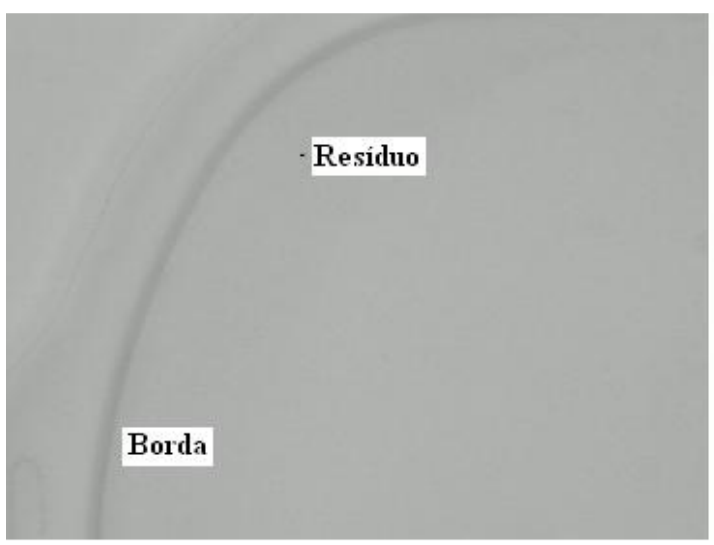

(a)
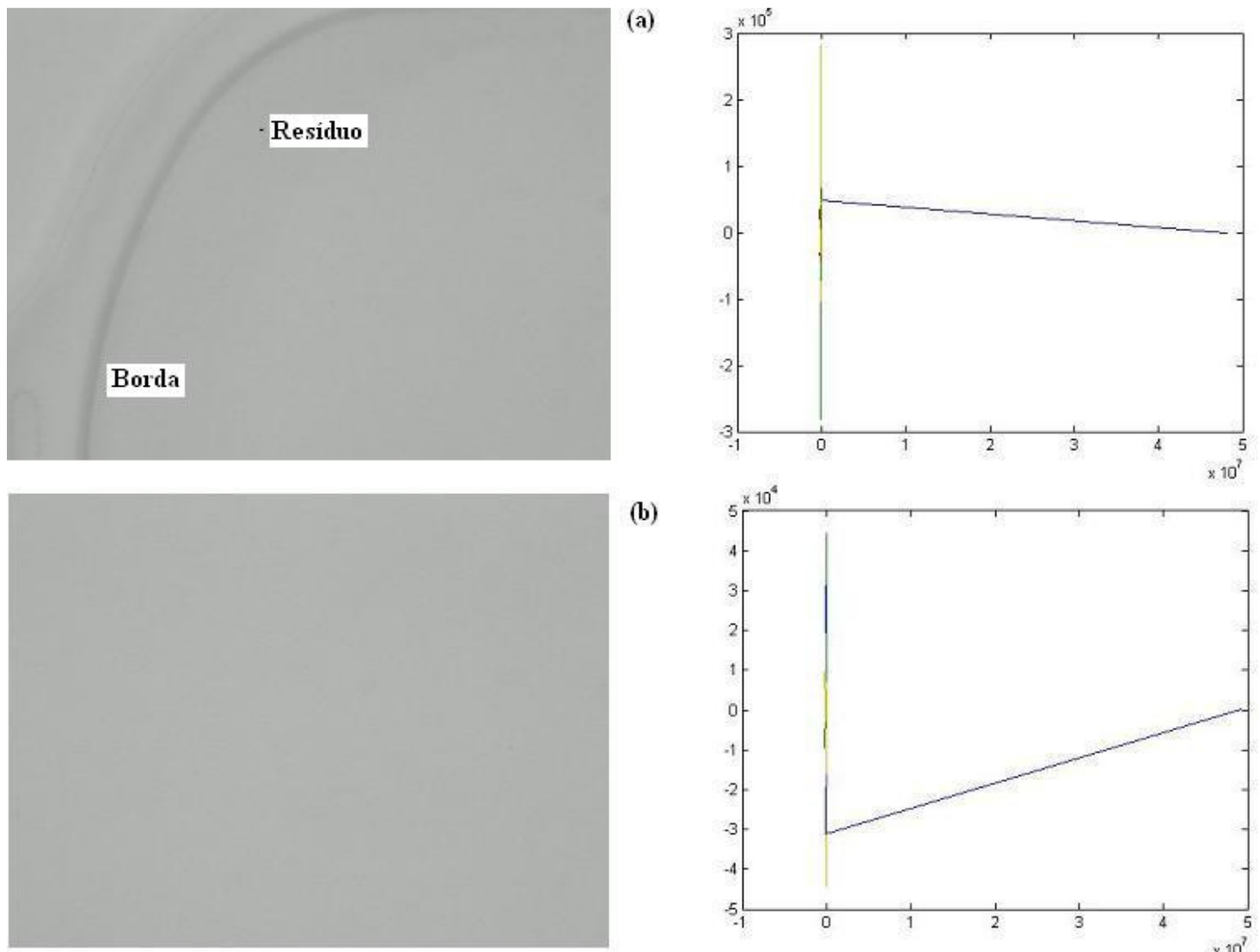

(b)
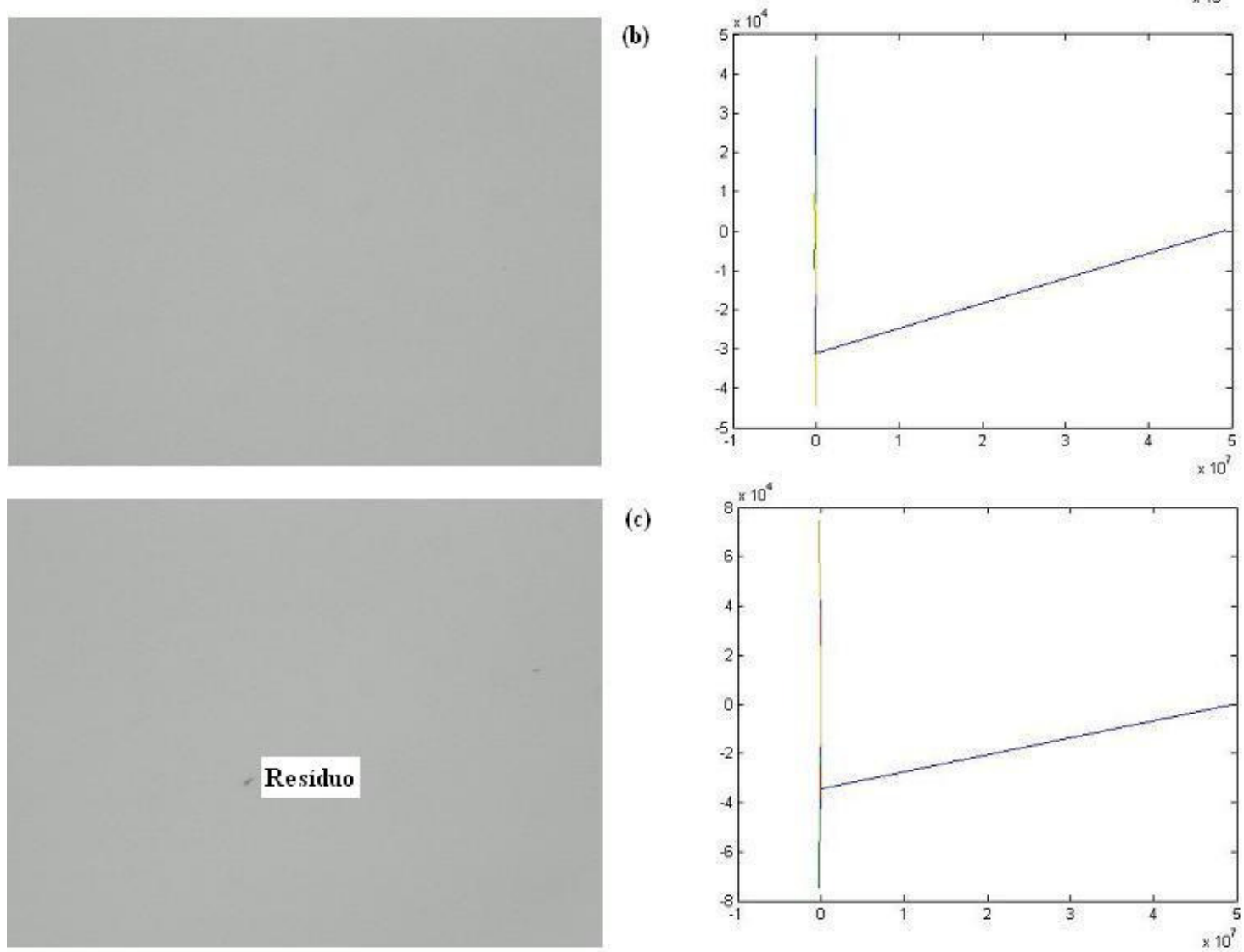

(c)

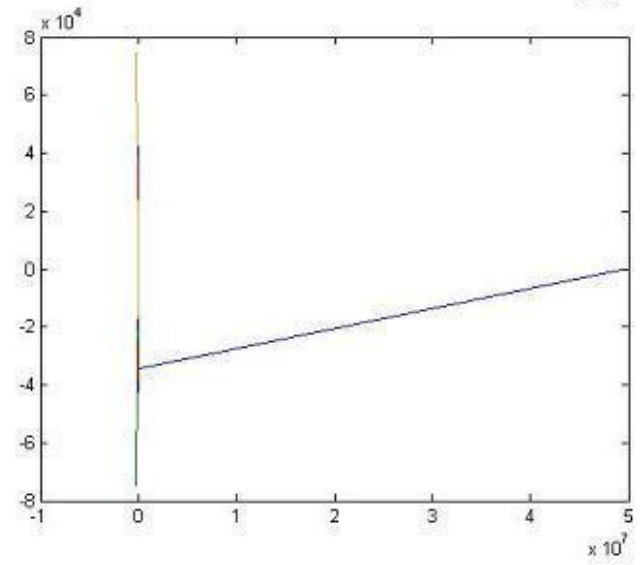

Figura 4. 13 - Aplicação da Transformada de Fourier em imagens de bolsa para coleta de sangue; (a) com borda e resíduo; (b) sem resíduos; (c) com resíduo. 
A figura 4.14 mostra o resultado da decomposição em dois níveis de uma imagem de bolsa para coleta de sangue, na qual o primeiro quadrante, subdividido em quatro partes, contém as imagens com o resultado do segundo nível e os outros contém os resultados do primeiro nível de decomposição. Cada nível de decomposição gera imagens com detalhes vertical $\left(V_{j}\right)$, horizontal $\left(H_{j}\right)$ e diagonal $\left(D_{j}\right)$.

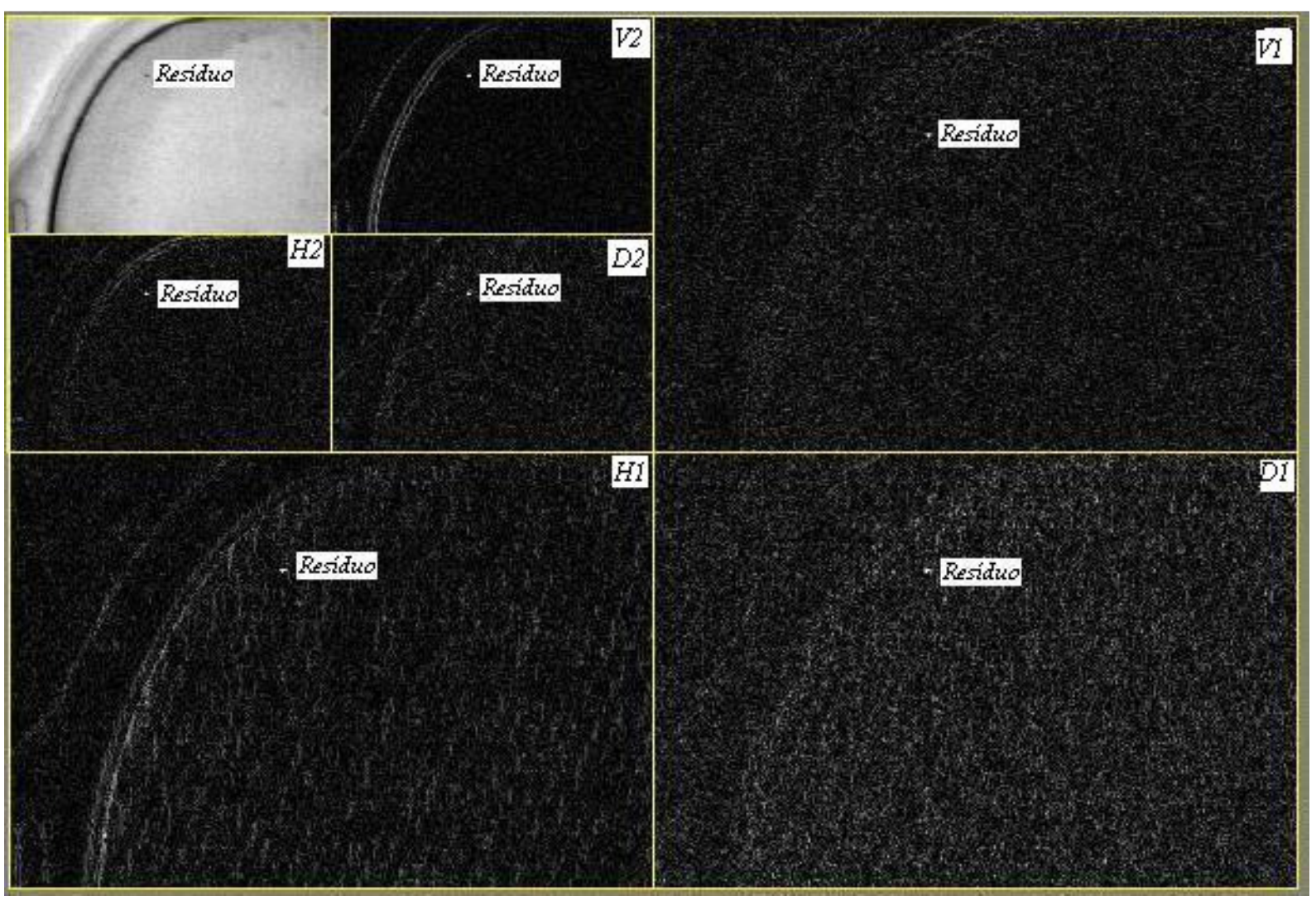

Figura 4. 14 - Resultado da decomposição em dois níveis.

Observando-se o resultado obtido com a aplicação da Transformada Wavelet notase que, no segundo nível, o resíduo é destacado e os efeitos causados pela textura do filme da bolsa são minimizados, como mostra a imagem ampliada (figura 4.15) do segundo nível de composição. 


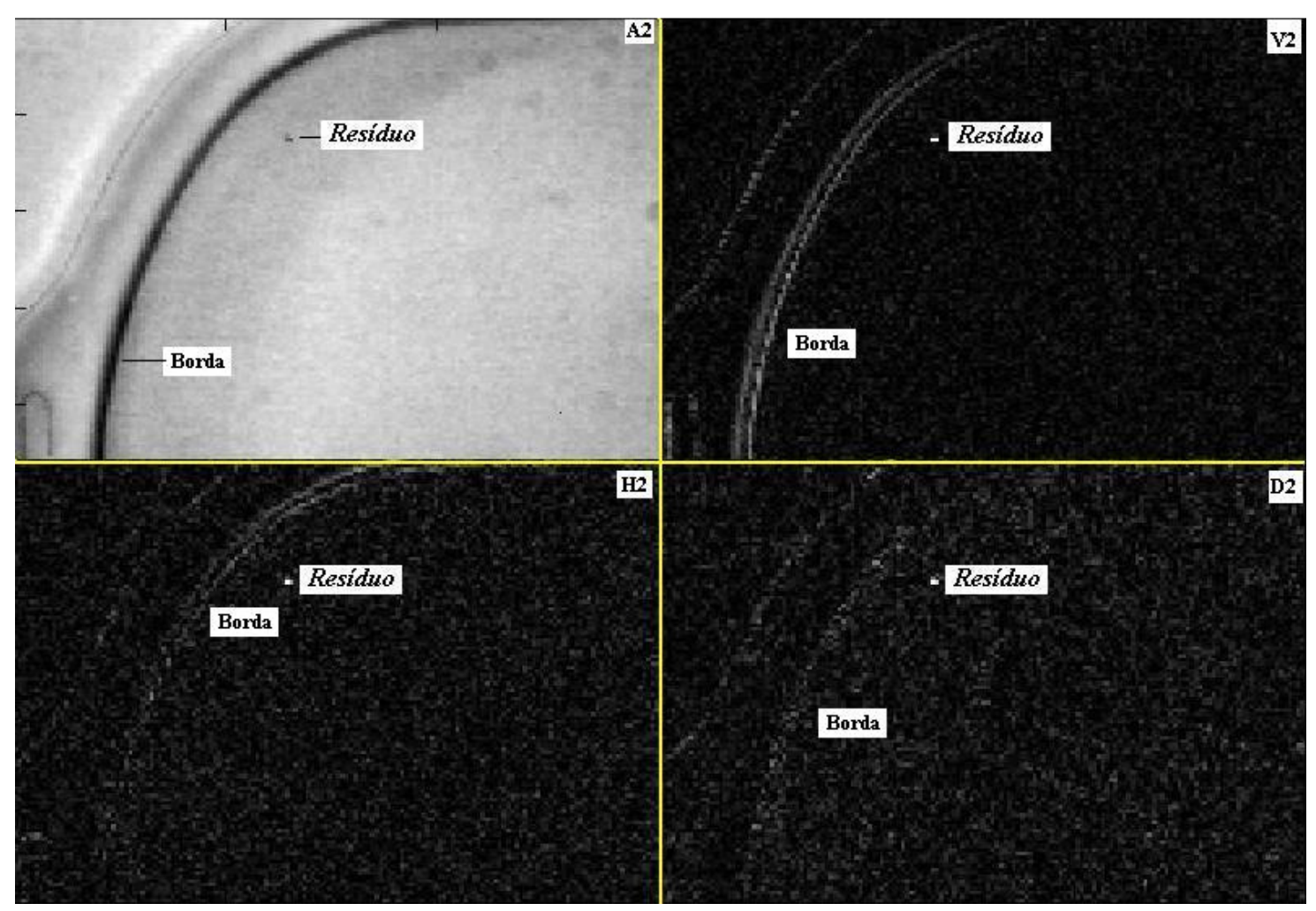

Figura 4. 15 - Imagem do segundo nível de decomposição.

Para se determinar qual imagem do segundo nível de decomposição $\left(A_{2} V_{2} H_{2} D_{2}\right)$ melhor destaca os resíduos, foram realizados testes com quarenta e cinco imagens do banco. As imagens escolhidas têm várias características como: imagens com resíduos, bordas, hímens, tear off e imagens sem resíduos.

Nestes testes foi verificado em qual das imagens do segundo nível os resíduos são realçados sem se confundirem com a borda e o ruído proveniente da textura do filme da bolsa minimizado.

Os testes constataram que a imagem de detalhe horizontal do segundo nível $\left(\mathrm{H}_{2}\right)$ obteve melhores resultados.

Observando-se a imagem com os coeficientes horizontais $\left(H_{2}\right)$ da figura 4.15 nota-se que parte das bordas também foram destacadas juntamente com o resíduo. 
Para não se detectar partes da borda da bolsa como resíduos, foi verificada a conectividade de todos os pixels, usando a vizinhança de quatro na vertical e na horizontal (N4(p)) e em seguida identificado quais os objetos (grupos de pixels conectados) na imagem que possuíam mais de 350 pixels conectados. Estes foram considerados bordas e removidos para não serem confundidos com resíduos. Como os maiores resíduos achados não ultrapassam 60 pixels, os agrupamentos removidos não se mostram resíduos.

Foi usado um limiar para gerar os pixels de interesse, e desta forma isolar os pontos de mais alta frequiência. Este limiar foi determinado em testes empíricos, com auxílio da base de imagens, observando-se as características dos resíduos. O valor do limiar foi estabelecido em 204.

Por fim, para cada agrupamento encontrado na imagem, foi verificada a quantidade de pixels que possuíam e considerado resíduos somente aqueles entre 10 e 60 pixels conectados, gerando-se uma imagem binária com apenas os pixels que representam resíduos, conforme mostra o exemplo da figura 4.16.

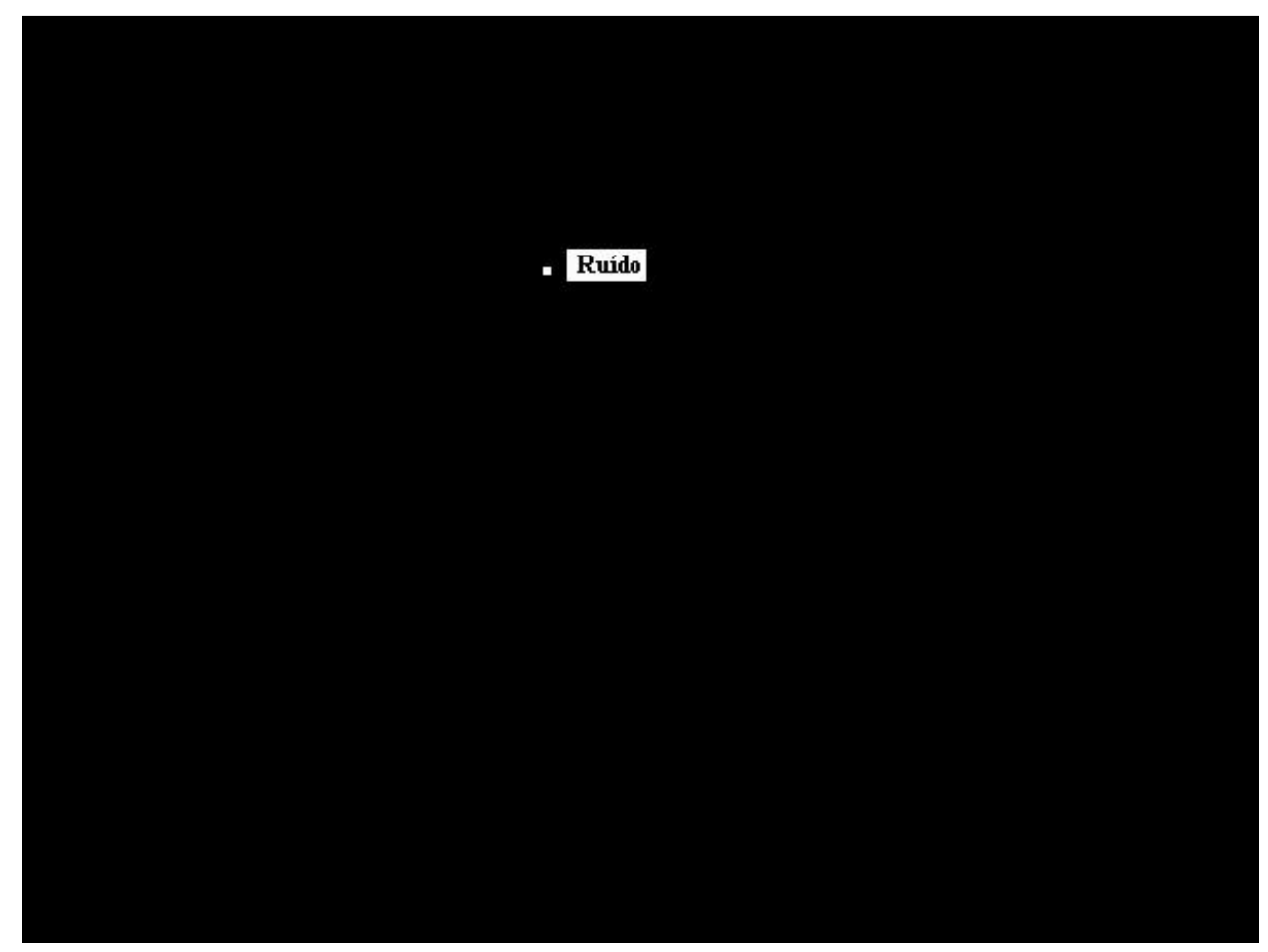

Figura 4. 16 - Exemplo de processamento de bolsa com ruído. 
As etapas da metodologia proposta para o processamento das imagens podem ser resumidas no diagrama de blocos da figura 4.17.

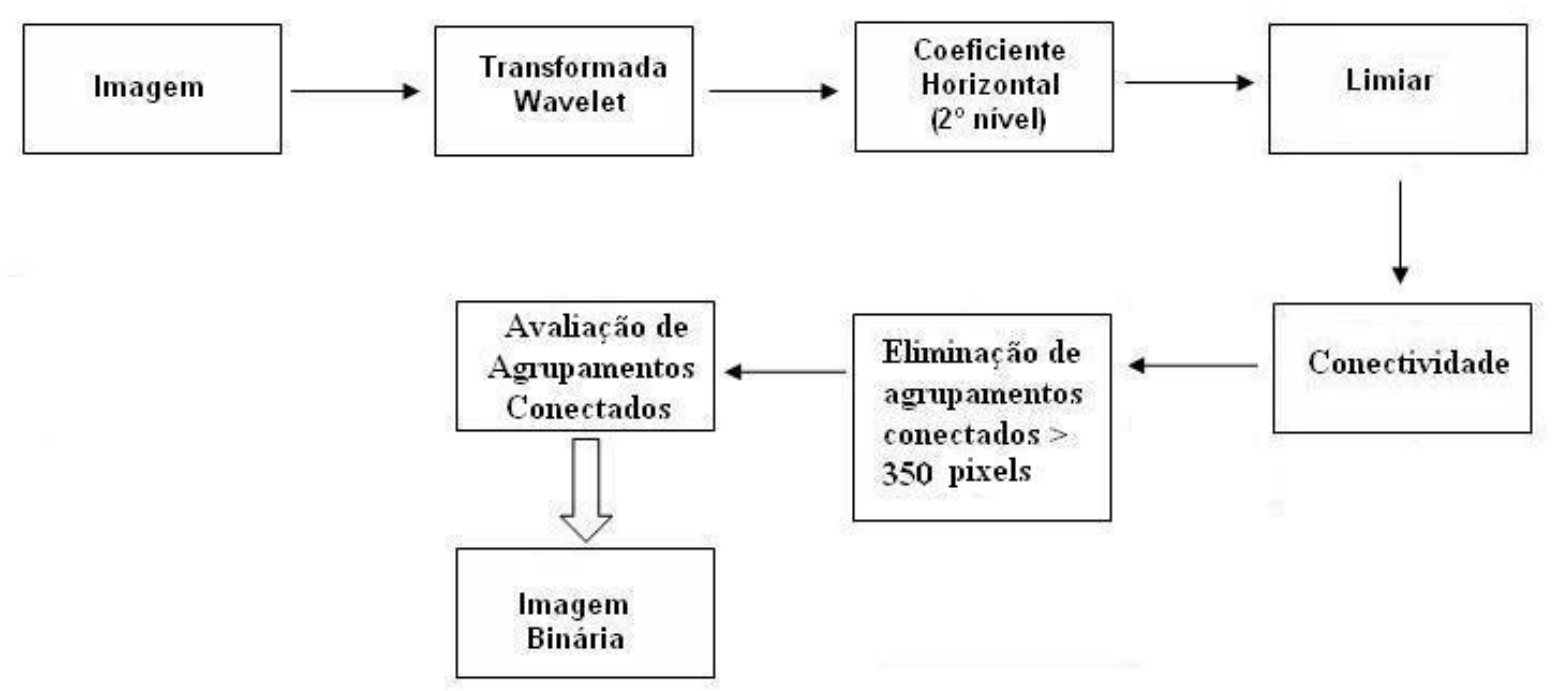

Figura 4. 17 - Diagrama do processamento das imagens.

$\mathrm{O}$ apêndice $\mathrm{B}$ mostra alguns exemplos de imagens com e sem resíduos e o resultado do processamento com a metodologia proposta.

\subsection{Considerações Finais}

Observando-se as figuras 4.3, 4.4 e 4.9, e analisando-se o espectro de Fourier das imagens observam-se componentes de alta freqüência. Como os resíduos a serem detectados são mais escuros que o resto da imagem, é de se supor que tais componentes estejam presentes nas bordas destes, o que induz o uso da Transformada Wavelet no processamento das imagens.

A Transformada Wavelet foi escolhida por sua capacidade para destacar as altas freqüências, aliado à capacidade de interpretação invariante da escala, e desta forma poder 
realçar os resíduos nas imagens de bolsas para coleta de sangue independente de sua forma ou material.

Além disso, a aplicação da Transformada Wavelet suavizou os efeitos da textura do filme das bolsas para coleta de sangue, diminuindo a quantidade de ruídos na imagem e contribuindo para o sucesso da metodologia proposta. 
Capítulo

\section{Resultados e Conclusões}

\subsection{Considerações Iniciais}

Para a comparação dos resultados obtidos foi realizada uma inspeção visual manual em cada bolsa para coleta de sangue utilizada na montagem do banco de imagens.

As bolsas foram previamente inspecionadas por um laboratório de controle de qualidade que as classificou e determinou a quantidade de resíduos.

O algoritmo desenvolvido foi também submetido a outras imagens de cem bolsas para coleta de sangue retiradas diretamente da linha de produção.

Na comparação dos resultados foi utilizada a análise estatística do Teste t Student (MARTINS, 2005) para amostras pareadas, com o intervalo de confiança de 95\%, sendo consideradas diferenças estatisticamente não significantes quando o valor de $\mathrm{p}<0,05$, ou seja, com baixo nível de incerteza.

O coeficiente de correlação de Pearson (MARTINS, 2005; VIEIRA, 1999) foi utilizado para análise comparativa entre os resultados das inspeções realizadas e a classificação do laboratório de controle de qualidade. Esta correlação varia de -1 a 1 , onde -1 indica correlação inversa e 1 a correlação perfeita. 
Para gerar as análises estatísticas foi usado o programa Graphpad Prim versão 3.02 da GraphPad Software Incorporated (GRAPHPAD, 2007).

\subsection{Inspeção Visual Manual}

As bolsas para coleta de sangue utilizadas na geração do banco de imagens, foram submetidas a uma nova inspeção visual manual através de três inspetoras da linha de produção.

Cada inspetora tem características e experiência diferentes, como acontece no trabalho de qualquer empresa. A Inspetora 1 tem 3 meses de experiência na função, a Inspetora 2, com um ano de experiência função e a Inspetora 3, um ano e dois meses de experiência na função. Nenhuma das inspetoras usa lentes corretivas.

Todas as inspetoras foram treinadas para exercer esta função e os treinamentos são realizados periodicamente de três em três meses.

Todo o processo de inspeção visual das bolsas para coleta de sangue é auditado anualmente pela Vigilância Sanitária para emissão do certificado de boas práticas de fabricação (Ver apêndice C).

As três inspetoras analisaram todas as quarenta e oito bolsas, tal como em suas atribuições diárias, ou seja, com a rotina de trabalho normal.

A tabela 5.1 apresenta os resultados obtidos pelas inspetoras, a média das três inspeções (para obter resultado único do sistema de inspeção visual) e a classificação realizada pelo laboratório de controle da qualidade (Resultado Esperado). A primeira coluna da tabela mostra o número da bolsa para coleta de sangue, e as outras colunas a quantidade de resíduos encontrada. 
Tabela 5. 1 - Resultados da inspeção visual manual com número de resíduos encontrados em cada bolsa.

\begin{tabular}{|c|c|c|c|c|c|}
\hline BOLSA & Inspetora 1 & Inspetora 2 & Inspetora3 & Média & Resultado Esperado \\
\hline 5 & 0 & 1 & 0 & 0 & 1 \\
\hline 6 & 1 & 1 & 0 & 1 & 1 \\
\hline 7 & 1 & 1 & 1 & 1 & 1 \\
\hline 8 & 0 & 0 & 0 & 0 & 0 \\
\hline 9 & 0 & 0 & 0 & 0 & 1 \\
\hline 10 & 0 & 0 & 0 & 0 & 0 \\
\hline 11 & 0 & 0 & 0 & 0 & 0 \\
\hline 12 & 0 & 0 & 0 & 0 & 0 \\
\hline 13 & 1 & 1 & 0 & 1 & 1 \\
\hline 14 & 0 & 0 & 0 & 0 & 0 \\
\hline 15 & 1 & 1 & 0 & 1 & 1 \\
\hline 16 & 0 & 2 & 1 & 1 & 0 \\
\hline 17 & 1 & 1 & 1 & 1 & 1 \\
\hline 18 & 1 & 1 & 0 & 1 & 1 \\
\hline 19 & 1 & 1 & 0 & 1 & 1 \\
\hline 20 & 0 & 1 & 1 & 1 & 2 \\
\hline 21 & 1 & 1 & 1 & 1 & 1 \\
\hline 22 & 1 & 1 & 1 & 1 & 1 \\
\hline 23 & 1 & 1 & 1 & 1 & 2 \\
\hline 24 & 0 & 1 & 1 & 1 & 1 \\
\hline 25 & 2 & 1 & 1 & 1 & 1 \\
\hline 26 & 0 & 1 & 1 & 1 & 1 \\
\hline 27 & 0 & 1 & 1 & 1 & 1 \\
\hline 28 & 0 & 1 & 1 & 1 & 1 \\
\hline 29 & 0 & 0 & 0 & 0 & 1 \\
\hline 30 & 4 & 1 & 1 & 2 & 4 \\
\hline 31 & 4 & 1 & 1 & 2 & 4 \\
\hline 32 & 2 & 1 & 1 & 1 & 2 \\
\hline 33 & 1 & 1 & 1 & 1 & 1 \\
\hline 34 & 1 & 1 & 1 & 1 & 1 \\
\hline 35 & 1 & 1 & 1 & 1 & 1 \\
\hline 36 & 1 & 1 & 1 & 1 & 1 \\
\hline 37 & 1 & 1 & 1 & 1 & 1 \\
\hline 38 & 1 & 1 & 1 & 1 & 1 \\
\hline 39 & 1 & 1 & 1 & 1 & 1 \\
\hline 40 & 1 & 1 & 1 & 1 & 1 \\
\hline 41 & 1 & 1 & 1 & 1 & 1 \\
\hline 42 & 4 & 1 & 1 & 2 & 4 \\
\hline 43 & 2 & 1 & 1 & 1 & 2 \\
\hline 44 & 1 & 1 & 1 & 1 & 1 \\
\hline 45 & 4 & 1 & 1 & 2 & 1 \\
\hline 46 & 4 & 0 & 0 & 1 & 2 \\
\hline 47 & 0 & 1 & 1 & 1 & 1 \\
\hline 48 & 4 & 1 & 1 & 2 & 1 \\
\hline 49 & 1 & 1 & 1 & 1 & 1 \\
\hline 50 & 1 & 1 & 0 & 1 & 1 \\
\hline 51 & 0 & 1 & 1 & 1 & 1 \\
\hline 52 & 1 & 1 & 1 & 1 & 1 \\
\hline
\end{tabular}


Comparativamente ao Resultado Esperado, considerando-se o número exato de resíduos anotados, a inspeção visual manual realizada mostra que cada inspetora teve desempenho diferente: a inspetora 1 conseguiu êxito em 68,75\%, ou seja, acerto de trinta e três bolsas em 48 examinadas; a inspetora 2 conseguiu êxito em 77,08\%, ou seja, trinta e sete bolsas das 48 inspecionadas e a inspetora 3 em 62,5\%, ou seja, acerto de trinta bolsas das 48 consideradas, como mostra a tabela 5.2.

Tabela 5. 2 - Resultados da inspeção visual manual

\begin{tabular}{|c|c|c|}
\hline Inspetora & \% Acerto & $\begin{array}{c}\text { Tempo } \\
\text { (Min.) }\end{array}$ \\
\hline 1 & 68,75 & 10 \\
\hline 2 & 77,08 & 15 \\
\hline 3 & 62,5 & 15 \\
\hline Média & 70,8 & 12 \\
\hline
\end{tabular}

Cada inspetora despendeu, em média 12 minutos para realizar a inspeção das quarenta e oito bolsas; a Inspetora 1 completou a tarefa em 10 minutos e as outras em quinze minutos.

\subsubsection{Análise Estatística dos Resultados}

As análises feitas através do Teste $\mathrm{t}$ Student para amostras pareadas entre as três inspetoras, a média das três inspeções (resultado único do sistema de inspeção visual) e a classificação do laboratório de controle de qualidade (Resultado Esperado), não apresentaram diferenças estatisticamente significantes em nenhuma das análises. A tabela 5.3 mostra os coeficientes de correlação de cada análise realizada.

Tabela 5. 3 - Coeficientes de correlação das análises realizadas.

\begin{tabular}{|c|c|}
\hline Inspetora & $\begin{array}{c}\text { Coeficiente de } \\
\text { correlação }\end{array}$ \\
\hline 1 & 0,7016 \\
\hline 2 & 0,2436 \\
\hline 3 & 0,3343 \\
\hline Média & 0,6690 \\
\hline
\end{tabular}


Observando-se a tabela 5.3 nota-se que a inspetora 1 obteve um coeficiente correlação menor que a inspetora 2, apesar de obter um percentual de acerto maior que a inspetora 2. Isso acontece devido à discrepância dos resultados obtidos pela inspetora comparativamente ao número de resíduos localizados. Vale lembrar que a média da tabela 5.3 representa um resultado único da inspeção visual manual (média da tabela 5.1).

A figura 5.1 mostra o gráfico de comparação de resultados entre a inspetora 1 e a classificação do laboratório de controle da qualidade (Resultado Esperado) .

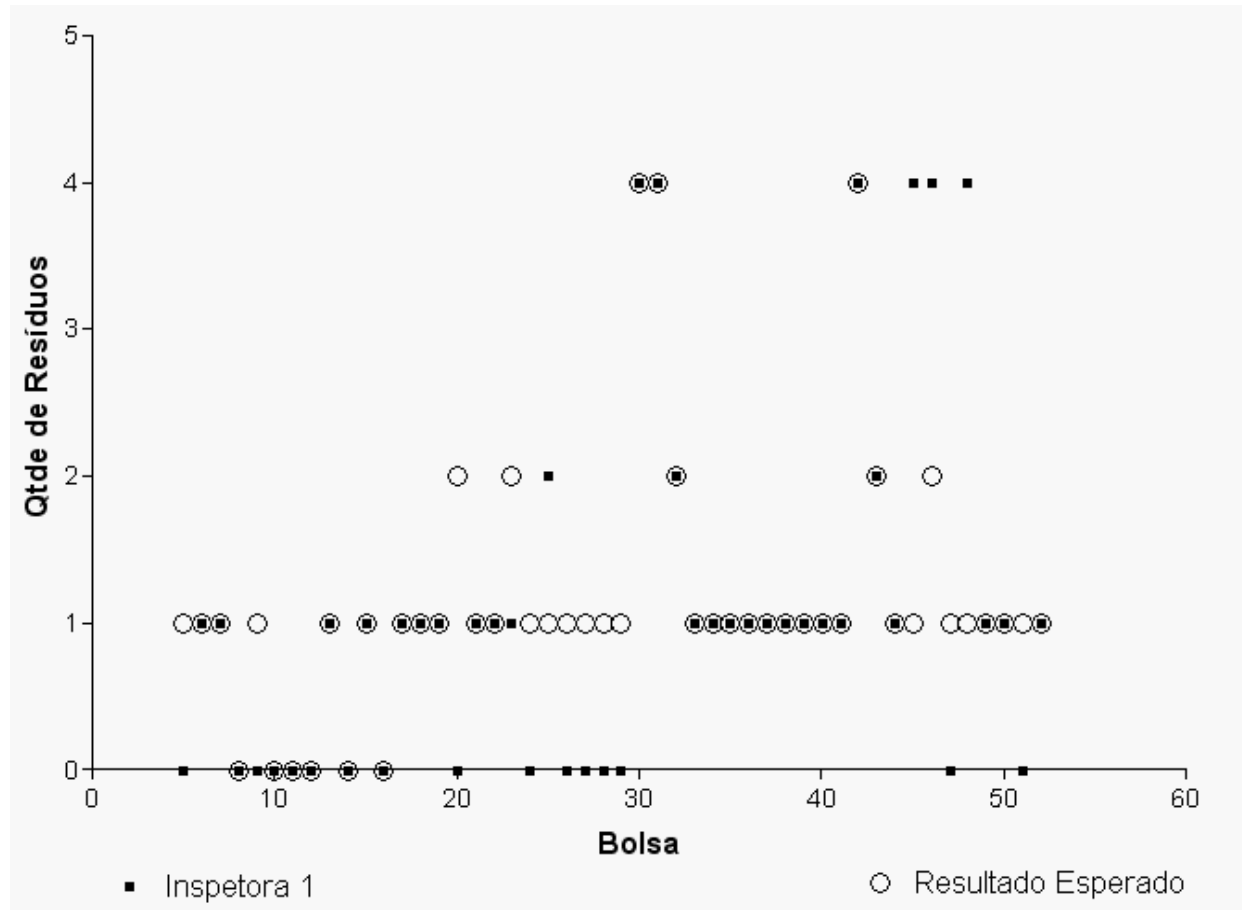

Figura 5. 1 - Comparação dos resultados da inspeção realizada pela Inspetora 1 e a classificação do laboratório de controle de qualidade.

A figura 5.2 mostra o gráfico com a comparação de resultados entre a inspetora 2 e a classificação do laboratório de controle da qualidade (Resultado Esperado) . 


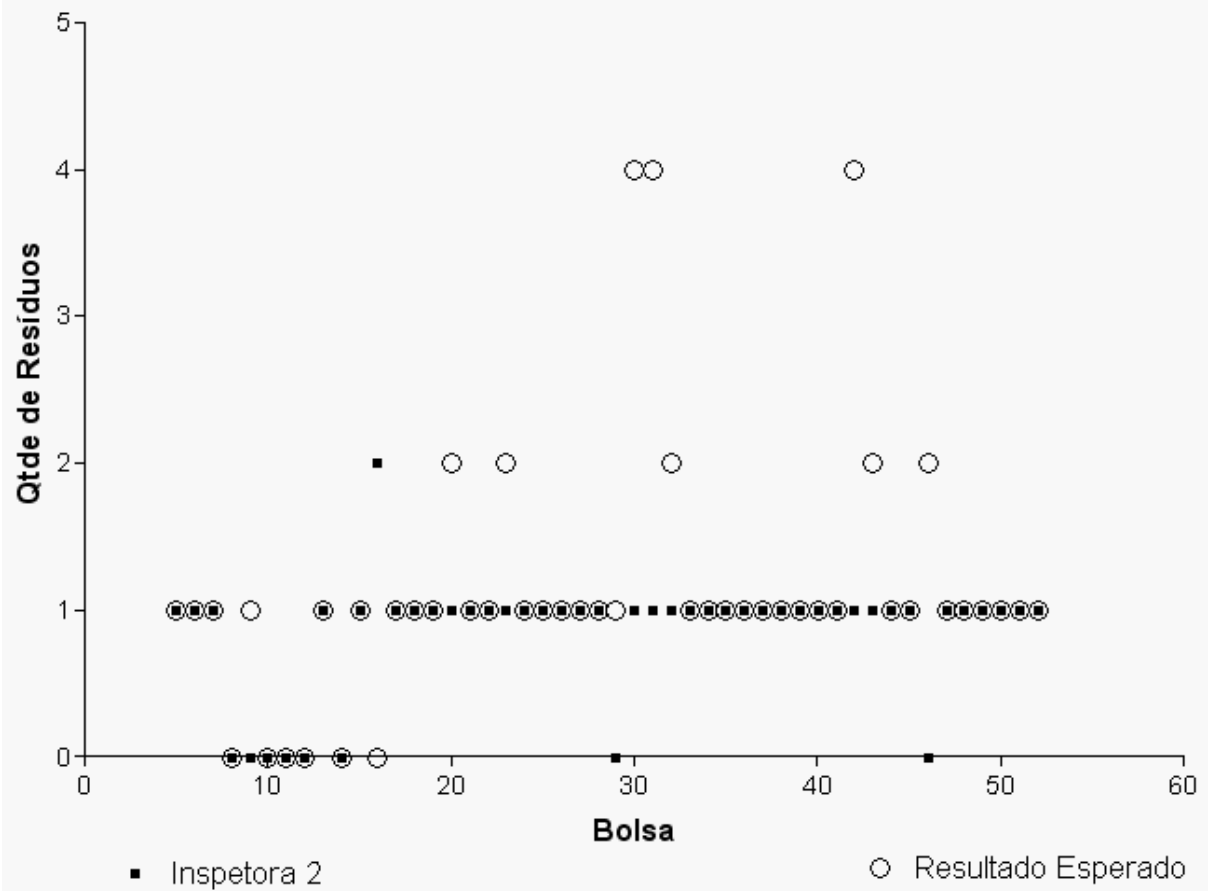

Figura 5. 2 - Comparação dos resultados da inspeção realizada pela Inspetora 2 e a classificação do laboratório do controle de qualidade.

A figura 5.3 mostra o gráfico com a comparação de resultados entre a inspetora 3 e a classificação do laboratório de controle da qualidade (Resultado Esperado) .

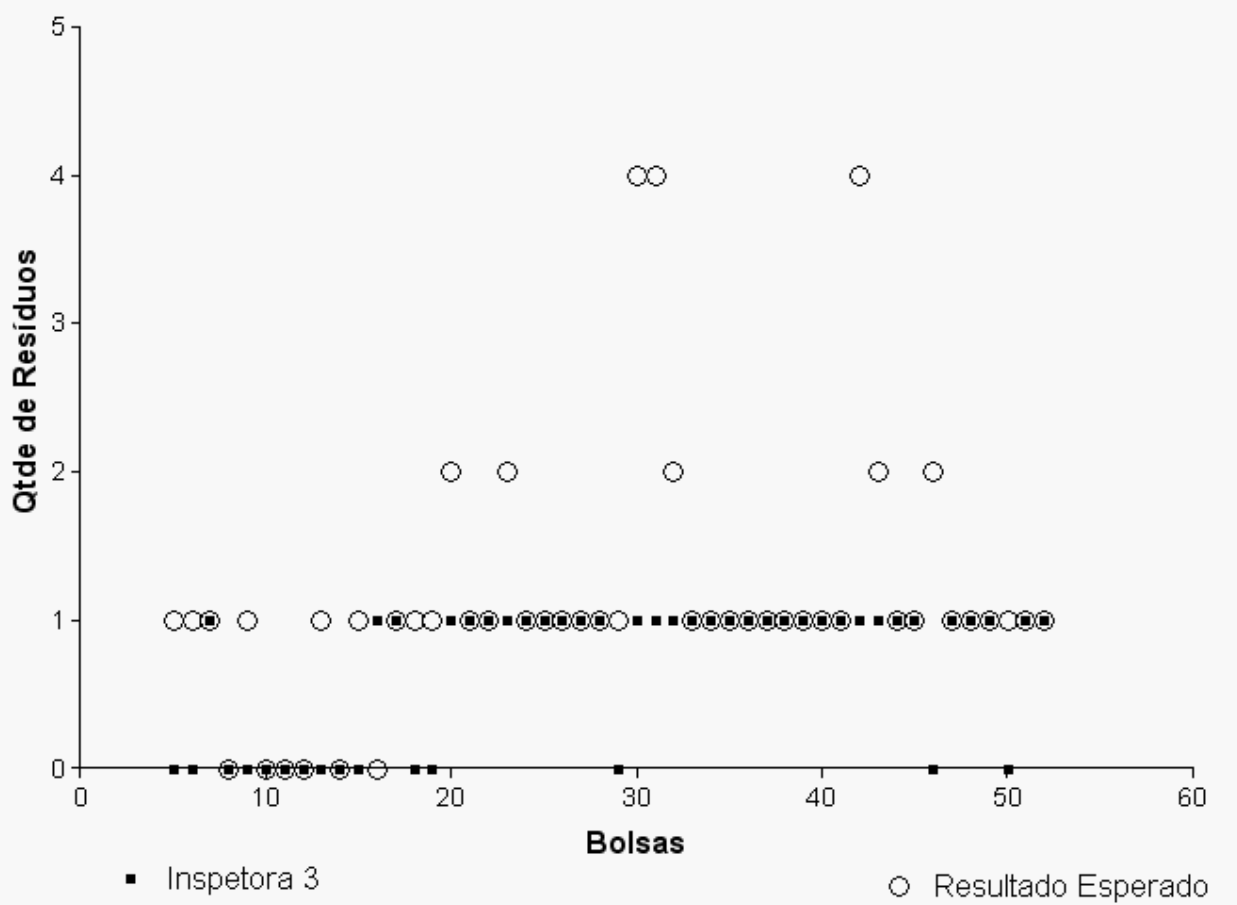

Figura 5. 3 - Comparação dos resultados da inspeção realizada pela Inspetora 3 e a classificação do laboratório de controle de qualidade. 
A figura 5.4 mostra o gráfico com a comparação dos resultados entre o valor médio de inspeção visual das inspetoras (Média na tabela 5.1) e a classificação do laboratório de controle de qualidade.

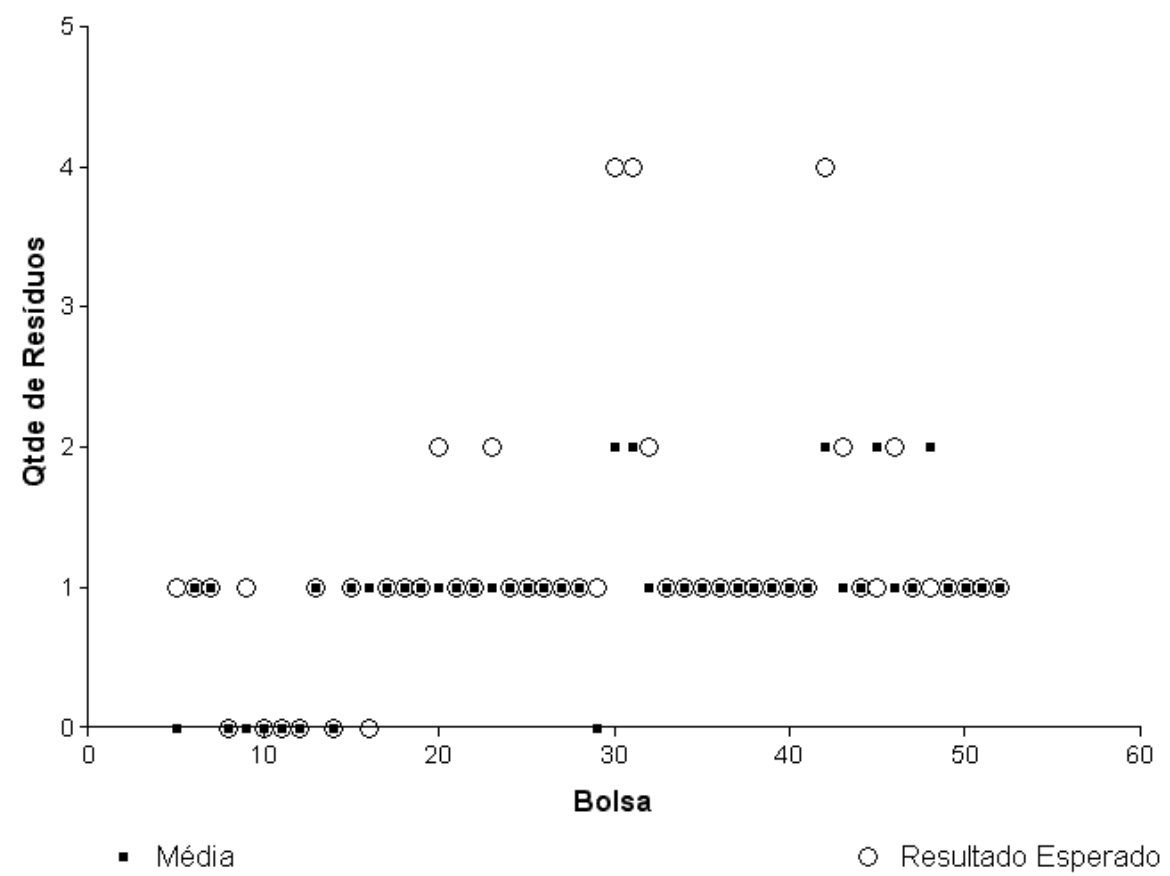

Figura 5. 4 - Comparação entre a média do processo de inspeção visual e a classificação do laboratório de controle de qualidade (Resultado Esperado).

\subsection{Resultados da Inspeção Visual Automática Aplicada ao Banco}

\section{de Imagens}

Para analisar as imagens do banco de imagens foi desenvolvido um algoritmo (Ver apêndice D) na plataforma Matlab versão 7.0 da MathWorks, Inc. Este algoritmo foi aplicado em todas as imagens das quarenta e oito bolsas utilizadas do banco de imagens. A figura 5.5 mostra um diagrama de blocos do algoritmo desenvolvido. 


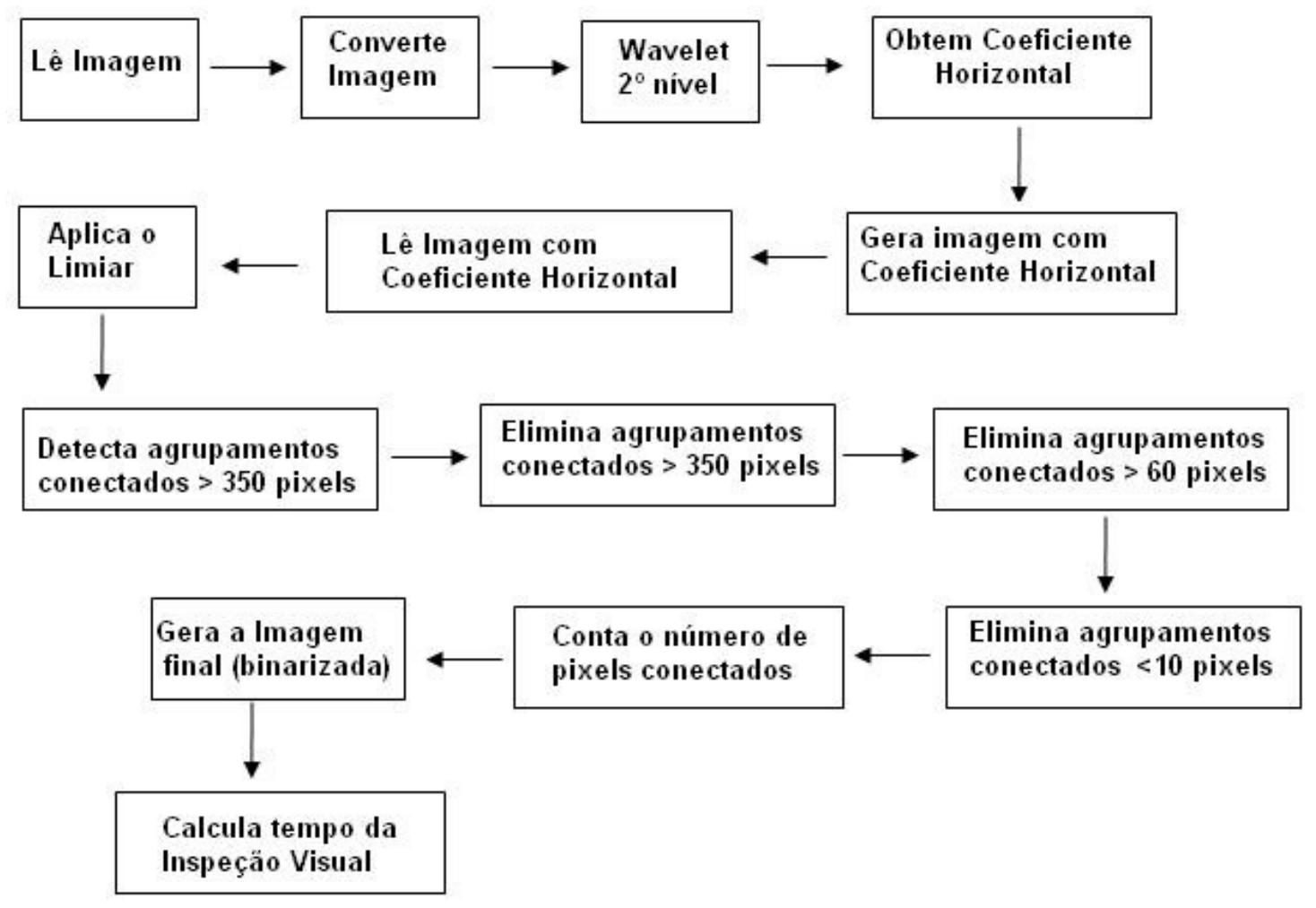

Figura 5. 5 - Digrama de blocos do algoritmo desenvolvido.

A tabela 5.4 mostra os resultados obtidos pelas inspetoras, os resultados da metodologia proposta neste trabalho e a classificação realizada pelo laboratório de controle de qualidade (Resultado Esperado). A primeira coluna da tabela 5.4 refere-se ao número da bolsa para coleta de sangue, e as demais colunas à quantidade de resíduos encontrada em cada inspeção realizada e pela metodologia proposta neste trabalho. 
Tabela 5. 4 - Resultados obtidos com a inspeção visual manual e com a metodologia proposta neste trabalho (número de resíduos encontrados em cada bolsa).

\begin{tabular}{|c|c|c|c|c|c|}
\hline & \multicolumn{3}{|c|}{ Ins peção Vis ual Manual } & \multirow{2}{*}{$\begin{array}{c}\text { Meto dologia } \\
\text { Prop osta }\end{array}$} & \multirow{2}{*}{$\begin{array}{l}\text { Resultado } \\
\text { Es perado }\end{array}$} \\
\hline BOLSA & Inspetora1 & Inspetora 2 & Inspetora 3 & & \\
\hline 5 & 0 & 1 & 0 & 1 & 1 \\
\hline 6 & 1 & 1 & 0 & 0 & 1 \\
\hline 7 & 1 & 1 & 1 & 1 & 1 \\
\hline 8 & 0 & 0 & 0 & 0 & 0 \\
\hline 9 & 0 & 0 & 0 & 1 & 1 \\
\hline 10 & 0 & 0 & 0 & 0 & 0 \\
\hline 11 & 0 & 0 & 0 & 0 & 0 \\
\hline 12 & 0 & 0 & 0 & 0 & 0 \\
\hline 13 & 1 & 1 & 0 & 0 & 1 \\
\hline 14 & 0 & 0 & 0 & 0 & 0 \\
\hline 15 & 1 & 1 & 0 & 1 & 1 \\
\hline 16 & 0 & 2 & 1 & 0 & 0 \\
\hline 17 & 1 & 1 & 1 & 1 & 1 \\
\hline 18 & 1 & 1 & 0 & 1 & 1 \\
\hline 19 & 1 & 1 & 0 & 1 & 1 \\
\hline 20 & 0 & 1 & 1 & 2 & 2 \\
\hline 21 & 1 & 1 & 1 & 1 & 1 \\
\hline 22 & 1 & 1 & 1 & 1 & 1 \\
\hline 23 & 1 & 1 & 1 & 2 & 2 \\
\hline 24 & 0 & 1 & 1 & 1 & 1 \\
\hline 25 & 2 & 1 & 1 & 1 & 1 \\
\hline 26 & 0 & 1 & 1 & 1 & 1 \\
\hline 27 & 0 & 1 & 1 & 1 & 1 \\
\hline 28 & 0 & 1 & 1 & 1 & 1 \\
\hline 29 & 0 & 0 & 0 & 1 & 1 \\
\hline 30 & 4 & 1 & 1 & 4 & 4 \\
\hline 31 & 4 & 1 & 1 & 4 & 4 \\
\hline 32 & 2 & 1 & 1 & 2 & 2 \\
\hline 33 & 1 & 1 & 1 & 1 & 1 \\
\hline 34 & 1 & 1 & 1 & 1 & 1 \\
\hline 35 & 1 & 1 & 1 & 1 & 1 \\
\hline 36 & 1 & 1 & 1 & 1 & 1 \\
\hline 37 & 1 & 1 & 1 & 1 & 1 \\
\hline 38 & 1 & 1 & 1 & 1 & 1 \\
\hline 39 & 1 & 1 & 1 & 1 & 1 \\
\hline 40 & 1 & 1 & 1 & 1 & 1 \\
\hline 41 & 1 & 1 & 1 & 1 & 1 \\
\hline 42 & 4 & 1 & 1 & 4 & 4 \\
\hline 43 & 2 & 1 & 1 & 2 & 2 \\
\hline 44 & 1 & 1 & 1 & 1 & 1 \\
\hline 45 & 4 & 1 & 1 & 1 & 1 \\
\hline 46 & 4 & 0 & 0 & 2 & 2 \\
\hline 47 & 0 & 1 & 1 & 1 & 1 \\
\hline 48 & 4 & 1 & 1 & 1 & 1 \\
\hline 49 & 1 & 1 & 1 & 1 & 1 \\
\hline 50 & 1 & 1 & 0 & 1 & 1 \\
\hline 51 & 0 & 1 & 1 & 1 & 1 \\
\hline 52 & 1 & 1 & 1 & 1 & 1 \\
\hline
\end{tabular}


A metodologia proposta neste trabalho identificou corretamente, ou seja, considerando-se o número total de resíduos em cada uma, a existência de resíduos em 46 das 48 bolsas analisadas, ou seja, com $96 \%$ de precisão. Apenas duas bolsas, a bolsa_6 e a bolsa_13, não foram corretamente analisadas. Estas bolsas têm como características, resíduos nas bordas da imagem, como mostra a figura 5.6.
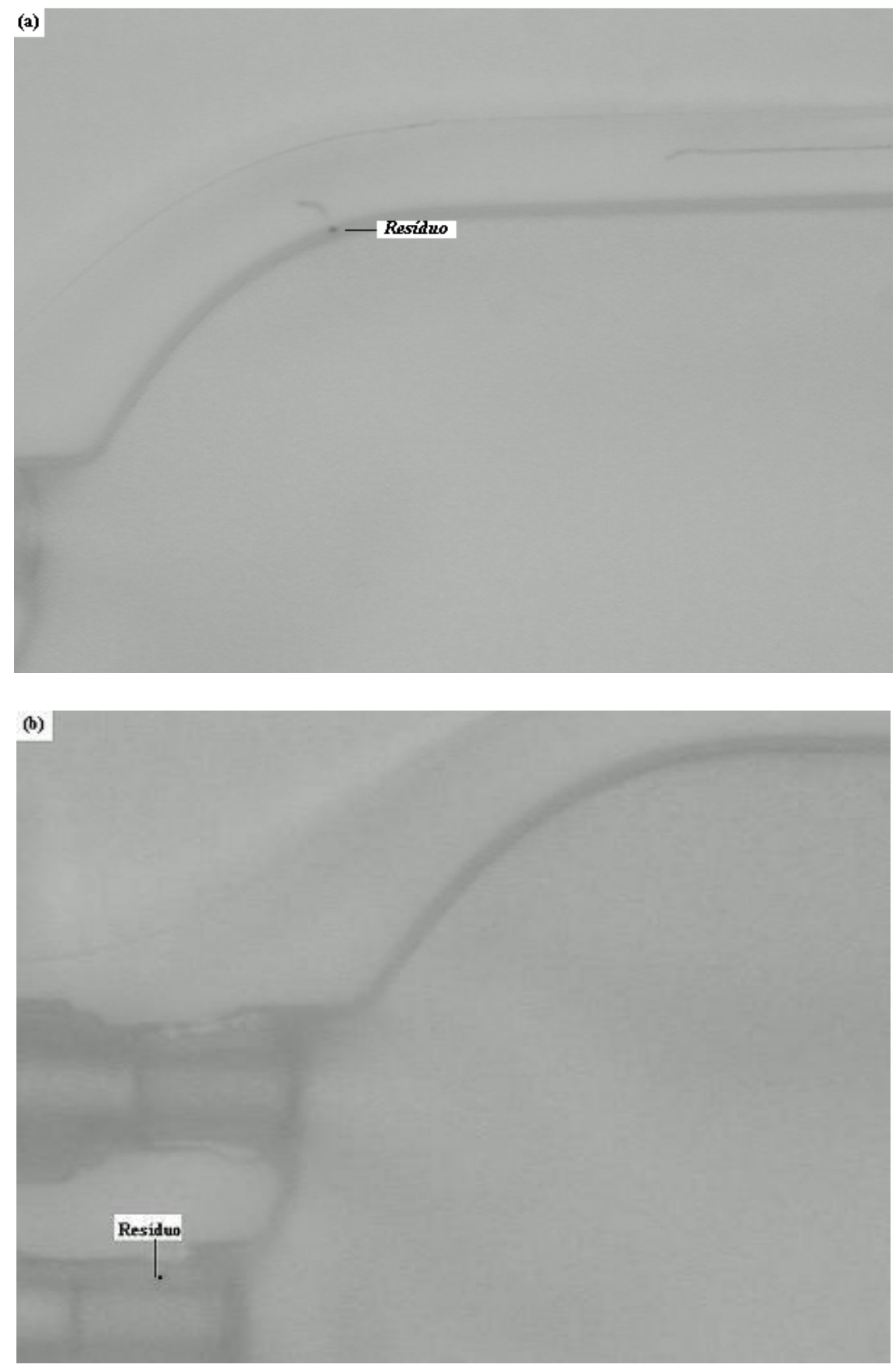

Figura 5.6 - (a) Imagem do resíduo da bolsa 6; (b) Imagem do resíduo da bolsa 13. 
O algoritmo não conseguiu identificar resíduos nessas imagens, porque o resíduo estava na borda da bolsa, e como a borda foi removida, também foi removida a informação com o resíduo.

A tabela 5.5 mostra os tempos de processamento para cada imagem analisada. Nesta tabela a primeira coluna (Im) refere-se ao número da imagem e a segunda (Tempo) ao tempo de processamento em segundos. Cumpre salientar que cada uma das 48 bolsas é subdividida em 8 imagens, além dessas imagens, foram capturadas imagens de partes das bolsas que representem cenas que possam gerar dificuldades no processamento e na classificação dos pixels de resíduos, somando no total 504 imagens.

Tabela 5. 5 - Tempo de processamento das imagens.

\begin{tabular}{|c|c|c|c|c|c|c|c|c|c|c|c|c|c|c|c|c|c|c|c|}
\hline Im & Tempo & Im & Tempo & Im & Tempo & Im & Tempo & Im & Tempo & Im & Tempo & Im & Tempo & Im & Tempo & Im & Tempo & Im & Tempo \\
\hline 1 & 1,4 & 51 & 1,4 & 101 & 1,4 & 151 & 1,4 & 201 & 1,3 & 251 & 5,1 & 301 & 1,4 & 352 & 1,4 & 403 & 1,4 & 454 & 1,5 \\
\hline 2 & 1,3 & 52 & 1,4 & 102 & 1,4 & 152 & 1,4 & 202 & 1,4 & 252 & 1,4 & 302 & 1,4 & 353 & 1,5 & 404 & 1,4 & 455 & 1,4 \\
\hline 3 & 1,3 & 53 & 1,4 & 103 & 1,4 & 153 & 1,5 & 203 & 1,4 & 253 & 1,3 & 303 & 1,4 & 354 & 1,3 & 405 & 1,4 & 456 & 1,4 \\
\hline 4 & 1,4 & 54 & 1,4 & 104 & 1,4 & 154 & 1,4 & 204 & 1,4 & 254 & 1,4 & 304 & 1,5 & 355 & 1,4 & 406 & 1,4 & 457 & 1,4 \\
\hline 5 & 1,4 & 55 & 1,3 & 105 & 1,4 & 155 & 1,4 & 205 & 1,4 & 255 & 1,4 & 305 & 1,3 & 356 & 1,4 & 407 & 1,4 & 458 & 1,4 \\
\hline 6 & 1,4 & 56 & 1,4 & 106 & 1,4 & 156 & 1,4 & 206 & 1,4 & 256 & 1,4 & 306 & 1,4 & 357 & 1,5 & 408 & 1,3 & \begin{tabular}{|l|}
459 \\
\end{tabular} & 1,5 \\
\hline 7 & 1,4 & 57 & 1,9 & 107 & 1,3 & 157 & 1,3 & 207 & 1,4 & 257 & 1,4 & 307 & 1,4 & 358 & 1,3 & 409 & 1,4 & 460 & 1,4 \\
\hline 8 & 1,3 & 58 & 1,4 & 108 & 1,2 & 158 & 1,4 & 208 & 1,4 & 258 & 1,4 & 308 & 1,1 & 359 & 1,4 & 410 & 1,4 & 461 & 1,4 \\
\hline 9 & 1,4 & 59 & 1,4 & 109 & 1,3 & 159 & 1,4 & 209 & 1,2 & 259 & 1,4 & 309 & 1,4 & 360 & 1,4 & 411 & 1,4 & 462 & 1,4 \\
\hline 10 & 1,3 & 60 & 1,5 & 110 & 1,4 & 160 & 1,4 & 210 & 1.4 & 260 & 1,4 & 310 & 1,3 & 361 & 1,4 & 412 & 1,4 & 463 & 1,5 \\
\hline 11 & 1,4 & 61 & 1,4 & 111 & 1,4 & 161 & 1,4 & 211 & 1,4 & 261 & 1,4 & 311 & 1,3 & 362 & 1,5 & 413 & 1,4 & \begin{tabular}{|l|}
464 \\
\end{tabular} & 1,3 \\
\hline 12 & 1,4 & 62 & 1,4 & 112 & 1,4 & 162 & 1,4 & 212 & 1,4 & 262 & 1,4 & 312 & 1,4 & 363 & 1,4 & 414 & 1,5 & 465 & 1,3 \\
\hline 13 & 1,4 & 63 & 1,4 & 113 & 1,4 & 163 & 1,4 & 213 & 1,4 & 263 & 1,4 & 313 & 1,4 & 364 & 1,4 & 415 & 1,4 & 466 & 1,3 \\
\hline 14 & 1,4 & 64 & 1,5 & 114 & 1,4 & 164 & 1,4 & 214 & 1,5 & 264 & 1,4 & 314 & 1,4 & 365 & 1,4 & 416 & 1,6 & 467 & 1,3 \\
\hline 15 & 1,4 & 65 & 1,4 & 115 & 1,4 & 165 & 1,4 & 215 & 1,4 & 265 & 1,4 & 315 & 1,4 & 366 & 1,5 & 417 & 1,4 & 468 & 1,4 \\
\hline 16 & 1,4 & 66 & 1,4 & 116 & 1,3 & 166 & 1,4 & 216 & 1,4 & 266 & 1,4 & 316 & 1,4 & 367 & 1,3 & 418 & 1,5 & 469 & 1,4 \\
\hline 17 & 1,1 & 67 & 1,4 & 117 & 1,4 & 167 & 1,4 & 217 & 1,4 & 267 & 1,4 & 317 & 1,4 & 368 & 1,3 & 419 & 1,4 & 470 & 1,4 \\
\hline 18 & 1,4 & 68 & 1,4 & 118 & 1,4 & 168 & 1,4 & 218 & 1,5 & 268 & 1,4 & 318 & 1.4 & 369 & 1,3 & 420 & 1.4 & 471 & 1,5 \\
\hline 19 & 1,4 & 69 & 1,4 & 119 & 1,4 & 169 & 1,4 & 219 & 1,4 & 269 & 1,4 & 319 & 1,4 & 370 & 1,4 & 421 & 1,4 & 472 & 1,4 \\
\hline 20 & 1,4 & 70 & 1,4 & 120 & 1,3 & 170 & 1,4 & 220 & 1,4 & 270 & 1,4 & 320 & 1,4 & 371 & 1,4 & 422 & 1,4 & \begin{tabular}{|l|}
473 \\
\end{tabular} & 1,4 \\
\hline 21 & 1,4 & 71 & 1,4 & 121 & 1,3 & 171 & 1,8 & 221 & 1,4 & 271 & 1,4 & 321 & 1,4 & 372 & 1,4 & 423 & 1,4 & 474 & 1,4 \\
\hline 22 & 1,4 & 72 & 1,4 & 122 & 1,4 & 172 & 1,4 & 222 & 1,4 & 272 & 1,4 & 322 & 1,4 & 373 & 1,4 & 424 & 1,4 & 475 & 1,5 \\
\hline 23 & 1,4 & 73 & 1,4 & 123 & 1,4 & 173 & 1,4 & 223 & 1,4 & 273 & 1,4 & 323 & 1,4 & 374 & 1,4 & 425 & 1,4 & 476 & 1,5 \\
\hline 24 & 1,4 & 74 & 1,4 & 124 & 1,4 & 174 & 1,4 & 224 & 1,3 & 274 & 1,4 & 324 & 1,4 & 375 & 1,4 & 426 & 1,4 & 477 & 1,5 \\
\hline 25 & 1,4 & 75 & 1,3 & 125 & 1.4 & 175 & 1,4 & 225 & 1,4 & 275 & 1,4 & 325 & 1,4 & 376 & 1,4 & 427 & 1,4 & 478 & 1,5 \\
\hline 26 & 1,4 & 76 & 1,4 & 126 & 1,4 & 176 & 1,4 & 226 & 1,4 & 276 & 1,3 & 326 & 1,4 & 377 & 1,4 & 428 & 1,4 & \begin{tabular}{|l|}
479 \\
\end{tabular} & 1,3 \\
\hline 27 & 1,3 & 77 & 1,4 & 127 & 1,4 & 177 & 1,4 & 227 & 1,3 & 277 & 1,3 & 327 & 1,6 & 378 & 1,4 & 429 & 1,4 & 480 & 1,4 \\
\hline 28 & 1,3 & 78 & 1,3 & 128 & 1,4 & 178 & 1,4 & 228 & 1,4 & 278 & 1,4 & 328 & 2,6 & 379 & 1,4 & 430 & 1,4 & 481 & 1,4 \\
\hline 29 & 1,3 & 79 & 1,4 & 129 & 1,4 & 179 & 1,4 & 229 & 1,4 & 279 & 1,4 & 329 & 1,6 & 380 & 1,3 & 431 & 1,4 & 482 & 1,4 \\
\hline 30 & 1,4 & 80 & 1,4 & 130 & 1,4 & 180 & 1,4 & 230 & 1,3 & 280 & 1,4 & 330 & 1,3 & 381 & 1,4 & 432 & 1,4 & 483 & 1,4 \\
\hline 31 & 1,4 & 81 & 1,4 & 131 & 1,5 & 181 & 1,4 & 231 & 1,3 & 281 & 1,4 & 331 & 1,4 & 382 & 1,4 & 433 & 1,4 & 484 & 1,4 \\
\hline 32 & 1,4 & 82 & 1,4 & 132 & 1,4 & 182 & 1,3 & 232 & 1,4 & 282 & 1,4 & 332 & 1,4 & 383 & 1,5 & 434 & 1,5 & 485 & 1,4 \\
\hline 33 & 1,4 & 83 & 1,4 & 133 & 1,4 & 183 & 1,3 & 233 & 1,4 & 283 & 1,3 & 333 & 1,4 & 384 & 1,4 & 435 & 1.4 & 486 & 1,4 \\
\hline 34 & 1,4 & 84 & 1,4 & 134 & 1,4 & 184 & 1,3 & 234 & 1,4 & 284 & 1,4 & 334 & 1,4 & 385 & 1,4 & 436 & 1,4 & 487 & 1,4 \\
\hline 35 & 1,4 & 85 & 1,3 & 135 & 1,5 & 185 & 1,3 & 235 & 1,3 & 285 & 1,4 & 335 & 1,4 & 386 & 1,4 & 437 & 1,4 & 488 & 1,4 \\
\hline 36 & 1,4 & 86 & 1,3 & 136 & 1,4 & 186 & 1,4 & 236 & 1,3 & 286 & 1,4 & 336 & 1.6 & 387 & 1.5 & 438 & 1.5 & 489 & 1,4 \\
\hline 37 & 1,4 & 87 & 1,3 & 137 & 1,4 & 187 & 1,3 & 237 & 1,4 & 287 & 1,4 & 337 & 1,4 & 388 & 1,4 & 439 & 1,3 & 490 & 1,4 \\
\hline 38 & 1,4 & 88 & 1,4 & 138 & 1,4 & 188 & 1,3 & 238 & 1.4 & 288 & 1,4 & 338 & 1,4 & 389 & 1,4 & 440 & 1,3 & 491 & 1,5 \\
\hline 39 & 1,4 & 89 & 1,4 & 139 & 1,4 & 189 & 1,4 & 239 & 1,4 & 289 & 1,4 & 339 & 1,4 & 390 & 1,4 & 441 & 1,3 & 492 & 1,4 \\
\hline 40 & 1,4 & 90 & 1,4 & 140 & 1,4 & 190 & 1,4 & 240 & 1,4 & 290 & 1,3 & 340 & 1,4 & 391 & 1.5 & 442 & 1,3 & \begin{tabular}{|l|}
493 \\
\end{tabular} & 1,4 \\
\hline 41 & 1,4 & 91 & 1,4 & 141 & 1,8 & 191 & 1,3 & 241 & 1,4 & 291 & 1,4 & 341 & 1,4 & 392 & 1,3 & 443 & 1,3 & 494 & 1,4 \\
\hline 42 & 1,4 & 92 & 1,4 & 142 & 1,4 & 192 & 1,3 & 242 & 1,3 & 292 & 1,4 & 342 & 1,4 & 393 & 1,4 & 444 & 1,4 & 495 & 1,4 \\
\hline 43 & 1,4 & 93 & 1,4 & 143 & 1,4 & 193 & 1,4 & 243 & 1,3 & 293 & 1,4 & 343 & 1,4 & 394 & 1,4 & 445 & 1,4 & 496 & 1,5 \\
\hline 44 & 1,4 & 94 & 1,4 & 144 & 1,4 & 194 & 1,4 & 244 & 1,3 & 294 & 1,4 & 344 & 1,4 & 395 & 1,5 & 446 & 1,4 & 497 & 1,4 \\
\hline 45 & 1,4 & 95 & 1,2 & 145 & 1,4 & 195 & 1,4 & 245 & 1,4 & 295 & 1,4 & 345 & 1,4 & 396 & 1,3 & 447 & 1,4 & 498 & 1,4 \\
\hline 46 & 1,5 & 96 & 1,4 & 146 & 1,3 & 196 & 1,4 & 246 & 1,3 & 296 & 1,4 & 346 & 1,4 & 397 & 1,4 & 448 & 1,5 & 499 & 1,4 \\
\hline 47 & 1,4 & 97 & 1,4 & 147 & 1,4 & 197 & 1,4 & 247 & 1,4 & 297 & 1,4 & 347 & 1,4 & 398 & 1,4 & 449 & 1,4 & 500 & 1,5 \\
\hline 48 & 1,4 & 98 & 1,4 & 148 & 1,4 & 198 & 1,4 & 248 & 1,4 & 298 & 1,4 & 348 & 1,4 & 399 & 1,4 & 450 & 1,4 & 501 & 1,3 \\
\hline 49 & 1,4 & 99 & 1,4 & 149 & 1,5 & 199 & 1,3 & 249 & 1,3 & 299 & 1,4 & 349 & 1,4 & 400 & 1,4 & 451 & 1.4 & 502 & 1,3 \\
\hline 50 & 1,4 & 100 & 1,4 & 150 & 1,4 & 200 & 1,2 & 250 & 1,4 & 300 & 1,5 & 350 & 1,4 & 401 & 1,3 & 452 & 1,5 & 503 & 1,3 \\
\hline & & & & & & & & & & & & 351 & 1,4 & 402 & 1,3 & 453 & 1,5 & 504 & 1,3 \\
\hline
\end{tabular}


O algoritmo levou em média 1,4 segundos para processar uma imagem e verificar a existência de resíduos (tempo médio de processamento de cada imagem da tabela 5.5). Nas oito imagens, que uma bolsa pode gerar, o tempo médio de inspeção foi de 11,2 segundos, ou seja, similar à média dos tempos das inspetoras humanas.

O tempo total para análise das 48 bolsas para coleta de sangue, levando-se em consideração o tempo médio para análise de uma bolsa, foi de aproximadamente 10 minutos.

Deve ser levado em conta que o algoritmo desenvolvido em Matlab teve como objetivo comprovar sua eficiência e certamente consome maior tempo do que se for desenvolvido em uma outra linguagem mais apropriada e compilada, como na Linguagem C, por exemplo.

\subsubsection{Análise Estatística dos Resultados}

A análise estatística feita através do Teste t Student para amostras pareadas comparando-se os resultados obtidos com a metodologia proposta neste trabalho e a classificação realizada pelo laboratório de controle de qualidade (Resultado Esperado), descritos na tabela 5.2, mostrou um coeficiente de correlação de 0.9753 . O gráfico da figura 5.7 apresenta a comparação de resultados entre a metodologia proposta neste trabalho e a classificação do laboratório de controle de qualidade. Pode-se observar o grande número de coincidências na quantidade de resíduos localizados em cada bolsa pela abordagem e o resultado esperado, classificado por um laboratório de controle de qualidade, o que é numericamente confirmado pelo alto valor do coeficiente de correlação. 


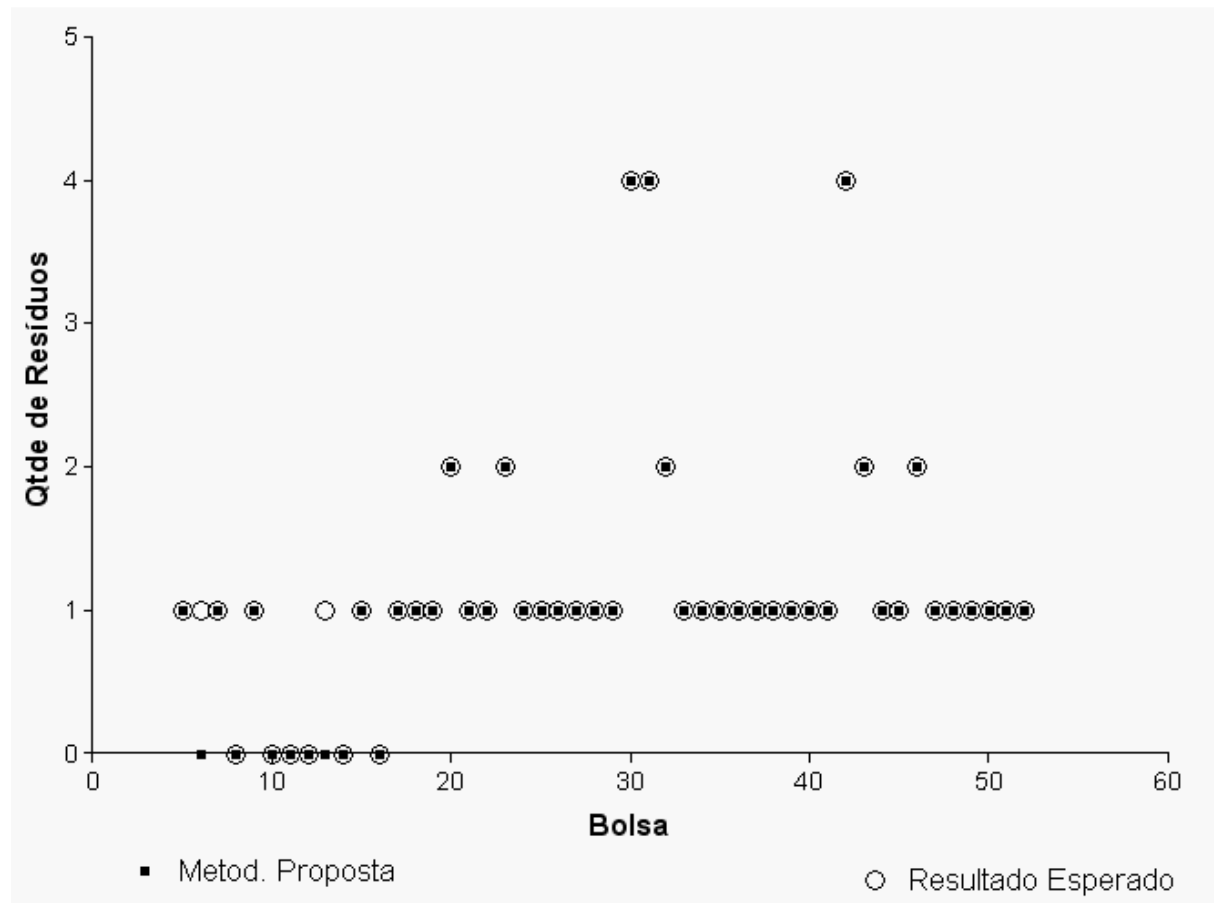

Figura 5.7 - Comparação dos resultados da inspeção visual automática e a classificação do laboratório de controle de qualidade.

\subsection{Resultados da Inspeção Visual Automática Aplicada às Bolsas}

\section{Retiradas da Linha de Produção}

Para se avaliar o desempenho do sistema de Inspeção Visual Automático desenvolvido neste trabalho, foram utilizadas também imagens de bolsas para coleta de sangue retiradas da linha de produção.

Foram retiradas da linha de produção cem bolsas para coleta de sangue, que foram inspecionadas, classificadas em "Com resíduo" e "Sem Resíduo” por um laboratório de controle de qualidade e em seguida numeradas de um a cem. Nenhuma das bolsas usadas nesta inspeção foi usada na geração das imagens do banco de imagens.

Nesta inspeção somente foi avaliado se existem ou não resíduos na bolsa para coleta de sangue, sem especificar a quantidade de resíduos encontrada. 
A captura das imagens foi realizada da mesma maneira que na geração do banco de imagens, considerando-se as oito imagens que uma bolsa pode gerar, sem imagens adicionais.

Os resultados desta inspeção estão demonstrados na tabela 5.6. Nesta tabela a primeira coluna refere-se ao número da bolsa para coleta de sangue; a segunda coluna os resultados obtidos com a metodologia proposta neste trabalho e a terceira coluna à classificação realizada pelo laboratório de controle de qualidade (Resultado Esperado). Na segunda e terceira colunas o número 1 indica que foi detectado resíduo e o número 0 indica que não foi detectado resíduo, sem especificar a quantidade deste.

Os resultados mostram que a abordagem desenvolvida neste trabalho conseguiu identificar corretamente resíduos em noventa e oito das cem bolsas analisadas, ou seja, com precisão de $98 \%$. Da mesma maneira o método não obteve êxito em duas bolsas, a bolsa_7 e a bolsa_12, porque os resíduos nestas bolsas estão localizados na borda da imagem, como mostra a figura 5.8.
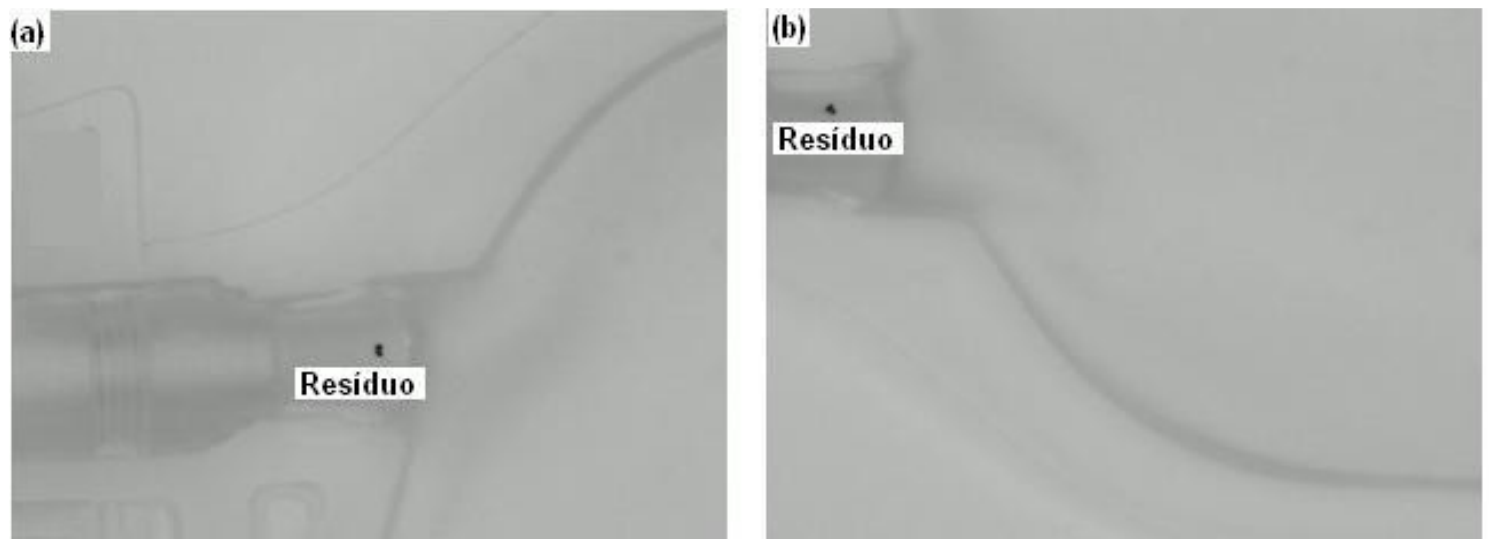

Figura 5.8 - (a) Imagem do resíduo da bolsa 7; (b) Imagem do resíduo da bolsa 12. 
Tabela 5. 6 - Resultados da Inspeção Visual Automática aplicada a bolsas retiradas da linha de produção.

\begin{tabular}{|c|c|c|}
\hline Bolsa & $\begin{array}{l}\text { Metodologia } \\
\text { Proposta }\end{array}$ & $\begin{array}{l}\text { Resultado } \\
\text { Esperado }\end{array}$ \\
\hline 1 & 1 & 1 \\
\hline 2 & 1 & 1 \\
\hline 3 & 1 & 1 \\
\hline 4 & 1 & 1 \\
\hline 5 & 1 & 1 \\
\hline 6 & 1 & 1 \\
\hline 7 & 0 & 1 \\
\hline 8 & 1 & 1 \\
\hline 9 & 1 & 1 \\
\hline 10 & 1 & 1 \\
\hline 11 & 1 & 1 \\
\hline 12 & 0 & 1 \\
\hline 13 & 1 & 1 \\
\hline 14 & 1 & 1 \\
\hline 15 & 1 & 1 \\
\hline 16 & 1 & 1 \\
\hline 17 & 1 & 1 \\
\hline 18 & 1 & 1 \\
\hline 19 & 1 & 1 \\
\hline 20 & 1 & 1 \\
\hline 21 & 1 & 1 \\
\hline 22 & 1 & 1 \\
\hline 23 & 1 & 1 \\
\hline 24 & 1 & 1 \\
\hline 25 & 1 & 1 \\
\hline 26 & 1 & 1 \\
\hline 27 & 0 & 0 \\
\hline 28 & 0 & 0 \\
\hline 29 & 0 & 0 \\
\hline 30 & 0 & 0 \\
\hline 31 & 0 & 0 \\
\hline 32 & 0 & 0 \\
\hline 33 & 0 & 0 \\
\hline 34 & 0 & 0 \\
\hline 35 & 0 & 0 \\
\hline 36 & 0 & 0 \\
\hline 37 & 0 & 0 \\
\hline 38 & 0 & 0 \\
\hline 39 & 0 & 0 \\
\hline 40 & 1 & 1 \\
\hline 41 & 0 & 0 \\
\hline 42 & 0 & 0 \\
\hline 43 & 0 & 0 \\
\hline 44 & 0 & 0 \\
\hline 45 & 0 & 0 \\
\hline 46 & 0 & 0 \\
\hline 47 & 0 & 0 \\
\hline 48 & 0 & 0 \\
\hline 49 & 0 & 0 \\
\hline 50 & 0 & 0 \\
\hline
\end{tabular}

\begin{tabular}{|c|c|c|}
\hline & Metodologia & Resultado \\
\hline Bolsa & Proposta & Esperado \\
\hline 51 & 0 & 0 \\
\hline 52 & 0 & 0 \\
\hline 53 & 0 & 0 \\
\hline 54 & 1 & 1 \\
\hline 55 & 0 & 0 \\
\hline 56 & 1 & 1 \\
\hline 57 & 0 & 0 \\
\hline 58 & 0 & 0 \\
\hline 59 & 0 & 0 \\
\hline 60 & 0 & 0 \\
\hline 61 & 0 & 0 \\
\hline 62 & 0 & 0 \\
\hline 63 & 0 & 0 \\
\hline 64 & 0 & 0 \\
\hline 65 & 0 & 0 \\
\hline 66 & 0 & 0 \\
\hline 67 & 0 & 0 \\
\hline 68 & 0 & 0 \\
\hline 69 & 0 & 0 \\
\hline 70 & 0 & 0 \\
\hline 71 & 0 & 0 \\
\hline 72 & 0 & 0 \\
\hline 73 & 0 & 0 \\
\hline 74 & 0 & 0 \\
\hline 75 & 0 & 0 \\
\hline 76 & 0 & 0 \\
\hline 77 & 0 & 0 \\
\hline 78 & 0 & 0 \\
\hline 79 & 0 & 0 \\
\hline 80 & 0 & 0 \\
\hline 81 & 0 & 0 \\
\hline 82 & 0 & 0 \\
\hline 83 & 0 & 0 \\
\hline 84 & 0 & 0 \\
\hline 85 & 0 & 0 \\
\hline 86 & 0 & 0 \\
\hline 87 & 0 & 0 \\
\hline 88 & 0 & 0 \\
\hline 89 & 0 & 0 \\
\hline 90 & 0 & 0 \\
\hline 91 & 0 & 0 \\
\hline 92 & 0 & 0 \\
\hline 93 & 0 & 0 \\
\hline 94 & 0 & 0 \\
\hline 95 & 1 & 1 \\
\hline 96 & 0 & 0 \\
\hline 97 & 0 & 0 \\
\hline 98 & 0 & 0 \\
\hline 99 & 0 & 0 \\
\hline 100 & 0 & 0 \\
\hline
\end{tabular}




\subsubsection{Análise Estatística dos Resultados}

A análise estatística feita através do Teste $\mathrm{t}$ Student para amostras pareadas, comparando-se os resultados da tabela 5.7, apresentou coeficiente de correlação de 0,9526. Ou seja, o alto valor deste coeficiente demonstra estatisticamente a viabilidade da nossa metodologia quando aplicada diretamente na linha de produção.

A figura 5.9 mostra o gráfico comparativo entre o resultado obtido com o algoritmo desenvolvido e a classificação do laboratório de controle de qualidade (Resultado Esperado).

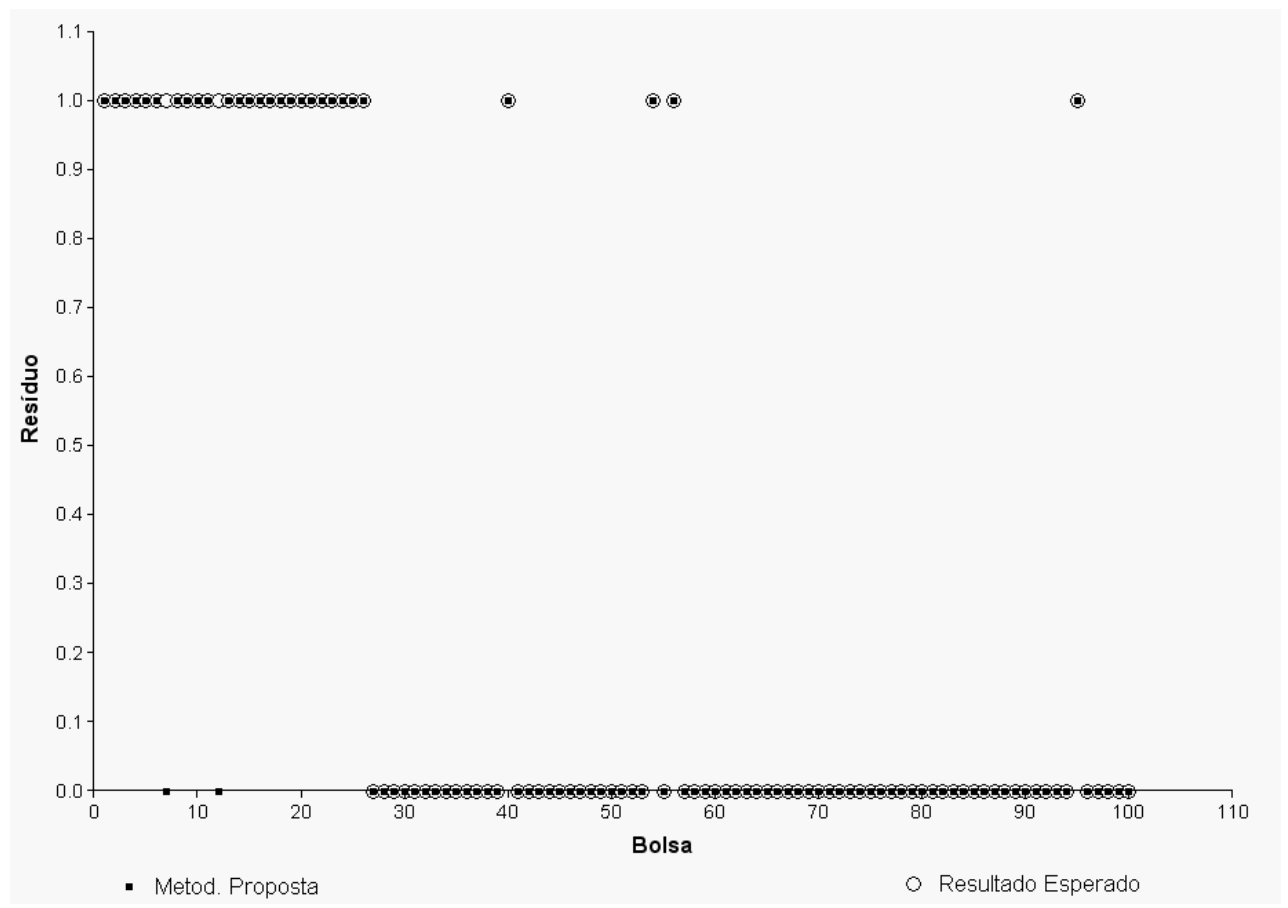

Figura 5. 9 - Comparação dos resultados da Inspeção Visual Automática das bolsas retiradas da linha de produção. 


\subsection{Conclusões}

Os resultados obtidos com as inspeções realizadas pelas inspetoras da linha de produção indicam que existem divergências na inspeção de uma mesma bolsa.

As análises estatísticas realizadas neste trabalho mostram que tanto o percentual de acerto, como o coeficiente de correlação, obtidos são pequenos quando a inspeção é realizada de maneira manual, mesmo que por inspetores treinados. Este fato expõe a fragilidade do processo e indica claramente a necessidade de automatização da Inspeção Visual.

O fator humano interfere nos resultados de maneira clara. Por exemplo, o resultado obtido pelas inspetoras na bolsa_46 são divergentes; a Inspetora 1 encontrou 4 resíduos e as outras duas não encontraram resíduo algum.

Portanto a automatização desta tarefa pode obter resultados mais uniformes com padrões mais bem definidos.

A metodologia proposta neste trabalho foi submetida a duas inspeções diferentes. A primeira utilizando imagens de um banco de imagens previamente gerado e comparando-se a quantidade de resíduos encontrada com a encontrada por um laboratório de controle da qualidade.

$\mathrm{Na}$ segunda inspeção foram usadas imagens de cem bolsas diferentes das utilizadas na geração do banco de imagens, verificando-se apenas a existência de resíduos, sem levar em conta a sua quantidade, comparando-se com os resultados do laboratório de controle de qualidade.

A metodologia de inspeção visual automática baseada em wavelets alcançou resultados promissores. Na primeira inspeção atingiu os melhores resultados, com o coeficiente de correlação de 0,9753 e o percentual de acerto de $96 \%$ das imagens analisadas. 
$\mathrm{Na}$ segunda inspeção obteve-se um coeficiente de correlação de 0,9526 com percentual de acerto de $98 \%$ das bolsas analisadas, demonstrando a viabilidade de se utilizar o sistema de Inspeção Visual Automático em linha de produção.

O tempo que o sistema de Inspeção Visual Automático levou para processar as imagens das 48 bolsas inspecionadas foi de aproximadamente 10 minutos, sendo que a média do tempo da inspeção manual foi de 12 minutos para as mesmas bolsas. Ou seja, o tempo de processamento do sistema automático, mesmo nesta versão implementada em Matlab, foi menor.

\subsection{Trabalhos Futuros}

No propósito de melhorar a metodologia para detecção de resíduos em bolsa para coleta de sangue desenvolvida neste trabalho, algumas melhorias podem ser consideradas. A metodologia proposta neste trabalho não conseguiu identificar resíduos nas bordas da imagem da bolsa para coleta de sangue. O emprego de uma abordagem usando morfologia matemática (GONZALEZ, 2000) poderia melhorar estes resultados.

Para a utilização de um Sistema de Inspeção Automática em tempo real, o tempo de inspeção é muito importante. O desenvolvimento de algoritmos em linguagens compiladas, como a linguagem $\mathrm{C}$, ou o desenvolvimento de C.I. customizado, por exemplo, pode otimizar o tempo de inspeção e viabilizar sua utilização em uma linha de produção. 


\section{Referências Bibliográficas}

ADORNI, C.A.; GONZAGA, A.; Da SILVA, I.N. (2006) Detecção de Resíduos em Imagens de Bolsas para Coleta de Sangue Utilizando um Sistema Fuzzy nos canais RGB, X Congresso Brasileiro de Informática em Saúde CIBIS - 2006, Sociedade Brasileira de Informática em Saúde, Joinvile, Anais p. 178-179.

ALMEIDA, O. C. P. (2006) Técnicas de Processamento de Imagens para Localização e Reconhecimento de Faces, Dissertação de Mestrado - Instituto de Ciências Matemáticas e da Computação (ICMC-USP) - Universidade de São Paulo.

BATCHELOR, B.G.; HILL, .A., HODGSON, D.G. (1985) Automated Visual Inspection, North-Holland: IFS Publi Carton,Ltd UK. .

BIANCHI, M. F. (2006) Extração de características de imagens de faces humanas através de Wavelets, PCA e IMPCA, Dissertação de Mestrado - Escola de Engenharia de São Carlos - Universidade de São Paulo. 
CARMEN, R. (1993) The selection of Plastic Materials for Blood Bags. Transfusion v. 1, p. $1-10$.

CASTElanO, C. R. (2006) Estudo Comparativo da Transformada Wavelet no

Reconhecimento de padrões da Íris Humana, Dissertação de Mestrado - Escola de Engenharia de São Carlos - Universidade de São Paulo.

COMYN, J. (1986) Polymer Permeability.England:Elsevier Applied science publisher Ltd, England, p. 1-7.

DAUBECHIES, I. (1990) The Wavelet Transform, Time Frequency Localization and Signal Analysis. IEEE Transactions on information Theory, 36 (5): 961- 1005.

DAUBECHIES, I. (1992) Ten Lectures en Wavelets, vol. 61 .CBMS-NSF Regional Conference Series in Appled Mathematics, Rutgers University and AT\&T Bell Laboratories.

ENCINAS JÚNIOR, W.S., (2000) Avaliação de técnicas de compressão de imagens para implementação em FPGA de granulidade fina, Tese de doutorado - Instituto de Física de São Carlos - Universidade de São Paulo.

FARIA, R. R. S., (1997) Aplicação de Wavelets na Análise de Gestos Musicais em Timbres de Instrumentos Acústicos Tradicionais, Dissertação de Mestado (Mestrado em Engenharia de Sistemas Eletrônicos) - Universidade de São Paulo.

FORNIER, A. (1995) Introduction in Wavelets and Their Applications in Computer Graphics, SIGGRAPH95. No. I, pp 5-33. 
GABOR, D. (1946) Theory of Communication. Journal of IEE, London, 93 :429-457.

GALVÃO, R. K. H., et al. (2001) Estudo Comparativo sobre Filtragem de Sinais Instrumentais usando Transformada de Fourier e Wavelet, Química Nova, Vol. 24, n. 6, p. $874-884$.

GONZALEZ, R.C., WOOD, R. (2000) Processamento Digital de Imagens, São Paulo: Edgar Blucher.

GRAPHPAD (2007). GraphPad Software Incorporated . Disponível em: <ll http://www.graphpad.com/prism/ > Acesso em: 12 dez. de 2007.

HAAR A. (1910) Zur Theorie der orthogonalen Funktionensysteme, Mathematische Annalen, pp 331-371.

HASHIMOTO, M. C. T. (1997) Estudo da preservação de Hemácias em diferentes bolsas de coleta com Di-octil-ftalato e anticoagulante citrato-fosfato-dextrose-adenina. Dissertação de Mestrado - Faculdade de Engenharia Química - Universidade de São Paulo.

HOLME S.; HEATON A.; MOMODS, G. (1989) Evaluation of a new, more oxygenpermeable, polyvinylchloride container. Transfusion, v. 29, p. 159-164.

LIMA, P. C. (2004), Wavelets: Teoria, Algoritmos e Aplicações. Departamento de matemática, UFMG. 
MALLAT, S., (1989) Theory for Multiresolution Signal Decomposition: The Representation. IEE Transaction on Pattern Analysis and Machine Intelligence, v 11, p.674-693.

MANO, E.B.D., (1991) Polímeros como Materiais de Engenharia, São Paulo: Edgard Blücher.

MARQUES FILHO, O.; VIEIRA NETO, H., (1999) Processamento Digital de Imagens, Rio de Janeiro: Brasport.

MARTINS A. G., (2005) Estatística Geral Aplicada, São Paulo: Atlas.

MISITI, M.; MISITI, Y.;OPPENHEIN, G.; POGGI, J-M. (2005) Wavelet Toolbox - For use Matlab - User Guide Verson3.

OLIVEIRA, Y. M. B. (1991) Estudo do efeito de processos de esterilização sobre propriedades de interesse para compostos de PVC plastificado utilizados na confecção de bolsas para coleta e transfusão de sangue. Dissertação de Mestrado em Engenharia Química - Universidade de Campinas.

PARRAGA, A., (2002) Aplicação da Transformada Wavelet Pocket na Análise e Classificação de vozes Patológicas, Dissertação de Mestrado (Mestrado em Engenharia Elétrica) - Universidade Federal do Rio Grande do Sul. 
SHAPIRO, J. S.; NOLAN, K. P.J. (1976) Stereochemistry of Polymerization, Polym. Sci. Polym.Symp. v. 55, p. 201, 1976.

STRANG, E.; NGUYEN, T. (1996) Wevelets and Filter Banks, Massachusetts, Wellesley Cambridge Press.

TITOW, W.V. (1984) PVC Technology. England: Elsevier Applied Science Publishers Ltda, v. 1, p. 4-7, 452-466.

USER, M., ALDROUBI, A. (1996) A Review of Wavelets in Biomedical applications. Proceeding of the IEEE, 84 (4) : 626-638.

WANG, J.Z. (2000) Sematics-Sensitive Integrated Matching for Picture Libraries and Biomedical Imagens Databases. Phd Dissertation, Departament of Biomedical Informatics of Stanford University.

VERCEZE, A. V. (1996) Avaliação de filmes de pvc plastificado utilizados na fabricação de Bolsas de Sangue. Dissertação de Mestrado - Faculdade de Engenharia Química Universidade de Campinas.

VERCEZE, A. V. (2006) Estudo físico e físico-químico de diferentes filmes de bolsas de sangue visando a segurança frente ao processamento hemoterapêutico. Tese Doutorado Faculdade de Ciências Farmacêuticas de Ribeirão Preto - Universidade de São Paulo,

VIEIRA, S. (1999) Estatística Para a Qualidade, São Paulo: Campus. 


\section{Apêndice A}

\section{PORTARIA N 950, DE 26 DE NOVEMBRO DE 1998}

O Secretário de Vigilância Sanitária do Ministério da Saúde, no uso de suas atribuições e considerando a necessidade de se estabelecer os requisitos mínimos necessários das bolsas plásticas para coleta e acondicionamento de sangue humano e seus componentes, resolve:

Art. $1^{\circ}$ Aprovar o Regulamento Técnico sobre Bolsas Plásticas para coleta e acondicionamento de sangue humano e seus componentes, constante do anexo desta Portaria.

Art. $2^{\circ}$ Esta Portaria entra em vigor na data de sua publicação.

GONZALO VECINA NETO

ANEXO

REGULAMENTO TÉCNICO

1 - OBJETIVO

2 - DEFINIÇÕES

3 - NORMAS DE REFERÊNCIA

4 - REQUISITOS GERAIS

5 - REQUISITOS ESPECÍFICOS

6 - ENSAIOS

1 - OBJETIVO

1.1 - Este regulamento fixa as condições exigíveis, incluindo aquelas pertinentes ao desempenho do plástico policloreto de vinila (PVC) plastificado com o di (2-etilhexil) ftalato(DEHP), trioctiltrimelitato (TOTM) ou outros que venham a ser aprovados pelo 
Ministério da Saúde, para bolsas plásticas, estanques, estéreis e apirogênicas, completas com tubo de coleta, agulha e tubo de transferência opcional para coleta, armazenamento, transporte, separação e administração de sangue total e seus componentes.

1.2 - As bolsas plásticas podem conter soluções anticoagulantes e/ou preservadoras dependendo da sua aplicação.

1.3 - Essas exigências para bolsas plásticas são necessárias para:

13.1 - Assegurar que a qualidade do sangue e seus componentes seja mantida a melhor possível.

1.3 2. - Possibilitar uma coleta, identificação, armazenamento, fracionamento e transfusão de seu conteúdo, de forma eficiente e segura, especialmente para reduzir-se ao mínimo os riscos devido a:

1.3.2.1 - Contaminação, particularmente a microbiológica

1.3.2 2 - Embolia gasosa.

1.3.2.3 - Erros na identificação de bolsas plásticas e das amostras de seu conteúdo.

1.3.2.4 - Interação entre bolsa plástica e seu conteúdo.

1.3.3 - Assegurar compatibilidade funcional com os equipos para transfusão de sangue de acordo com a ISO 1135/4.

1.3.4 - Possibilitar o máximo de resistência à ruptura e à deterioração da bolsa plástica fabricada com o mínimo de massa e volume.

\section{2 - DEFINIÇÕES}

\section{1 - Bolsa plástica.}

O termo "bolsa plástica" é utilizado neste Regulamento Técnico para definir o recipiente completo com o tubo de coleta e agulha, os tubos de saída, as soluções anticoagulantes e/ou preservadoras e os tubos de transferência e recipientes associados, quando existentes.

\section{2 - Esterilidade}

Ausência de todo microorganismo capaz de multiplicar-se.

2.3 - Volume nominal

Volume de sangue a ser envasado no recipiente, conforme indicado no rótulo pelo fabricante.

2.4 - Vida útil/validade

Período entre a data de esterilização e a data em que o produto não poderá mais ser utilizado para coleta de sangue. 


\section{5 - Lote}

Para bolsas plásticas com solução anticoagulante e/ou preservadora, o termo "lote" significa a quantidade de bolsas preparadas e cheias com um único lote de solução anticoagulante e esterilizada em um único ciclo.

Para bolsas plásticas vazias, o termo "lote" significa a quantidade de bolsas preparadas em um dia de trabalho e esterilizadas em um ciclo.

\section{3 - NORMAS DE REFERÊNCIA}

3.1 - Farmacopéia Brasileira

3.2 - Farmacopéia Européia

3.3 - Farmacopéia Americana

3.4 - Norma ISO 3826 ou similar nacional

3.5 - Norma ISO 1135/4

3.6 - Norma DIN 13097

3.7 - Lei 6360/76

3.8 - Decreto $79094 / 77$

3.9 - Portaria Conjunta SVS/SAS 01/96

\section{4 - REQUISITOS GERAIS}

4.1 - As bolsas plásticas devem ser transparentes, incolores, flexíveis, estéreis, apirogênìcas, isentas de toxicidade, resistentes nas condições de uso e compatíveis com o conteúdo sob condições normais de estocagem.

As bolsas devem ser estáveis biológica, química e fisicamente em relação ao seu conteúdo durante o período de validade e não devem permitir a entrada de microorganismos. Não devem liberar qualquer substância acima dos limites especificados para a solução anticoagulante e/ou preservadora, sangue ou componentes, quer por interação química ou dissolução física.

NOTA - O processo de fabricação deve garantir um volume mínimo de ar dentro das bolsas, de modo a permitir a coleta e fracionamento do volume integral de sangue.

\section{5 - REQUISITOS ESPECÍFICOS}

\section{1 - Dimensões.}

Figura 1: Representação esquemática de bolsa plástica. 
Nota:Apenas os valores dimensionados são obrigatórios.

Tabela 1 - Dimensões para bolsas plásticas, áreas para rótulo e capacidade nominal (Guia de Referência apenas)

\begin{tabular}{|c|c|c|c|c|c|}
\hline $\begin{array}{l}\text { Capacidade Nominal } \\
(\mathrm{mL})\end{array}$ & $\begin{array}{l}\text { Largura Interna } \\
\text { (b1) } \\
(\mathrm{mm})\end{array}$ & $\begin{array}{l}\text { Altura } \\
(\mathrm{h} 1) \\
(\mathrm{mm})\end{array}$ & Interna & $\begin{array}{l}\text { Tam } \\
(\mathrm{mm}) \\
\text { (b2+ }\end{array}$ & ea do rótulo \\
\hline 100 & 75 & 120 & & 60 & 85 \\
\hline 250 & 120 & 130 & & 90 & 85 \\
\hline 400 & 120 & 170 & & 100 & 100 \\
\hline 500 & 120 & 185 & & 100 & 100 \\
\hline
\end{tabular}

5.1.1 - A bolsa plástica deve ser fornecida com uma pinça a ser usada no tubo de coleta, de modo a não permitir a passagem de ar e a contaminação do sangue durante a coleta. $\mathrm{O}$ tubo de coleta, com no mínimo $800 \mathrm{~mm}$ de comprimento, deve ter marcações idênticas com intervalos em torno de $75 \mathrm{~mm}$ entre si, ao longo do tubo, para serem usados como amostras-piloto para análise.

5.1.2 - No caso de bolsas plásticas de transferência, o comprimento do tubo de transferência deve ser de, no mínimo, $600 \mathrm{~mm}$ e deve conter marcações idênticas com intervalos em torno de $75 \mathrm{~mm}$ entre si, ao longo do tubo.

5.1.3 - As bolsas plásticas devem permitir coletar a quantidade de sangue e seus componentes estipulada pelo Ministério da Saúde, ou seja, um volume de sangue e correspondente volume de solução anticoagulante e/ou preservadora num total de $500 \mathrm{~mL}$ e também permitir sua adaptabilidade aos copos de centrífugas usuais e sua centrifugação, com volume nominal das bolsas satélites entre 300 e $500 \mathrm{~mL}$.

\section{2 - Tubos de coleta e de transferência}

52.1 - As bolsas plásticas devem ser providas com um tubo de coleta ou um ou mais tubos de transferência para permitir a coleta e separação do sangue e seus componentes.

O tubo de transferência deve ser montado com um dispositivo que atue primeiro como um selo e depois, quando quebrado, permita livre fluxo dos componentes do sangue.

5.2.2 - Os tubos devem ser tais que possam ser selados hermeticamente e não colapsem em condições normais de uso.

5.2.3 - Em inspeção visual os tubos não devem apresentar cortes, bolhas, dobras ou outros defeitos

5.2.4 - Não deve haver vazamento nas junções entre os tubos e o corpo da bolsa plástica quando realizado teste de resistência, conforme 6.1.2. 


\section{3 - Agulha para coleta.}

5.3.1 - A agulha deve ser conectada ao tubo de coleta, coberta com a capa protetora. A capa protetora deve prevenir vazamentos da solução anticoagulante e/ou preservadora da bolsa plástica, durante a estocagem, para manter a esterilidade do sistema e ser facilmente removível. A capa protetora deve ser a prova de violação e fabricada de tal forma que seja impossível recolocá-la ou, qualquer tentativa de manipulação seja claramente observada.

5.3.2 - A agulha para coleta deve resistir, sem soltar-se do conjunto, quando ensaiada conforme 6.1.3.

\subsection{3 - As agulhas devem atender às especificações da norma DIN 13097.}

\section{4 -Tubos de saída}

5.4.1 - As bolsas plásticas devem possuir um ou mais tubos de saída para administração de sangue e seus componentes através de um equipo de transfusão. $\mathrm{O}(\mathrm{s})$ tubo(s) de saída deve(m) possuir uma membrana perfurável, não selável novamente, que permita a conexão do equipo de transfusão sem vazamento durante a administração ou condições de uso, incluindo esvaziamento sobre pressão. Para assegurar o intercambiamento, o tubo de saída deve possuir tamanho e forma que permitam a introdução de um equipo de transfusão, possuindo um dispositivo de perfuração e vedação, de acordo com a ISO 1135/4. Antes da perfuração da membrana pelo dispositivo de perfuração e vedação, o tubo de saída deve ficar firmemente ocluso pela mesma.

5.4.2 - Cada tubo de saída deve ser selado e montado com um lacre hermético à prova de violação para manter a esterilidade interna.

5.4.3 - As bolsas plásticas devem ter meios de suspensão ou posicionamento que não interfiram no uso da bolsa durante coleta, armazenamento, processamento, transporte e administração, conforme 6.1.9.

\section{5 - Amostras-Piloto}

A bolsa plástica deve ser projetada de modo que amostras-piloto de identidade inconfundível possam ser coletadas para execução dos ensaios de laboratório, sem que o sistema fechado da bolsa seja violado.

\section{6 - Embalagem primária}

As bolsas plásticas devem ser acondicionadas em embalagem, de modo a atender os seguintes critérios:

5.6.1 - As bolsas plásticas não devem perder mais do que 2,5\% $(\mathrm{m} / \mathrm{m})$ de água da solução anticoagulante e/ou preservadora, durante um ano de estocagem a 50\% de umidade relativa, a $(23+2)^{\circ} \mathrm{C}$ e pressão atmosférica.

5.6.2 - A vida útil da bolsa plástica deve ser estabelecida pelo fabricante com base no dado de estabilidade. Quando contém solução anticoagulante e/ou preservadora, a vida útil não deve exceder aquela em que a perda de água é igual a $5 \%(\mathrm{~m} / \mathrm{m})$. 
5.6.3 - O interior da embalagem não deve interagir com o seu conteúdo e deve ser tratado para prevenir a formação e crescimento de bolor ou fungos. Em caso de utilização de fungicidas químicos deve-se comprovar que não há penetração prejudicial ou deterioração da bolsa plástica e seu conteúdo.

5.6.4 - A embalagem plástica deve ser selada de maneira tal que seja inviolável.

5.6.5 - A embalagem deve ser suficientemente forte para resistir a danos sob condições normais de manuseio e uso.

5.6.6 - As bolsas plásticas e seus componentes devem ser dispostos na embalagem de modo que os tubos de coleta, conexão e transferência não fiquem torcidos ou sofram deformações permanentes.

\section{7 - Marcação e Rotulagem}

Os rótulos devem estar em conformidade com a legislação vigente e atender aos seguintes requisitos:

\subsection{1 - Rotulagem da bolsa plástica}

O rótulo deve conter as seguintes informações:

a) Composição da solução anticoagulante e/ou preservadora;

b) natureza e volume em mL, ou massa em g, da solução anticoagulante e/ou preservadora e o volume em $\mathrm{mL}$, ou massa em $\mathrm{g}$, de sangue a ser coletado;

c) a inscrição: "Não deve ser utilizada se houver sinal de deterioração e/ou diminuição do volume";

d) a inscrição: "Artigo de uso único. Destruir após o uso";

e) a inscrição: "Não perfure - produto estéril e apirogênico";

f) nome e endereço do produtor e do importador e nome do técnico responsável, seu número de inscrição e sigla da autarquia profissional;

g) número do lote;

h) data de fabricação e validade em destaque;

i) processo de esterilização;

j) espaço reservado para registrar o grupo $\mathrm{ABO}$ e $\mathrm{Rh}$, resultados dos testes de sorologia, número de referência apropriado das amostras-piloto e também um espaço para quaisquer outras exigências da regulamentação nacional.

\subsection{2 - Rotulagem da Embalagem}


Se o rótulo da bolsa plástica não for visível através da embalagem, esta deverá conter as seguintes informações:

a) Nome e endereço do produtor e do importador e nome do técnico responsável, seu número de inscrição e sigla da autarquia profissional;

b) declaração do conteúdo;

c) data de fabricação e validade;

d) número do lote;

5.7.3 - Outras impressões:

a) Instruções para uso da bolsa plástica.

b) Instruções para estocagem após a abertura da embalagem.

NOTA - Ficará a critério do produtor colocá-las no rótulo, na embalagem ou bula.

5.7.4 - Rotulagem do recipiente de embarque.

O rótulo deve conter as seguintes informações:

a) Nome e endereço do produtor;

b) declaração do conteúdo;

c) instruções para estocagem;

5.7.5 - Rótulo da bolsa plástica

O rótulo deve ser tal que:

a) Deixe uma parte da bolsa visível e livre de marcações para que o conteúdo possa ser inspecionado visualmente;

b) a impressão se mantenha legível durante todo tempo de uso;

c) permita anotações em tinta permanente, atóxica e a prova dcágua;

d) o adesivo, quando usado, não permita ou favoreça o crescimento de microorganismos e não tenha efeito de deterioração na bolsa plástica ou no seu conteúdo;

e) qualquer tentativa de remoção do rótulo deve resultar na sua destruição;

f) quando a bolsa for submetida ao ensaio descrito em 6.1.4. o rótulo não deve separar-se dela, nem ser removido e o conteúdo impresso no mesmo deve permanecer legível.

5.8 - Esvaziamento sob pressão 
As bolsas plásticas devem esvaziar-se, sem vazamento, em 2 minutos quando ensaiadas conforme 6.1.1.

5.9 - Velocidade de coleta

As bolsas plásticas devem ser projetadas de tal modo que possam ser enchidas em menos de 8 minutos com o volume de sangue a ser coletado, quando ensaiadas conforme 6.1.5.

\subsection{0 - Transparência}

A opalescência da suspensão padrão deve ser percebida quando observada através da bolsa e comparada com outra similar cheia com água, quando ensaiada conforme 6.1.6.

\subsection{1. - Permeabilidade ao vapor d'água}

As bolsas plásticas contendo ou não solução anticoagulanre e/ou preservadora, quando ensaiadas conforme 6.1.7, não devem apresentar perda de massa maior que $1 \%$.

\subsection{2 - Resistência a deformação e vazamento}

As bolsas plásticas não devem sofrer deformação ou vazamento quando ensaiadas conforme 6.1.8.1 e 6.1.8.2.

\subsection{3 - Estabilidade térmica}

As bolsas plásticas devem atender aos requisitos de tração do tubo, alça de suspensão, resistência a deformação e vazamento, após submetidas às condições descritas em 6.1.10.

5.14 - Solução anticoagulante e/ou preservadora

\subsection{1 - Volume do conteúdo}

O volume não deve diferir daquele rotulado em mais que $10 \%$ quando ensaiado conforme 6.1.11.

\subsection{2 - Absorvância}

A absorvância da solução anticoagulante não deve ser maior que 0,5 quando realizado ensaio conforme 6.1.12.

Nota: Ensaio aplicável apenas às soluções glicose - citrato e glicose - citrato - fosfato.

$$
5.14 .3-\mathrm{pH}
$$

Deve estar entre 5,0 e 6,0 quando realizado ensaio conforme 6.1 .13

\subsection{4 - Teor dos componentes}

Os valores encontrados nos ensaios realizados nas amostras de soluções anticoagulante e/ou preservadoras, conforme 6.2.1 a 6.2.6, não devem diferir dos especificados na tabela abaixo: 
Solução de Adenina, Glicose, Fosfato e Citrato (CPDA)

\begin{tabular}{|l|l|l|}
\hline COMPONENTE & $\begin{array}{l}\text { TEOR (g/1000 mL de } \\
\text { solução) }\end{array}$ & ENSAIO \\
\hline $\begin{array}{l}\text { Fosfato diácido de sódio } \\
\text { monoidratado (NaH2PO4 . H2O }\end{array}$ & entre 2,11 e 2,33 g & 6.2 .1 \\
\hline Glicose monoidratada & entre 30,30 e 33,50 g & 6.2 .2 \\
(C6H12O6.H2O) & entre 24,98 e 27,61g & 6.2 .3 \\
\hline Citrato de Sódio Diidratado & entre 6,21 e 6,86 g & 6.2 .4 \\
\hline C6H5Na3O7.2H2O & entre 0,247 e 0,303 g & 6.2 .5 \\
\hline Sódio & Entre 2,85 e 3,15 g & 6.2 .6 \\
\hline Adenina (C5H5N5) & Ácido cítrico anidro (C6H8O7) & \\
\hline
\end{tabular}

B - Solução de Glicose, Fosfato e Citrato (CPD)

\begin{tabular}{|c|c|c|}
\hline COMPONENTE & $\begin{array}{l}\text { TEOR g/1000 } \mathrm{mL} \\
\text { solução) }\end{array}$ & ENSAIO \\
\hline \begin{tabular}{|l}
$\left(\begin{array}{l}\text { Fosfato diácido de } \\
\text { monoidratado }\end{array}\right.$ \\
$(\mathrm{NaH} 2 \mathrm{PO} 4$. H2O $)$ \\
\end{tabular} & entre 2,11 e $2,33 \mathrm{~g}$ & 6.2 .1 \\
\hline $\begin{array}{l}\text { Glicose } \\
(\mathrm{C} 6 \mathrm{H} 12 \mathrm{O} . \mathrm{H} 2 \mathrm{O}) \\
\end{array}$ & entre 24,22 e $26,77 \mathrm{~g}$ & 6.2 .2 \\
\hline $\begin{array}{l}\text { Citrato de Sódio Diidratado } \\
(\mathrm{C} 6 \mathrm{H} 5 \mathrm{Na} 3 \mathrm{O} 7.2 \mathrm{H} 2 \mathrm{O})\end{array}$ & entre 24,98 a $27,61 \mathrm{~g}$ & 6.2 .3 \\
\hline Sódio & entre 6,21 a $6,86 \mathrm{~g}$ & 6.2 .4 \\
\hline Ácido cítrico anidro (C6H8O7) & entre 2,85 a $3,15 \mathrm{~g}$ & 6.2 .6 \\
\hline
\end{tabular}

C - Solução de Glicose e Citrato (ACD)

Solução A

\begin{tabular}{|c|c|}
\hline COMPONENTE & $\begin{array}{l}\text { TEOR (g/1000 } \mathrm{mL} \quad \text { de } \\
\text { solução) }\end{array}$ \\
\hline $\begin{array}{l}\text { Glicose } \\
(\mathrm{C} 6 \mathrm{H} 12 \mathrm{O} 6 . \mathrm{H} 2 \mathrm{O})\end{array}$ & entre 23,28 a $25,73 \mathrm{~g}$ \\
\hline $\begin{array}{l}\text { Citrato de Sódio Diidratado } \\
(\mathrm{C} 6 \mathrm{H} 5 \mathrm{Na} 3 \mathrm{O} 7 . \mathrm{H} 2 \mathrm{O})\end{array}$ & entre 20,59 a $22,75 \mathrm{~g}$ \\
\hline Acido Cítrico Anidro (C6H8O7) & entre 6,93 a $7,66 \mathrm{~g}$ \\
\hline
\end{tabular}

Solução B 


\begin{tabular}{|l|l|l|}
\hline COMPONENTE & $\begin{array}{l}\text { TEOR (g/1000 } \mathrm{mL} \\
\text { solução) }\end{array}$ & de ENSAIO \\
\hline $\begin{array}{l}\text { Glicose } \\
\text { (C6H12O6.H2O) }\end{array}$ & monoidratada entre 13,96 a 15,44 g & 6.2 .2 \\
\hline $\begin{array}{l}\text { Citrato de Sódio Diidratado } \\
\text { (C6H5Na3O7.H2O) }\end{array}$ & entre 12,37 a 13,67 g & 6.2 .3 \\
\hline Ácido Cítrico Anidro (C6H8O7) & entre 4,18 a 4,62 g & 6.2 .6 \\
\hline
\end{tabular}

D - Solução CPD/ SAG - Manitol - Solução 1

SAG-Manitol 1

\begin{tabular}{|l|l|l|}
\hline COMPONENTE & $\begin{array}{l}\text { TEOR (g/1000 mL de } \\
\text { solução) }\end{array}$ & ENSAIO \\
\hline $\begin{array}{l}\text { (Glicose monoidratada } \\
\text { (C6H12O6.H2O) }\end{array}$ & entre 8,55 e 9,45g & 6.2 .2 \\
\hline Manitol (C6 H13 O6) & entre 4,99 e 5,51g & 6.2 .2 \\
\hline Adenina (C5 H5 N5) & entre 0,161 e 0,177 g & 6.2 .5 \\
\hline Cloreto de Sódio (NaCI) & entre 8,33 e 9,20 g & $\begin{array}{l}6.2 .4 \text { (Dosar sódio e } \\
\text { expressar o resultado como } \\
\text { NaCl) }\end{array}$ \\
\hline
\end{tabular}

E - Solução CPD/Sag-manitol - Solução 2

SAG-Manitol 2

\begin{tabular}{|l|l|l|}
\hline COMPONENTE & $\begin{array}{l}\text { TEOR (g/1000 mL de } \\
\text { solução) }\end{array}$ & ENSAIO \\
\hline Glicose monoidratada & entre 20,90 e 23,10g & 6.2 .2 \\
\hline C6H12O6.H2O) & entre 7,12 e 7,87g & 6.2 .2 \\
\hline Adeninina (C5 H5 N5) & entre 0,256 e 0,283g & 6.2 .5 \\
\hline Cloreto de Sódio (NaCI) & entre 8,55 e 9,45g & $\begin{array}{l}\text { 6.2.4 (Dosar sódio e } \\
\text { expressar o resultado como } \\
\text { NaCI) }\end{array}$ \\
\hline
\end{tabular}

\subsection{5 - Extrato}

Os limites constantes da tabela abaixo não devem ser excedidos quando da realização de ensaios conforme Farmacopéia Brasileira

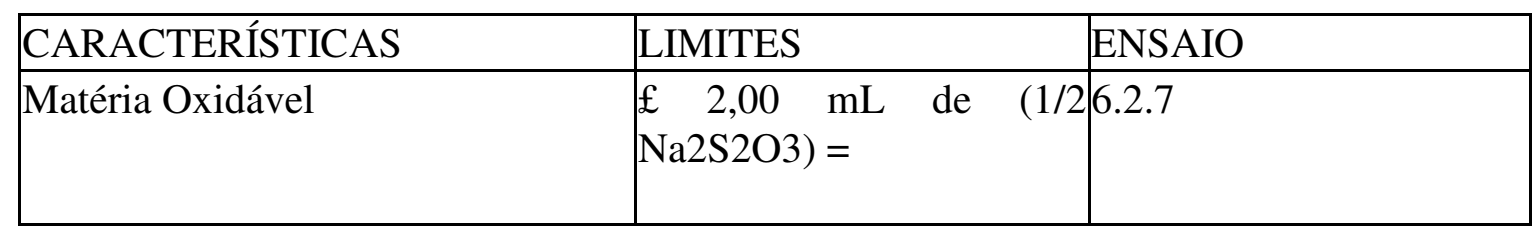




\begin{tabular}{|l|l|l|}
\hline & $0,01 \mathrm{~mol} / \mathrm{L}$ & \\
\hline Amônia (NH3) & $£ 2,0 \mathrm{mg} / \mathrm{L}$ & 6.2 .8 \\
\hline íons cloreto & $£ 4 \mathrm{mg} / \mathrm{L}$ & 6.2 .9 \\
\hline Acidez ou alcalinidade & $£ 0,4 \mathrm{~mL}$ de $\mathrm{NaOH}=0,01$ & 6.2 .10 \\
& $\begin{array}{l}\mathrm{mol} / \mathrm{L} \text { de } \mathrm{Hcl}=0,01 \\
\mathrm{~mol} / \mathrm{L}\end{array}$ & \\
\hline Resíduo por evaporação & $£ 3,0 \mathrm{mg} / 100 \mathrm{~mL}$ & 6.2 .11 \\
\hline Absorção Ultravioleta (UV) & entre 230 e $250 \mathrm{~nm} £ 0,3$ & 6.2 .12 \\
\hline Di (2-etil-hexil) ftalato extraível & entre 251 e $360 \mathrm{~nm} £ 0,1$ & \\
\hline
\end{tabular}

5.14.6 - 5-Hidroximetilfurfural - Quando ensaiadas conforme 6.21.4, as soluções devem obedecer aos limites da tabela abaixo:

\begin{tabular}{|l|l|l|}
\hline SOLUÇÃO & TEOR GLICOSE & LIMITE \\
\hline$£$ & & $\cdot$ \\
\hline$£ 5 \mathrm{ppm}$ & & \\
\hline$£ 3 \mathrm{ppm}$ & & $\cdot$ \\
\hline CPD & 24,22 A 26,77 & $£ 5 \mathrm{ppm}$ \\
\hline
\end{tabular}

\subsection{7 - Biológicos}

5.14.7.1 - Citotoxicidade "in vitro". O material ensaiado não deve apresentar um índice de resposta (IR) maior que o controle, quando ensaiado conforme 6.3.1.

\subsubsection{2 - Toxicidade Sistêmica Aguda}

Os animais tratados conforme 6.3.2 não devem apresentar sinais de toxicidade ou morte.

\subsubsection{3 - Esterilidade}

As bolsas plásticas não devem apresentar crescimento microbiano quando ensaiadas conforme 6.3.3.

5.14.7.4 - Apirogenicidade / ausência de endotoxinas

As bolsas plásticas devem ser apirogênicas / isentas de endotoxinas quando testadas conforme um dos métodos descritos em 6.3.4.

\subsubsection{5 - Hemólise}

As bolsas plásticas quando ensaiadas conforme 6.3.5 não devem apresentar hemólise, determinada pela absorção do branco maior que 0,01 .

6.0 Ensaios 


\subsection{Ensaios Físicos}

\subsubsection{Esvaziamento sob pressão}

A bolsa plástica quando cheia com um volume de água à temperatura de $(23 \pm 2)^{\circ} \mathrm{C}$ igual a sua capacidade nominal e conectada a um equipo de transfusão conforme especificação ISO1135-4, através de um tubo de saída (ver 5.4), deve esvaziar-se, sem vazamento, dentro de 2 minutos quando gradualmente comprimida entre duas superfícies planas (pratos) sob uma pressão interna de $40 \mathrm{kPa}$ acima da pressão atmosférica.

\subsection{2 - Tração nos tubos}

Realizar teste conforme Farmacopéia Brasileira.

\subsection{3 - Fixação da agulha}

Aplicar e manter uma força de tração de $20 \mathrm{~N}$ ao longo do eixo longitudinal durante 15 segundos.

\subsection{4 - Permanência do Rótulo}

As bolsas plásticas, cheias com água até sua capacidade nominal e seladas, devem ser armazenadas por 5 dias a uma temperatura $(5 \pm 1)^{\circ} \mathrm{C}$. Esse período inicial deve ser seguido de um período de 24 horas a uma temperatura máxima de $-40^{\circ} \mathrm{C}$ e então $24 \mathrm{~h}$ a $(5 \pm 1)^{\circ} \mathrm{C}$. As bolsas plásticas rotuladas e/ou com identificação impressa devem ser submersas em um reservatório de água mantido a uma temperatura de $(20 \pm 1)^{\circ} \mathrm{C} 24 \mathrm{~h}$.

\subsection{5- Velocidade de coleta}

Conectar o recipiente, por meio de tubo previamente munido de agulha de punção, a um reservatório contendo solução de mesma viscosidade que o sangue, tal como solução de sacarose a $33,5 \% \mathrm{p} / \mathrm{V}$ a $37^{\circ} \mathrm{C}$, mantendo diferença de $9,3 \mathrm{kPa}$ entre pressão atmosférica e pressão interna, com a base do recipiente e a parte superior da bolsa plástica no mesmo nível.

\subsection{6 - Transparência}

Encher as bolsas plásticas com um volume de suspensão opalescente padrão (preparada conforme instruções abaixo) igual a sua capacidade nominal, diluída para uma absorvância entre 0,37 e 0,43 em $640 \mathrm{~nm}$ numa célula de $1 \mathrm{~cm}$.

6.1.6.1- Preparo da suspensão opalescente padrão:

\section{A - Reagentes}

1 - Solução de sulfato de hidrazina

Dissolver $1,0 \mathrm{~g}$ de sulfato de hidrazina em água destilada e diluir para $100 \mathrm{~mL}$. Deixar em repouso por 4 a 6 horas. 
1 - Solução de hexametilenotetramina

Dissolver 2,5 g de hexametilenotetramina em $25 \mathrm{~mL}$ de água destilada em um frasco de 100 mL com tampa.

3 - Suspensão opalescente primária

Adicionar à solução de hexametilenotetramina $25 \mathrm{~mL}$ da solução de sulfato de hidrazina. Misturar e deixar em repouso por 24 horas.

Esta suspensão é estável por 2 meses, quando estocada em recipiente de vidro, isento de defeitos na superfície. A suspensão não deve aderir ao vidro e deve ser bem misturada antes do uso.

4 - Suspensão opalescente padrão

Diluir $15 \mathrm{~mL}$ da suspensão opalescente primária para $1000 \mathrm{~mL}$ com água destilada.

Esta suspensão deve ser recentemente preparada e pode ser estocada por, no máximo, 24 horas.

\subsection{7 - Permeabilidade ao vapor da água}

Introduzir na bolsa, contendo solução anticoagulante e/ou preservadora ou não, um volume de solução $0,9 \%(\mathrm{~m} / \mathrm{v})$ de cloreto de sódio até completar seu volume nominal. Fechar a bolsa, pesar e manter a mesma a $(5 \pm 1)^{\circ} \mathrm{C}$ em uma atmosfera com umidade relativa de $(50 \pm 5) \%$ por 21 dias. Pesar novamente.

\subsection{8 - Resistência a deformação e vazamento}

6.1.8.1 - Encher o recipiente com água a $(5 \pm 1)^{\circ} \mathrm{C}$, acidificada por adição de $1 \mathrm{~mL}$ de ácido clorídrico diluído SR até seu volume nominal. Envolver a bolsa plástica em papel absorvente impregnado de azul de bromofenol diluído 1:5 SI, ou de outro indicador apropriado, e seco. Centrifugar a $5000 \mathrm{rpm}$ por 10 minutos a $(5 \pm 1)^{\circ} \mathrm{C}$. Não deve ocorrer qualquer vazamento sobre o papel indicador, e nem qualquer deformação permanente.

7 - Encher o recipiente com água a $(5 \pm 1)^{\circ} \mathrm{C}$, acidificada por adição de $1 \mathrm{~mL}$ de ácido clorídrico diluído SR até seu volume nominal. Centrifugar a $5000 \mathrm{rpm}$ por 30 minutos a (5 $\pm 1)^{\circ} \mathrm{C}$, seguindo-se 30 minutos a $37^{\circ} \mathrm{C}$. Não deve ocorrer qualquer vazamento, quando comprimida gradualmente entre duas superfícies planas (pratos) revestidas com papel indicador, a uma pressão equivalente a $100 \mathrm{kPa}$ acima da pressão atmosférica alcançada em 1 minuto e mantida por 10 minutos à temperatura de $(23 \pm 2)^{\circ} \mathrm{C}$.

\subsection{9 - Alça de Suspensão}

Os meios de suspensão ou posicionamento devem ser capazes de suportar, sem se romper, uma força de $20 \mathrm{~N}$ aplicada ao longo do eixo longitudinal dos tubos de saída, durante 60 minutos, a uma temperatura de $(23 \pm 2)^{\circ} \mathrm{C}$.

Nota: Este teste será realizado apenas após a realização do teste de estabilidade térmica. 


\subsubsection{0 - Estabilidade Térmica}

Colocar a bolsa plástica em uma câmara com temperatura inicial de 20 a $23^{\circ} \mathrm{C}$. Esfriar rapidamente a uma temperatura de $-80^{\circ} \mathrm{C}$, mantendo esta temperatura por $24 \mathrm{~h}$. Elevar a temperatura a $50^{\circ} \mathrm{C}$, mantendo-se assim por $12 \mathrm{~h}$. Deixar esfriar à temperatura ambiente. A bolsa deve satisfazer os ensaios de residência a deformação e vazamento, tração dos tubos, permeabilidade ao vapor d?água, esvaziamento sob pressão e alça de suspensão.

\subsubsection{1 - Volume do conteúdo}

Esvaziar completamente bolsas e tubos, recolhendo a solução anticoagulante numa proveta.

\subsubsection{2 - Absorvância}

Medir a absorvância da solução anticoagulante no intervalo entre 250 e $350 \mathrm{~nm}$, utilizando como líquido de compensação uma solução anticoagulante de composição idêntica que não tenha estado em contato com o material plástico, autoclavada em frasco de vidro boro-silicato sob as mesmas condições utilizadas no processo de esterilização das bolsas plásticas. A absorvância máxima a $280 \mathrm{~nm}$ não deve ser superior a 0,5 .

$$
6.1 .13-\mathrm{pH}
$$

Proceder o ensaio conforme Farmacopéia Brasileira.

6.2 - Ensaios Químicos e Físicoquimicos:

6.2.1 - Fosfato diácido de sódio

Seguir metodologia constante na USP.

6.2.2 - Glicose, frutose e manitol:

\subsubsection{1 - Cromatografia;}

6.2.2.1.1. - Aparelhagem e material:

a - Cromatógrafo líquido

b - Coluna para carboidratos com resina de troca catiônica na forma $\mathrm{Ca}(300 x 6,5) \mathrm{mm}$.

c - Forno para coluna

d - Detetor de índice de refração

e - Balança analítica

f - Vidraria de laboratório

6.2.2.1.2 - Condições de análise: 
a - Fase móvel: água deionizada e degaseificada

b - Fluxo: 0,5mL/min.

c - Temperatura do forno: $(80-90)^{\circ} \mathrm{C}$

d - Tempo de retenção:

Glicose: 10,2 $\min$.

Frutose: $12.0 \mathrm{~min}$.

Manitol: 13,9 min.

\subsubsection{3 - Ensaio:}

Pipetar 3 alíquotas de 5,0mL da solução anticoagulante e/ou preservadora e diluir para $50,0 \mathrm{~mL}$ com água deionizada, em balão volumétrico.

Injetar alíquotas de $20,0 \mathrm{~mL}$ em duplicata e medir as áreas dos picos correspondentes a glicose, frutose e manitol.

\subsubsection{4 - Preparo das curvas de calibração:}

Pesar alíquotas de glicose USP, frutose USP e manitol USP (secos a $80^{\circ} \mathrm{C}$, à vácuo, por 3 horas) e dissolver com água deionizada, em balão volumétrico, para obter soluções com as seguintes concentrações, conforme a amostra a ser analisada:

\begin{tabular}{|c|c|c|c|}
\hline AMOSTRA & $\begin{array}{l}\text { Glicose Monoidratada } \\
(\mathrm{mg} / \mathrm{mL})\end{array}$ & $\begin{array}{l}\text { Frutose } \\
\text { Monoidratada } \\
(\mathrm{mg} / \mathrm{mL})\end{array}$ & $\begin{array}{l}\text { Manitol } \\
\text { Anidro }(\mathrm{mg} / \mathrm{mL})\end{array}$ \\
\hline $\begin{array}{l}\text { Solução } \\
\text { Anticoagulante } \\
\text { CPDA }\end{array}$ & 2,71 & 0,15 & |---------------- \\
\hline & 3,03 & 0,25 & \begin{tabular}{|l|}
----- \\
\end{tabular} \\
\hline . & 3,35 & 0,35 & \begin{tabular}{|l|}
----- \\
\end{tabular} \\
\hline $\begin{array}{l}\text { Solução } \\
\text { Anticoagulante } \\
\text { CPD }\end{array}$ & 2,16 & 0,14 & ----- \\
\hline & 2,42 & 0,18 & \begin{tabular}{|l|}
----- \\
\end{tabular} \\
\hline & 2,68 & 0,22 & \begin{tabular}{|l|}
----- \\
\end{tabular} \\
\hline Solução & 2,09 & 0,096 & ----- \\
\hline
\end{tabular}




\begin{tabular}{|c|c|c|c|c|c|c|}
\hline \multicolumn{7}{|l|}{$\begin{array}{l}\text { Anticoagulante } \\
\text { CD } \\
\end{array}$} \\
\hline . & 2,33 & 1,40 & 0,18 & 0,108 & $-----\cdot$ & \\
\hline 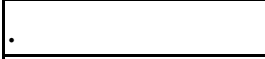 & 2,57 & 1,54 & 0,20 & 0,120 & $---\cdot$ & \\
\hline $\begin{array}{l}\text { Solução } \\
\text { Preservadora } \\
\text { Sag-manitol }\end{array}$ & 0,75 & 1,87 & 0,057 & 0,14 & 0,45 & 0,63 \\
\hline & 0,85 & 2,09 & 0,065 & 0,16 & 0,50 & 0,71 \\
\hline & 0,95 & 2,31 & 0,073 & 0,18 & 0,55 & 0,79 \\
\hline
\end{tabular}

Injetar alíquotas de $20,0 \mathrm{~mL}$ em duplicata e medir as áreas correspondentes a glicose, frutose e manitol.

Plotar as médias das áreas obtidas para cada solução contra as concentrações das mesmas em $\mathrm{mg} / \mathrm{mL}$ de glicose monoidratada, frutose monoidratada e manitol anidro

\subsubsection{5 - Resultados:}

Calcular o conteúdo de glicose monoidratada, frutose monoidratada e manitol anidro em g/L de solução anticoagulante e/ou preservadora usando a seguinte expressão:

$\mathrm{A}=10 . \mathrm{C}$

Onde: C - concentração em $\mathrm{mg} / \mathrm{mL}$ de glicose monoidratada, frutose monoidratada ou manitol anidro, determinada na curva de calibração.

\subsubsection{2 - Gravimetria (somente para glicose)}

Seguir metodologia constante da USP

Nota 1: Os teores de glicose + frutose serão genericamente expressos como glicose monoidratada ou anidra.

Nota 2: A Cromatografia Líquida será o método de escolha em caso de divergência de resultados na análise de glicose

\subsection{3 - Citrato de Sódio:}

\subsubsection{1 - Método A (espectrofotometria):}

Seguir metodologia constante na USP.

6.2.3.2 - Método B (cromatografia líquida):

6.2.3.2.1 - Aparelhagem e material: 
a) Cromatógrafo líquido

b) Coluna C-18 (250x4)mm $5 \mathrm{~mm}$

c) Detetor de ultravioleta

d) Balança analítica

e) Vidraria de laboratório

6.2.3.2.2 - Condições de análise:

a) Fase móvel: DDSS 100mg, H3PO4 1mL, H2O qsp 1.000mL / MeOH (2:3)

b) Solvente: H3PO4 1mL, H2O qsp 1.000mL / MeOH (2:3)

c) Fluxo: $0,8 \mathrm{~mL} / \mathrm{min}$

d) $1=235 \mathrm{~nm}$

e) Tempo de retenção:

Citrato: 3,6 min.

Adenina: 4,8 min.

\subsubsection{3 - Ensaio:}

Pipetar 3 alíquotas de 5,0mL da solução anticoagulante e/ou preservadora, adicionar 4,0mL de HCI $0,1 \mathrm{~N}$ e diluir para 50,0mL em balão volumétrico, com o solvente.

Injetar em cromatógrafo alíquotas de $20,0 \mathrm{~mL}$ em duplicata e medir as áreas dos picos correspondentes ao citrato e a adenina.

\subsubsection{4 - Preparo das curvas de calibração:}

Pesar com precisão alíquotas de 21,25 (sag-manitol - 1) ou 33,75 (sag manitol - 2 e CPDA) mg de adenina USP, conforme a amostra a ser analisada, dissolver e diluir para 100,0 mL com HCI $0,1 \mathrm{~N}$, em balão volumétrico, para obter solução estoque com concentrações de 0,2125 ou $0,3375 \mathrm{mg} / \mathrm{mL}$, respectivamente.

Pesar com precisão alíquotas de citrato de sódio, 2H2O USP, adicionar alíquotas de 3,0, 4,0 e $5,0 \mathrm{~mL}$ da solução estoque de adenina em balão volumétrico de $50 \mathrm{~mL}$, para obter soluções com as seguintes concentrações, conforme a amostra a ser analisada.

\begin{tabular}{|l|l|l|}
\hline AMOSTRA & $\begin{array}{l}\text { Citrato de Sódio } \\
\text { Diidratado }(\mathrm{mg} / \mathrm{mL})\end{array}$ & Adenina \\
& Solução Anticoagulante $(\mathrm{mg} / \mathrm{mL})$ \\
\hline
\end{tabular}




\begin{tabular}{|c|c|c|c|c|}
\hline CPDA & & & & \\
\hline & 3,09 & & 0,027 & \\
\hline . & 3,40 & & 0,034 & \\
\hline $\begin{array}{l}\text { Solução Anticoagulante } \\
\text { CPD }\end{array}$ & 2,78 & & ------ & \\
\hline . & 3,09 & & ------- & \\
\hline. & 3,40 & & ------- & \\
\hline $\begin{array}{l}\text { Solução Anticoagulante } \\
\text { ACD }\end{array}$ & 2,99 & 1,79 & ------- & \\
\hline & 3,32 & 1,99 & |------- & \\
\hline & 3,65 & 2,19 & ------- & \\
\hline $\begin{array}{l}\text { Solução Preservadora } \\
\text { Sag-manitol }\end{array}$ & ----- & & 0,013 & 0,020 \\
\hline . & ------ & & 0,017 & 0,027 \\
\hline . & ------- & & 0,021 & 0,034 \\
\hline
\end{tabular}

Injetar alíquotas de 20,0 mL em duplicata e medir as áreas correspondentes ao citrato de sódio total e a adenina.

Plotar as médias das áreas obtidas para cada solução padrão contra as concentrações das mesmas em $\mathrm{mg} / \mathrm{mL}$ de citrato total expresso em citrato de sódio diidratado e adenina.

\subsubsection{5 - Resultados:}

a) Calcular o conteúdo de citrato expresso em citrato de sódio diidratado total ou adenina em g/L de solução anticoagulamente e/ou preservadora usando a seguinte expressão:

$\mathrm{A}=10 \times \mathrm{C}$

Onde: $\mathrm{C}=$ concentração $\mathrm{em} \mathrm{mg} / \mathrm{mL}$ de citrato total ou adenina determinada na curva de calibração.

b) Calcular a quantidade de citrato de sódio diidratado em g/L de solução anticoagulante e/ou preservadora usando a expressão:

$\mathrm{D}=\mathrm{A}-(\mathrm{B} \times 294,10)$

$(92,12)$

Onde: $\mathrm{A}=$ Concentração total de citrato em g/L (conforme 6.2.3.2.5. a)

B = Concentração, em g/L de ácido cítrico anidro livre na solução (conforme 6.2.6).

\subsection{4 - Sódio:}

Seguir metodologia constante da USP.

\subsection{5 - Adenina:}




\subsubsection{1 - Método A:}

Seguir metodologia constante da USP.

6.2.5.2 - Método B (cromatografia líquida):

Seguir procedimento 6.2.3.2

\subsection{6 - Ácido Cítrico}

Seguir metodologia constante da USP.

\subsection{7 - Matéria Oxidável}

Seguir metodologia constante da Farmacopéia Brasileira.

6.2.8 - Amônia

Seguir metodologia constante da Farmacopéia Brasileira.

6.2.9 - Cloreto

Seguir metodologia constante da Farmacopéia Brasileira.

6.2.10 - Acidez/alcalinidade

Seguir metodologia constante da Farmacopéia Brasileira.

6.2.11 - Resíduo por evaporação

Seguir metodologia constante da Farmacopéia Brasileira.

6.2.12 - Absorção do extrato (UV)

Seguir metodologia constante da Farmacopéia Brasileira.

6.2.13 - Di (2-etil-hexil) ftalato extraível

Seguir metodologia constante da Farmacopéia Brasileira.

6.2.14- 5 - HMF (5 - Hidroximetilfurfural)

6.2.14.1 - Método A - Espectrofotometria

Metodologia descrita na Farmacopéia Européia

6.2.14.2 - Método B - Cromatografia líquida

6.2.14.2.1 - Aparelhagem e material: 
a) cromatógrafo líquido

b) coluna C-18 (150 x 4) $\mathrm{mm} 5 \mathrm{~mm}$

c) detector de ultravioleta

d) balança analítica

e) vidraria de laboratório

6.2.14.2.2 - Condições de análise:

a) fase móvel $\mathrm{H} 2 \mathrm{O}$ / MeOH (95:5)

b) fluxo: $0,8 \mathrm{~mL} / \mathrm{min}$.

c) $1=280 \mathrm{~nm}$

d) tempo de retenção: 9,6 min.

\subsubsection{3 - Ensaio:}

Injetar em cromatógrafo alíquotas de 500,0 mL da solução anticoagulante e/ou preservadora, em duplicata, e medir as áreas do pico correspondente ao 5 - hidroximetilfurfural.

6.2.14.2.4 - Preparo da curvas de calibração:

Pesar com precisão alíquotas de 5 - hidroximetilfurfural. Dissolver e diluir com água destilada, em balão volumétrico, para obter soluções com concentrações conhecidas de 2,0 , 4,0, 5,0 e 6,0 mg/L.

Injetar alíquotas de 500,0 mL de cada solução padrão, em duplicata, e medir as áreas correspondentes ao 5 - hidroximetilfurfural.

Plotar as médias das áreas obtidas para cada solução padrão contra as concentrações das mesmas em $\mathrm{mg} / \mathrm{L}$ de 5 - hidroximetilfurfural.

\subsubsection{5 - Resultado:}

Determinar o conteúdo de 5 - hidroximetilfurfural em $\mathrm{mg} / \mathrm{L}$ da solução anticoagulante e/ou preservadora a partir da curva de calibração.

\section{3 - Ensaios Biológicos}

6.3.1 - Citotoxicidade

Seguir metodologia constante da USP.

6.3.2 - Toxicidade Sistêmica Aguda 
Seguir metodologia constante da Farmacopéia Brasileira.

\subsection{3 - Esterilidade}

Seguir metodologia constante da Farmacopéia Brasileira.

\subsection{4 - Pirogênio/Endotoxinas bacterianas}

Seguir metodologia constante na Farmacopéia Brasileira para o teste de pirogênio e metodologia da USP para endotoxinas bacterianas.

Nota: O pirogênio "in vivo" será o método de escolha em caso de divergência de resultados.

6.3.5 - Hemólise

Seguir metodologia constante da Farmacopéia Brasileira.

\section{0 - APLICAÇÃO DOS ENSAIOS}

Ensaios de tipo e lote são listados em 7.1 e 7.2.

7.1 - Ensaios de tipo

Todos os ensaios previstos neste Regulamento devem ser realizados para fins de Registro junto ao Ministério da Saúde e ser repetidos sempre que houver uma mudança significativa de processo, formulação de plástico ou solução anticoagulante ou preservadora.

7.2 - Ensaios de lote

Realizar a cada lote de fabricação os seguintes ensaios, no produto final:

7.2.1 - Volume do conteúdo (6.1.11)

7.2.2 - $\mathrm{pH}(6.1 .13)$

7.2.3 - 5 - HMF, quando aplicável (6.2.14)

7.2.4 - Teor dos componentes da solução anticoagulante e/ou preservadora (6.2.1 a 6.2.7)

7.2.5 - Esterilidade (6.3.3)

7.2.6 - Pirogênio/Endotoxinas bacterianas (6.3.4) 
Apêndice B

Exemplos de Imagens processadas

Resíduo 


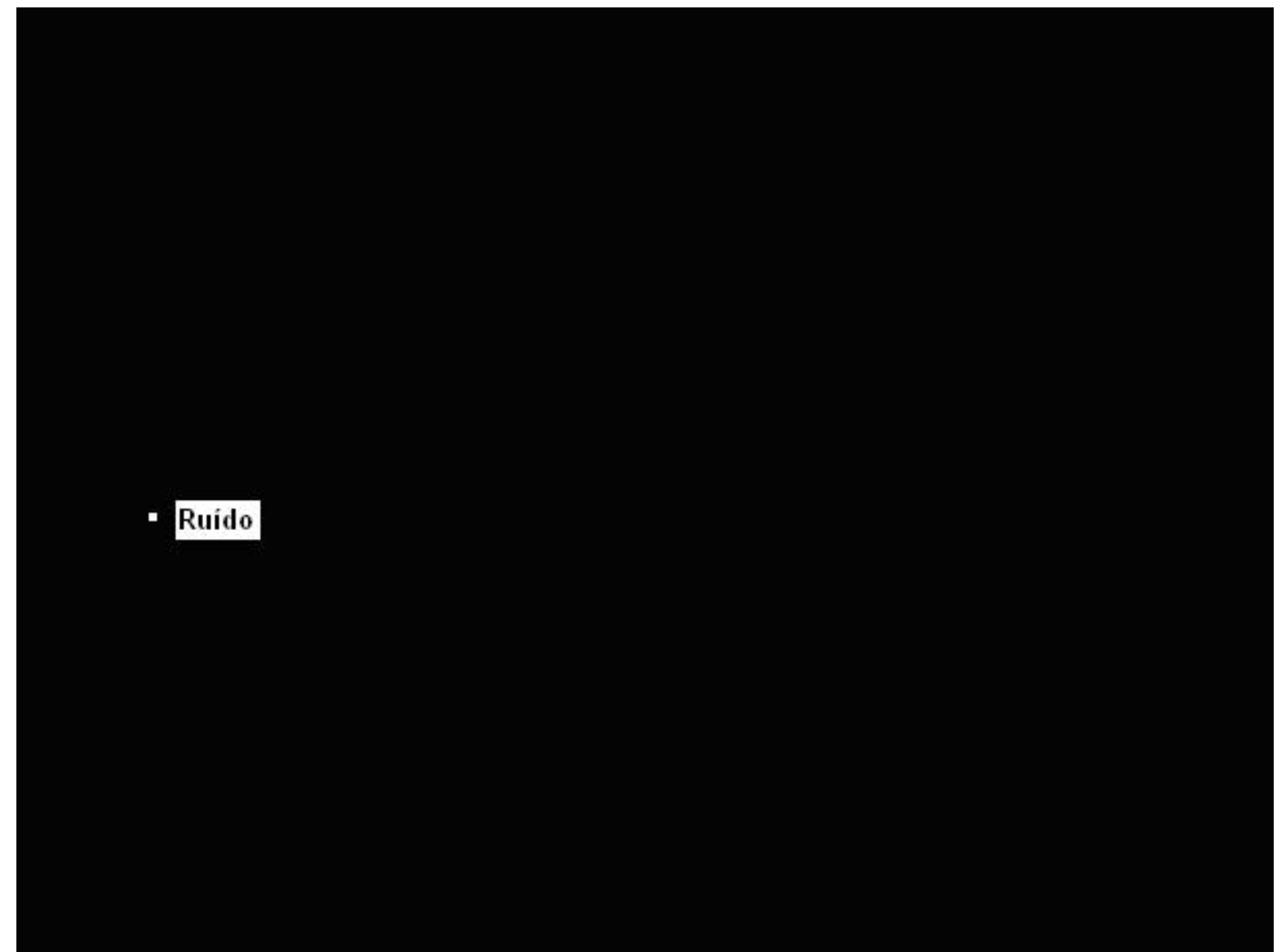

Figura B. 2 - Resultado do processamento da imagem da figura B1atrvés da metodologia proposta. 


\section{Resíduo}

\section{Borda}

Figura B. 3 - Imagem com resíduo e borda 


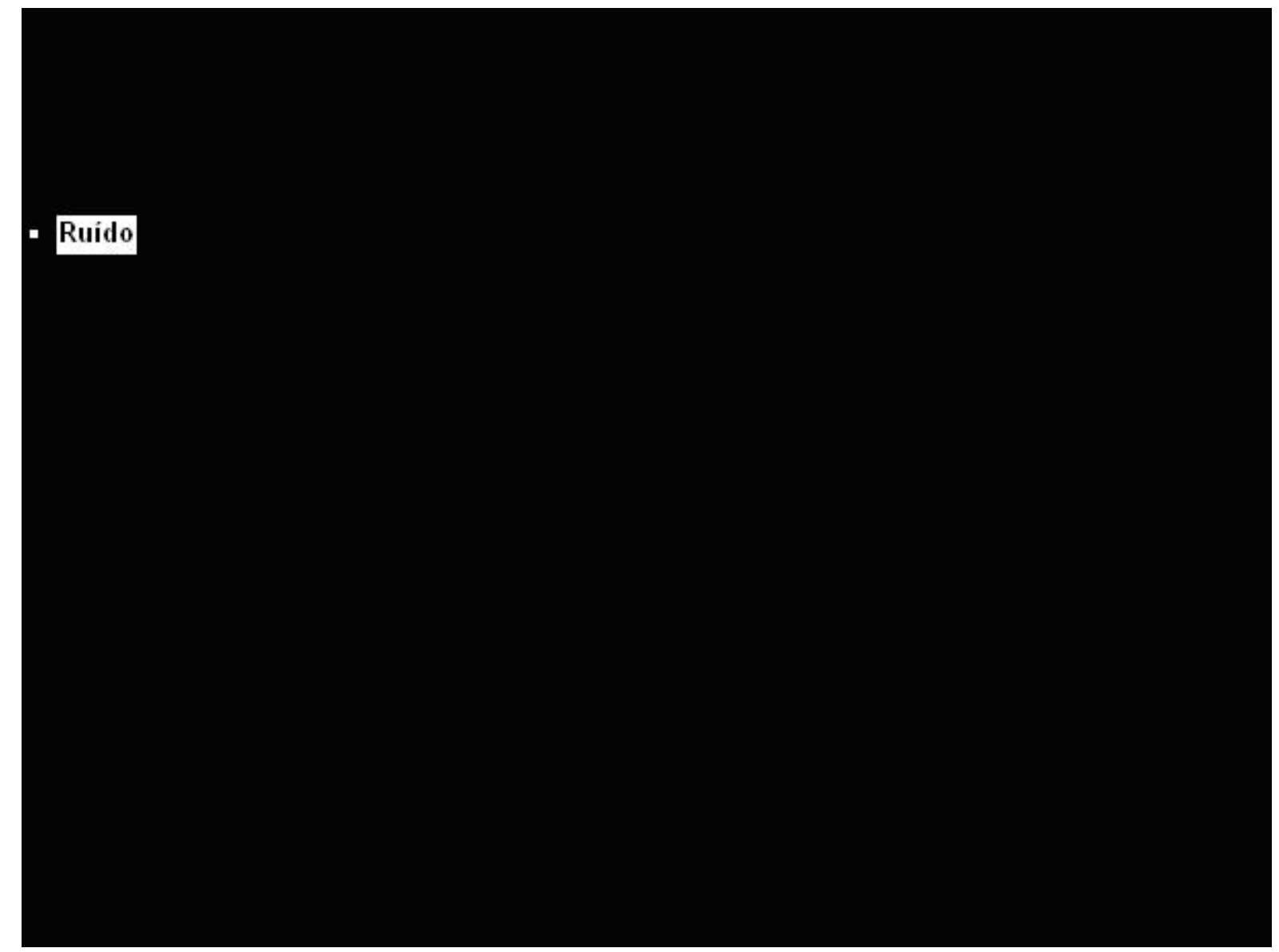

Figura B. 4 - Realce do resíduo e eliminação da borda da bolsa. 
Borda

Figura B. 5- Imagem sem resíduo. 


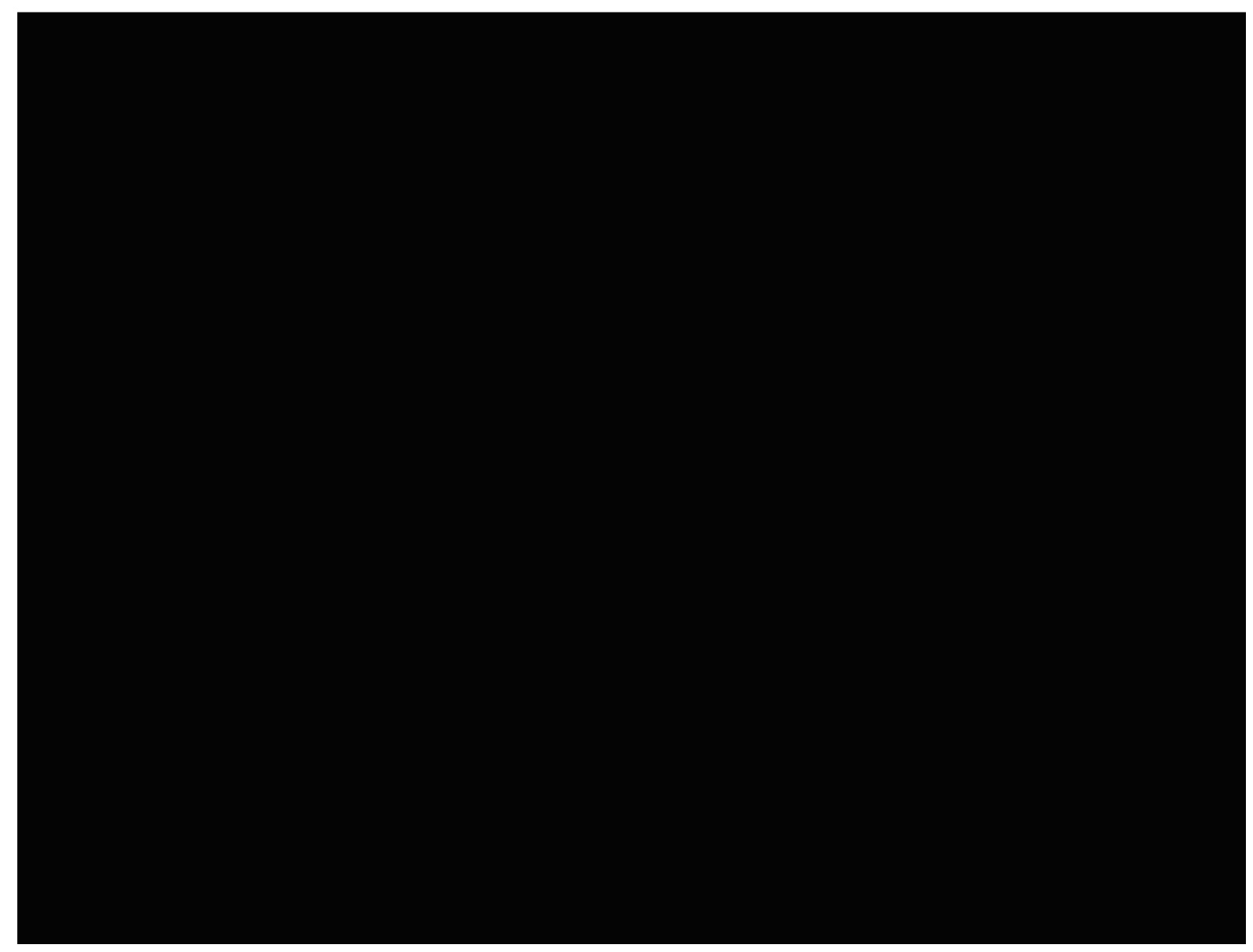

Figura B. 6 - Eliminação da borda da bolsa e ausência de resíduo. 
Borda

Resíduo

Figura B. 7- Imagem com hímem e resíduo. 


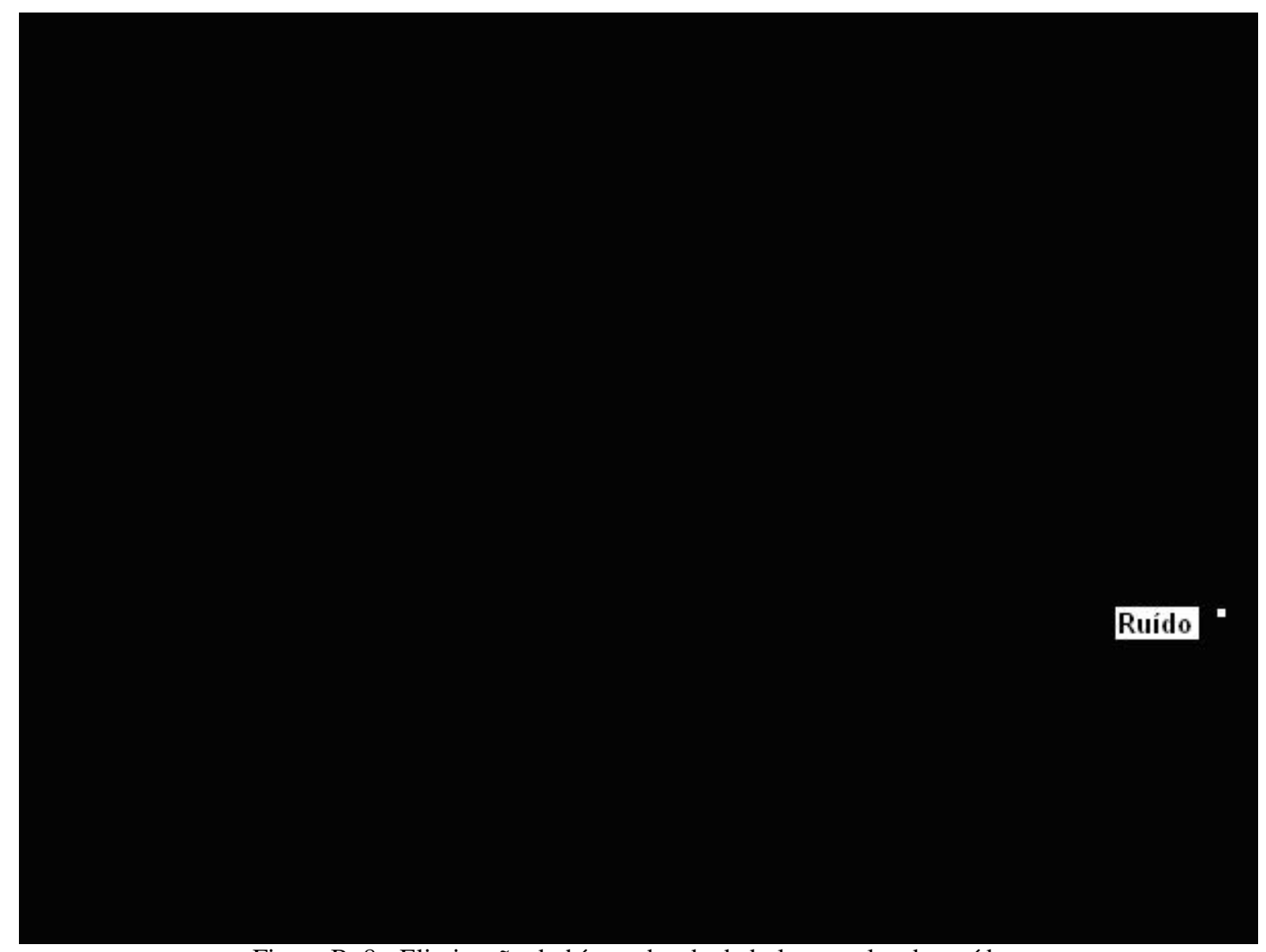

Figura B. 8 - Eliminação do hímen, borda da bolsa e realce do resíduo. 


\section{Sistema de Qualidade dos Fornecedores (Boas Práticas de Fabricação e}

\section{Controle)}

As Boas Práticas de Fabricação e Controle, constituem os requisitos que devem ser adotados pelas empresas fabricantes e importadoras de produtos correlatos, visando garantir a qualidade do sistema de produção e fornecimento de seus produtos. A verificação da conformidade das Boas Práticas de Fabricação e Controle de produtos correlatos com os requisitos previstos na regulamentação descrita a seguir, é realizada pelos inspetores da vigilância sanitária.

- $\quad$ Portaria SVS nº 686, de 27/8/98 Internaliza a Resolução Mercosul GMC n 65/96, que estabelece os requisitos para as Boas Práticas de Fabricação e Controle em Estabelecimentos de Produtos para Diagnóstico de Uso "in-vitro".

- Resolução - RDC n ${ }^{\circ} 59$, de 27 de junho de 2000 Determina a todos fornecedores de produtos médicos, o cumprimento dos requisitos estabelecidos pelas "Boas Práticas de Fabricação de Produtos Médicos". 


\section{Algoritmo Desenvolvido}

function $[G, H 2, T]=$ residuohaar_p(p_img);

$\mathrm{t} 1=$ now

img=strcat('bolsa',p_img,'.bmp');

imgh=strcat('h',p_img,'.jpg');

imgr=strcat('r',p_img,'.jpg');

$A=\operatorname{imread}(i m g)$;

$A=$ double $(A)$

$\operatorname{Xrgb}=0.2990^{\star} A(:,:, 1)+0.5870^{\star} A(:,:, 2)+0.1140^{\star} A(:,:, 3) ;$

NbColors = 256;

$\mathrm{X}=$ wcodemat $(\mathrm{Xrgb}, \mathrm{NbColors})$;

map $=$ gray $($ NbColors $)$;

$[\mathrm{C}, \mathrm{S}]=$ wavedec2$\left(\mathrm{X}, 2\right.$, 'haar' $\left.^{\prime}\right)$

$\mathrm{H} 2$ = wrcoef2('h',C,S,'haar',2);

in2 $=($ wcodemat $(\mathrm{H} 2,256))$;

imwrite (ih2,map,imgh,'jpeg');

$\operatorname{imh}=$ imread(imgh); 


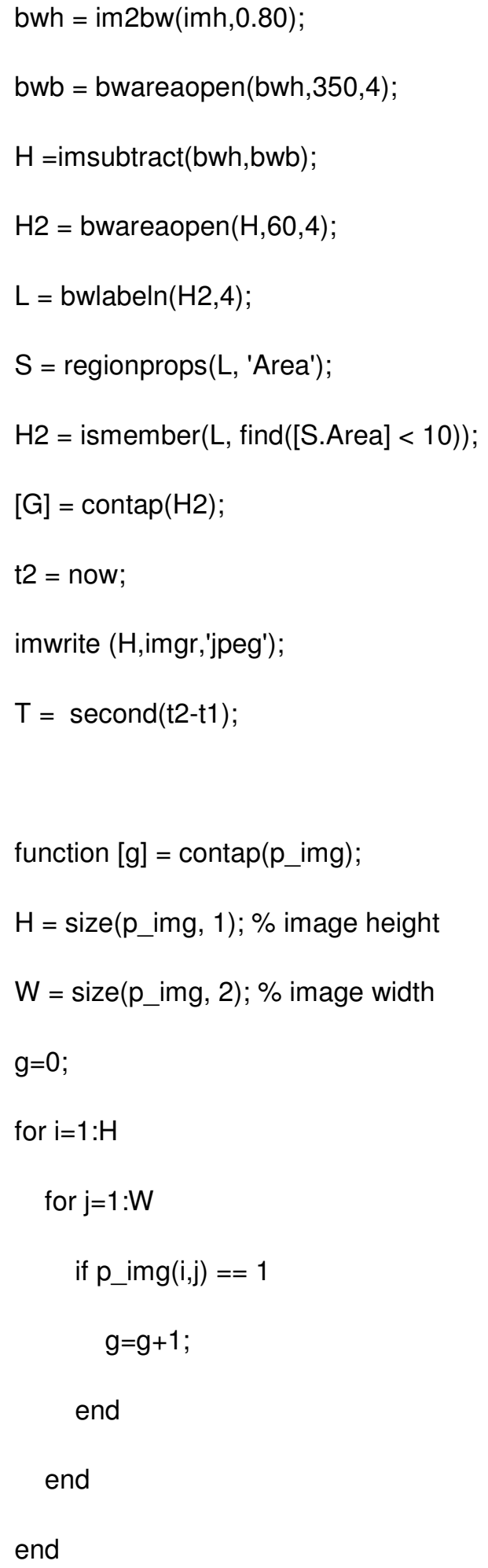

